\title{
Is Cut-Flower Industry Promotion by the Government Negatively Affecting Pollinator Biodiversity and Environmental/Human Health in Uganda?
}

\author{
Bin Mushambanyi Théodore Munyuli ${ }^{1,2,3,4}$ \\ ${ }^{1}$ Academic Affairs and Research Program, Cinquantenaire University (UNIC/Lwiro), D.S. Bukavu, South-Kivu Province, \\ Democratic Republic of Congo \\ ${ }^{2}$ Departments of Biology and Environment, National Center for Research in Natural Sciences (CRSN/Lwiro), D.S. Bukavu, \\ South-Kivu Province, Democratic Republic of Congo \\ ${ }^{3}$ Centre of Research for Health Promotion (CRPS), Department of Nutrition and Dietetics, Institute of Higher Education in \\ Medical Techniques (ISTM/Bukavu), P.O. Box 3036, Bukavu, South-Kivu Province, Democratic Republic of Congo \\ ${ }^{4}$ Department of Natural Resources and Environmental Economics, Faculty of Natural Resources and Environmental Sciences, \\ Namasagsali Campus, Busitema University, P.O. Box 236, Tororo, Uganda
}

Correspondence should be addressed to Bin Mushambanyi Théodore Munyuli; tmunyuli@gmail.com

Received 27 September 2013; Accepted 30 October 2013; Published 16 March 2014

Academic Editors: I. Bisht, H. Ford, R. Rico-Martinez, and P. K. S. Shin

Copyright (C) 2014 Bin Mushambanyi Théodore Munyuli. This is an open access article distributed under the Creative Commons Attribution License, which permits unrestricted use, distribution, and reproduction in any medium, provided the original work is properly cited.

\begin{abstract}
A study was conducted from 2010 to 2012 around the flower growing areas in central Uganda to generate baseline information on the status of pollinators. Primary data were gathered using a questionnaire that aimed at determining farmers and flower farm officials' perceptions on the impact of activities carried out inside greenhouses on pollinators, human health, and on crop production in the surroundings. Results indicated that the quantity of pesticides and fertilizers applied daily varied among the different flower farms visited. Bee species richness and abundance varied significantly $(P<0.01)$ according to flower farm location, to the landscape vegetation type, and to field types found in the surrounding of flower farms. Bee richness found around flower farms varied in number from 20 to 40 species in total across seasons and years. Bee density increased significantly with the increase in flower density. Small-scale farmers were aware of the value and importance of pollination services in their farming business. There was no clear evidence of a direct effect of agrochemicals application on bee communities living in the surrounding habitats. There is a need for further research to be conducted on human health risks and for toxicological studies on soils, plants, flowers, and bees in the farm landscape.
\end{abstract}

\section{Introduction}

Due to government policy of enhancing crop productivity in response to population growth, agricultural modernization in many forms is increasing at high speed in Uganda. Uganda produces approximately 11.1 million tonnes of flowers and is the second largest in South Saharan Africa after Nigeria. Uganda is among the top 10 producing flowers in the world. The first rose farms in Uganda were planted in 1992 and since then, the country flower industry has grown gradually. The average exports of flowers increased from US $\$ 9.72$ million in 1998 to US\$29.45 million in 2009. About $95 \%$ of the production is exported and 5\% is sold on local market or thrown away [1]. Uganda's floricultural sector has over the last 16 years emerged as an important nontraditional export earner, contributing over US $\$ 35$ million in foreign exchange earnings in 2012 and directly employing over 6500-9000 people. The current government of Uganda's objective for the flower industry is to stimulate its rapid development because of its contribution to the diversification of the export base and rural development. 
Practically, cut-flower industry is growing in Uganda. Currently, there are many flower firms established in the country. However, various stakeholders from government departments/agencies, the academia, research organization, community based organizationss, and nongovernmental organizations are of the view that this industry is impacting the health of the environment and the health of human beings [1]. Biodiversity (such as bee biodiversity) is suspected to be affected (disappearing) in the surrounding of flower farms [1]. Therefore, there was a need to conduct a baseline study to gather information about the potential effect of flower farms on pollinators (bees).

A pollinator is the biotic agent (vector) that moves pollen from the male (anthers) of a flower to the female (stigma) of a flower [2]. Pollinators are a key component of global biodiversity that play an important functional role in most terrestrial ecosystems [2]. They represent a key ecosystem service that is vital to the maintenance of both wild plant communities and agricultural productivity [3-6]. Pollinators are critically important for the maintenance of the human agricultural enterprise, since they provide vital ecosystem services to crops and wild plants through their pollinating activities [79]. The most important pollinators in the world are bees. Bees are essential for healthy and diverse ecosystems through their pollinating activities. Approximately $80 \%$ of flowering plants depend on pollinators, mainly bees. However, bees constitute a fragile link to food production chains due to their vulnerability to various factors, mainly anthropogenic factors. Without pollinators (bees), ecosystem functioning, trophic cascades, and the survival and maintenance of genetic diversity of many wild plant populations would be at risk and economic yields of crops may suffer a drastic reduction $[2,10]$. Hence, pollination is an essential step in the production of fruits and many vegetables [11]. An estimated 70\% of world crops experience increases in size, quality, or stability because of pollinator services, benefiting $35 \%$ of the global food supply $[7-10,12,13]$. Animal pollination also contributes to the stability of food prices, food security, food diversity, and human nutrition [14-16].

The value of pollination to agricultural production worldwide is currently estimated to be worth $€ 153$ billion per year or approximately $39 \%$ of the world crop production value ( $€ 675$ billion) from the total value of 46 insect pollinated direct crop species [14-16]. This value (€153 billion) is of more than $€ 600$ billion when added the economic benefit received from beekeeping products (sale of honey, propolis, etc.).

Though crop pollinators include a wide array of insects (e.g., beetles, butterflies, flies, etc.), bees are the most important and effective of these pollinators $[14,15]$. As the world's primary pollinators, bees are a critically important functional group because, roughly $90 \%$ of the world's plant species are pollinated by animals and the main animal pollinators in most ecosystems are bees [15-17]. Although other taxa including butterflies, flies, beetles, wasps, bats, birds, lizards, and mammals can be important pollinators in certain habitats and for particular plant species, none achieve the numerical dominance as flower visitors worldwide as bees [18]. The likely reason for this is that unlike other taxa, bees are obligate florivores throughout their life cycle, with both adults and larvae depending on floral products, primarily pollen and nectar. Bees (Hymenoptera: Apoidea) constitute an extremely species rich fauna, with an estimated 20,000-30,000 species worldwide [19-21] but approximately 3000 afrotropical species and only 700-1100 species recorded in Uganda so far [2128].

The tropics are home to immense faunal and floral diversity and encompass much of the world's biodiversity hotspots including bees [19]. Much of the tropics exist as a mosaic of agricultural lands and forest patches, and these human-altered landscapes can have strong impacts on local bee biodiversity [21-28]. Tropical Sub-Saharan Africa is also characterized by strong ecological and agricultural dependencies on pollination $[24,25]$. Hence, pollination shortage/ decline is of great concern for food security in a continent where scientists are just beginning to understand how anthropogenic land-use impacts wild and managed pollinators. Since bees are very important in agricultural production, their status is therefore of great concern not only to the farmers but to any responsible government as well, as it has a direct impact on people's livelihoods and the economy. This concern can therefore be translated into developing management techniques for the conservation of effective native bee species.

Although bees provide enormous ecological and economic benefits to flowering plants, wildlife, and humans, they are, however, under increasing threat from anthropogenic factors. There is considerable evidence for the negative impacts of habitat alteration on pollinators in highly disturbed regions of the world $[28,29]$, particularly in Europe and North America [29]. Pollinator crisis exists even in tropical and subtropical areas, where natural habitat is well represented [28]. Studies indicate that native pollinator populations face many threats, and evidence of a global pollination crisis is steadily growing $[28,29]$. Currently, there are sufficient scientific evidence of a sizeable decrease in the population and range of many pollinators such as bees, butterflies, moths, hummingbirds, and bats from most biomes of the globe $[29,30]$.

Pollinators are at risk from numerous threats and this, in turn, threatens the many benefits people and ecosystems derive from pollination services. Drivers (disturbance types) of pollinator loss/decline [31, 32] include seminatural and natural habitats loss/degradation (destruction) and fragmentation through intensive land-use, misuse/over-use of toxic pesticides in agriculture (agricultural chemicals), pathogens $[31,32]$, alien species, toxic effects of secondary compounds produced by genetically engineered plants [33], and climate change and the interactions between them [34-36]. The current challenge for the conservation of pollination services in rural landscapes is to better quantify the relative importance of a range of drivers (and pressures) and in particular their simultaneous synergistic effects in order to understand the magnitude of their impact, particularly if these are coupled with the clear ecological and economic risks associated with pollinator loss and crop yield failures $[35,36]$ such as agriculture intensification activities.

Agricultural intensification has got around 13 components of intensification [20-24]. However, the use of insecticides and fungicides is the component known to have consistent negative effects on biodiversity and ecosystem services 
delivery [35, 37]. Agriculture modernization or modern agricultural practices (agrochemical applications), landscape fragmentation, and habitat degradation have been identified as key drivers that negatively affect bee populations in rural landscapes by the elimination of resources needed for successful reproduction such as nesting sites and pollen and nectar sources [35]. In Uganda, agricultural intensification is taking place. An example of agricultural modernization in Uganda includes the upsurge of the floriculture industry. Flower farms with high agrochemical inputs are clear evidence of agricultural modernization. The negative effects of agrochemicals on biodiversity in farmlands are well documented [35-39]. As mentioned above, pesticides are considered a threat to pollinators $[40,41]$ although little is known about the potential impacts of their widespread use on pollination services in flower growing regions in Uganda.

The negative effects of agrochemicals (synthetic insecticides, botanical insecticides, miticides, acaricides, biologicals and natural enemies, fungicides, herbicides, seed dressing, adjuvant, nematicides, horticultural detergents, flower preservatives, plant growth regulators, foliar fertilizers, soil amendments, chelates, specialty fertilizers, grain storage insecticides, termiticides, rodenticides, etc.) on biodiversity in farmlands are well documented [35, 38, 39]. As mentioned above, pesticides are considered as a threat to pollinators $[40,41]$ although little is known about the potential impact of their widespread use on pollination services in habitats surrounding flower growing regions in Uganda. Since it is well established that agricultural chemicals can pose negative effects to biodiversity and to the environment of the areas where they have been applied [40,41], loss of biodiversity around flowers is therefore expected in Uganda. However, assessing negative effects of agrochemicals applied by flower farms on biodiversity in the surrounding environment is very challenging since these agrochemicals are applied inside greenhouses and therefore expected to have almost no effect on the surrounding environment.

To our knowledge, there exists no study on the impact of inorganic fertilizer (NPK) application in greenhouses of flower farms on pollinators living in the surrounding habitats. Even when studies of the impact of fertilizers on biodiversity exist, they generally conclude the overall range of effects of inorganic fertilizers on species richness and abundance being arguably negligible or of little impact [42]. Contrastingly, Le Féon et al. [41] showed that increased nitrogen (and related inorganic fertilizer) input can cause a decline in floral resource diversity and abundance (nectariferous native plants) in European farmland habitats.

Overall, there is a need to determine the trends in response of biotic organisms (including bees) to inorganic fertilizations in and outside flower farms since they are agrochemicals and they cannot be without disturbance on surrounding local ecosystems. The best way to detect negative effects of pesticides application by the flower farm on biodiversity is to study responses of most sensitive biota to pesticides application regimes. Pollinators (bees) are the best candidates for such studies. They are good bioindicators of environmental health [42-44]. Since it is well established that agricultural chemicals can have negative effects on biodiversity and on the environment of the areas where they have been applied, loss of biodiversity around flowers is expected [40]. However, assessing negative effects of agrochemicals applied by flower farms on biodiversity in the surrounding environment is very challenging since these agrochemicals are applied inside greenhouses and therefore expected to have almost no effect on the surrounding environment.

Local people's experiences and perceptions of the effects of rural development projects (e.g., flower farm industry) are often not reported or taken into account by decision-makers despite strong arguments that local opinions can help in building a policy enabling achieving a win-win conservation/ development scenario to meet development targets, and that a community's willingness to become involved in decisionmaking for the establishment of a project in their village is closely linked to their past experiences and to their perception of the benefit. Much as gender-based differences exist in perceptions of problems, integrating understanding of people's perceptions with field observations of the functioning of environmental systems is critical for developing sustainable resource management activities. Previous work examining farmers' perceptions about importance of pollinators in crop production has shown that farmers often have acute and accurate awareness of problems, and they can propose effective interventions, even if they appear unable or unwilling to tackle them [24].

In the absence of relevant information, decision-makers may be obliged to formulate their policies based on perceptions and views of farmers that appear very relevant. Since historical data collections do not exist in Uganda, it is difficult to know which bee species has declined. Thus, farmers' surveys remain the only reliable source of information that can help to provide researchers with an idea or an indication of what might have happened in the environment few years ago. Using farmers' knowledge and perceptions about changes in bee populations over the last 5 to 50 years can help to understand what happened in the area several years ago and potential causes that led to such a situation.

Even though pollinator declines are a global biodiversity threat, drivers of pollination decline/loss in natural and in agricultural ecosystems of Uganda have not been taken into account by policy-makers, conservationists, and researchers, although Ugandan agriculture owe much of its production to services delivered by locally available diverse pollinator species [20-25]. The real magnitude of pollinator decline is not easy to determine, particularly in countries like Uganda where there has been no historical data collections.

Based on the above background, there was a need to assess bee activities in the surrounding environment where different flower farms have been established. Accurate measurements of population densities (visitations) and species richness of bees are essential for any meaningful assessment of decline [23-25]. For nonsocial bees, this can be done with direct counts of individuals and classical abundance measures. For social bees, however, the number of colonies rather than the number of individuals is the crucial parameter for conservation [36] and assessment of decline. Density estimates derived from direct counts of bees are tedious and can be unreliable because natural nests are hard to detect particularly when there is little time in the field. For rapid surveys, the number 
of individuals can be used to give an indication on the potential richness of colonies in the landscape because the number of colonies in the wild can be sometimes very difficult to assess. The census of managed hives and detection of wild colonies of honeybees within a radius of $0.1-3 \mathrm{~km}$ from a given sampling location can exhaustively be surveyed but it needs personnel with knowledge of local beekeeping operations. Therefore, for a study of short period ( $<3$ years) like the one presented here, the spatiotemporal assessment of visitations of different bee species to flowering plants in a given habitat can be a useful approach to detect historical or previous changes (decline, increase) in bee species and populations in relationship to farm management and local and landscape drivers such as pesticide application intensity, availability of floral resources, and so forth.

Currently, there exist no studies from Uganda addressing effects of multiple drivers on bee abundance and species richness. Information on how pollinators respond to different drivers may improve the understanding of the nature, causes, and consequences of declines in pollinator services at a local and national scale, as well as providing light on how to invest for the development of mitigation options to slow the decline of pollinators in Uganda.

As previously highlighted, in Uganda, there have been various protestations and complaints of farmers and various stakeholders from government agencies, academia, research organizations, civil society organisations, and nongovernmental organisations about the boom of flower farms [1]. There were strong views and suspicion regarding the negative unknown impact of flower farms on health of humans, environment, and biodiversity in areas where the flower farms have been established. Consequently, there was a need to check whether these claims/complaints had a scientific foundation, when regarding effects on sensitive taxa such as bees. A preliminary field visit was conducted by the researcher and from that visit, it was pointed out that pollinators (specifically bees) inhabiting the surrounding of flower growing areas were likely to be at risk of disappearing. To verify this suspicion, an in-depth field study was therefore needed to be conducted. This was found to be necessary to ascertain community complaints.

The general objective of this study was therefore to conduct a rapid assessment on the status of pollinators (bees) around flower farms in central Uganda and provide guidelines on the preparation of a monitoring plan for the pollinators in the flower growing areas around Lake Victoria.

The specific objectives were (i) to gather information on the agrochemicals used by flower farms and their potential impacts on pollinator bees inhabiting the surroundings of the flower farms; (ii) to measure pollinator activities and assess the richness, abundance, and diversity of bees in relationship to landscape and habitat types found in the surroundings of flower farms; (iii) to assess the level of knowledge of pollination service importance in crop production by small-scale farmers living in the surroundings of flower farms; (iv) to document perceptions of local people with regards to cause of pollinator decline in their villages, (v) to collect views and perceptions of farmers about benefits and negative effects of the flower farms established in their villages; (vi) to collect views of farmers on the ways to promote flower industry in a sustainable manner (floriculture industry that matches people's needs and desires, requirements for living in a clean nonpolluted environment); (vii) to outline bee monitoring and conservation strategies in the flower farm growing regions.

\section{Materials and Methods}

2.1. Study Area Description, Visits to Flower Farms, and Dialogue with Production Managers. This study was conducted in the banana-coffee system of Lake Victoria Arc covering several districts of central Uganda. The study zone (latitude: $0.5^{\circ} 31^{\prime} 22^{\prime \prime}$; longitude: $31^{\circ} 11^{\prime} 71^{\prime \prime}$; altitude: $1080-1325 \mathrm{~m}$ ) is characterized by ferris oils with high to medium fertility level and receives on average $1000-1800 \mathrm{~mm}$ of rainfall per annum on a bimodal pattern (rainy seasons: March-May, September-November; semidry to dry seasons: June-August, December-February) with $28.7 \pm 2.77^{\circ} \mathrm{C}$ and $68.65 \pm 8.91 \%$ of mean annual temperature and relative humidity, respectively [22-26]. But the rainfall amounts and patterns are unpredictable. The study zone belongs to the Lake Victoria phytochorion [23-25] with shrubs of Acacia spp., legume trees, melliferous plant species, Papyrus, and palms ranging from 2 to $15 \mathrm{~m}$ high dominating the remnant secondary vegetation [20-22]. In this study region, coffee (Coffea canephora, Pierre ex Froehner) is the main cash crop and banana the main staple food crop. Several pollinator-dependent food and cash crops are grown in small-scale monoculture and/or polyculture fields that are integrated into this coffee-banana agroforestry system including home-gardens. There were no standard crops per study sites but most crops were found grown in almost all study sites. Crops grown as sole or in association with coffee and or banana include cassava (Manihot esculentum L.), sweetpotato (Ipomoea batatus L.), maize (Zea mays L.), beans (Phaseolus vulgaris L.), groundnut (Arachis hypogea L.), tomato (Lycopersicon esculentum L.), watermelon (Citrullus lanatus L.), pumpkin (Cucurbita moschata L.), cucumber (Cucumis sativus L.), melon (Cucumis melo L.), chilies (Capsicum spp.), and several other fruits, vegetables, and horticultural crops (cabbage, onion, etc., egg plants, sim-sim, etc.). The majority of these crops are grown in smallscale monoculture and or polyculture fields that are integrated into the coffee-banana agroforest production systems. The agroforestry system is also dominated by several native/indigenous fruit and agroforestry tree species. Banana-coffee agroforests and small-scale farms cover about $60 \%$ of the land, whereas mixed mosaic seminatural habitats cover approximately $40 \%$ of the farm-landscape studied. There exist in this study region some large monoculture plantations (sugar cane plantations, coffee plantations, tea plantations, etc.) and some flower farms companies.

Rural central Uganda is a mosaic landscape where "islands" of patches of natural habitats (forest fragments, forest reserves, wetlands, woodlands) and linear (eg., hedgerows) and nonlinear (fallow fields, grasslands, woodlots, cattle pastures, or rangelands) features of seminatural habitats [21] that serve as "field boundaries" of the variety of smallscale fields are found scattered within agricultural matrices. 
Compared to other districts of the country, the study area (central Uganda) is also characterized by high demographic pressure, limited access to arable lands, continuous cultivation, and over-exploited lands under unrevised land policies [20]. All study sites had also some forest remnant tree species retained within them, ranging from 1 to 175 trees/ha found both in crop fields as well as inside remnant natural vegetations scattered inside the forest. Flower farms are located in four major zones of central Uganda: the first zone is Entebbe airport zone located at $60 \mathrm{~km}$ from Kampala city (example: Wagagai flower farm and Rosebud-II. Wagagai and Rosebud II are separated by a distance of $30 \mathrm{~km}$ ). The second zone is in Mukono district located at about $250 \mathrm{~km}$ from Kampala city (example: Mairye estates), the third zone is Ntungamo zone located at about $500 \mathrm{~km}$ far away from Kampala city (example: Pear flower farm). In addition, mantel test $(P<$ 0.05 ) showed that there was no evidence of significant spatial autocorrelation between pollinator counts on transects within a landscape surrounding a flower farm. The distance between greenhouses and people's homes varied from a flower farm to another one: $>20 \mathrm{~m}-100 \mathrm{~m}$. In many cases, small-scale gardens are established closer $(0-20 \mathrm{~m})$ to greenhouses. Thus, field visits were conducted to make a rapid survey on the status of pollinators (bees) around the flower farms in the Lake Victoria shores. To be able to understand the actual activities and operations within the flower farm, four flower farms were visited out of a total of 12 existing and operating flower farms in central Uganda, given the budgetary and time constraints. The 4 selected flower farms included Fiduga (located at $15 \mathrm{~km}$ far from Kampala, Wakiso district), Pearl flower farm (located at about $400 \mathrm{~km}$ far from Kampala in Ntungamo district), Mairye estates (located at $30 \mathrm{~km}$ far from Kampala in Mukono district) and Wagagai flower famr (located at about $40 \mathrm{~km}$ far away from Kampala along Entebbe airport road). Overall, commercial floriculture is still a new industry in Uganda, dating back to only 1993. Cut-flowers, cut foliage and, to a lesser degree, pot plant cuttings are the main outputs. Cut-flowers include a variety of roses, chrysanthemum cuttings, carnations, and summer flowers. The four flowers grow different types of flowers and varieties (Table 1) and apply different levels of pesticides. The major flower varieties grown and exported from Kenya are roses, carnation, alstroemeria, lisianthus, statice, and cut foliage. Rose flower dominates.

Flower farm visits were conducted for two years (2010 to 2012). During a visit of each flower farm, discussions with production manager were engaged by the researchers. The discussion focused on collection of information likely to enlighten the potential negative effect of activities conducted at the flower farm on pollinators as well as collecting information likely to help generate information that is more rewarding to policy-makers. During the course of discussions, various types of information were collected, mainly, information about the type of agrochemicals (pesticides, fertilizers) used by the flower farms, the type of varieties grown, the type of production conducted (e.g., exporting flowers cuts or stems or roses), the total number of people employed (including the proportion of females employed), the total size of the flower farm (including the number of hectares in production), the number of years since the flower farm was established, the monthly total production exported, the gross income from sale of flower products, the costs of labor, the costs of other general inputs, costs of pesticides/fertilizers purchases, and information about measures taken to control runoff of chemicals into the surrounding environment. The researcher visited stores of agrochemicals to confirm trade names reported by the flower farm production managers. In addition, production managers were asked whether they understood pollination and if pollination by bees was an important factor in their production business.

\subsection{Landscape/Habitat, Bee Biodiversity, and Floral Resources Surveys}

2.2.1. Landscape/Habitat Surveys. After farmers' interviews, surveys of bees were conducted in different landscape/ habitats in the immediate surroundings of the flower farms. For each flower farm, surveys were conducted in all directions considering the flower farm to be at the center. Two types of fields were found in the surroundings of flower farms: cultivated fields and noncultivated fields. The type of dominant landscape vegetations characterizing these cultivated and uncultivated fields were cropland and grassland vegetations. Cropland vegetation types that dominated cultivated fields were composed of a mixture of crops grown under various cropping/agroforestry systems. The grassland vegetation types that dominated the uncultivated fields were composed by a mosaic of seminatural habitats. The dominant habitat types in the croplands were different land-use types or crop associations (e.g., maize + beans + banana), whereas the dominant seminatural habitats in grasslands were pastures, fallows, woodlots, hedgerows, field margins, and so forth.

\subsubsection{Transect Counts for Bee Surveys. Different beneficial} insect taxa respond to agricultural practices at different spatial scales and often at multiple spatial scales [45]. Therefore, it was found important to assess bee diversity and visitations at different spatial scales by placing sampling transects at different distances from the flower farm. Placing sampling transects at different distances was sought to help in determining at which spatial scale chemical applications in the flower farms could affect significantly activities of bees in cultivated and noncultivated fields in the surrounding landscape habitats. The collection on bees was conducted for five consecutive rounds across dry and rainy seasons during two years (2010-2012) at regular periods (dates) of visits of the flowers farms. Hence, five transects were set from the edge of the flower farm into either croplands or grasslands or both. Transects were established, extending from the flower farm boundary into farmlands. Transects were separated by a distance of $3-5 \mathrm{~km}$. They were set in north, east, west, and southern part of each flower farm. With this distance, bee samples were independents since the normal foraging distance of most bees is $2 \mathrm{~km}$. Each transect measured a total length of $2.2 \mathrm{~km}$. Bees were sampled on these transects $(20 \mathrm{~m}$ large $\times 2.2 \mathrm{~km}$-long) at $0-10 \mathrm{~m}, 500 \mathrm{~m}, 1500 \mathrm{~m}$, and $2000 \mathrm{~m}$ from the edge of the flower farm. Transects were set parallel to flower farms at the above mentioned distances. Plots were set 
TABLE 1: Example of type/category of flower varieties grown by different flower farms.

\begin{tabular}{|c|c|c|}
\hline MAIRYE & PEARL and WAGAGAI & FIDUGA \\
\hline Category of cut-flowers & Intermediate Varieties & 120 varieties of Crysantemum cuttings \\
\hline Sweet heart & Red Calypso (Red) & Eg. Ibis lime, Nimba, Copper, Maiko, Noa, Parrot \\
\hline Super sweet heart & Akito (White) & City, Art Sunny, Ludmilla, Fire, Zembla, Avoriaz \\
\hline \multirow[t]{2}{*}{ Intermediate } & Blushing Akito (Pink) & Grand Salmon, Zakumi, Goody, Fuego, Voyager, Lexy, Breezers, \\
\hline & Jetset (Yellow) & Tory, Safin Purple, Bacardi Yellow, Managua, \\
\hline Varieities are & Mylo (Pink) & Vivid Cream, Tuvalu Sunny, Kindly Salmon, Zembla Cream, \\
\hline For Super sweet heart: & Inka (Bicolur Red/Yellow) & Champagne Pink, Ibis Pearl, Ping Pong, Browny, \\
\hline Valentino & Tropizal Amazon (Orange) & Motown, Baracardi, Raisa, Verdy \\
\hline Akito & Sonrisa (Yellow) & Rwins, Merlot, Art, Ping Pong, Kuga, Quinty \\
\hline Banjo & Jupiter (Yellow) & Kindly, Ludmilla, Puma Sunny, Redstart \\
\hline \multicolumn{3}{|l|}{ For sweet heart: } \\
\hline Tropical Amazon & Wild Calypso (Hot Pink) & Leopard, Zembla Yellow, Grand Pink, Athos, Anastasia Pink, \\
\hline Jet Set & Belle Rose (Pink) & Crystal, Streamer Splendid, Dance Sunny, Felling Green Dar \\
\hline Red Ribbon & & Handsome, Gabd Cherry, Froggy, Arctic Queen, Roma, Ping Pong, \\
\hline \multirow[t]{2}{*}{ Red Giant } & & Marabou, Fire, Parrot, Noa, Nimba, Kaitylnn, Tiger, Harley, Browny \\
\hline & & Cheops, Purple Rain, Sound, Delianne Yellow, Ritmo, Charming, \\
\hline Intermediate varieties & & Salinas, Jazzy, Husky, Oxana, Clearity, Lollipop Purple, Falcon \\
\hline Blashing Akito & & Joker, campus, Candor, le Mans, Planet, Lexy, Sarasarane Pink, \\
\hline Lambada & & Syrup, Moonlight, Lerbin, Minty, Anky, Edge, Katinka, Marabou, Marimo, \\
\hline \multirow[t]{10}{*}{ Frisco } & & Lollipop Yellow, Vogue, Energy, Magic, Teror, Ferry, Fuego, Central \\
\hline & & Leopard, Voyager, Swan, Puma, Vatican, Stromboli, Crystal Pink, Classy, \\
\hline & & Diva, Starling, Zodiac Lilac, Vulcano Dark, Spider White, Punch, \\
\hline & & Copper, Juicy, Chamapagne Ora, Boris Becker, Rocky, Pisang, \\
\hline & & Merlot, Rosas, Goody Orange, Supernova, Froggy, Gin Pink, Berdy, Pelican \\
\hline & & Eleonora Lilac, Vireo, Snowdown, Cheeks, Ritmo, Tigerrag, Ely, Charming \\
\hline & & Greenbird, Avoriaz, Swan, Motto, Katinka, Sound, Vivid, Vivid Cream \\
\hline & & Dance Salmon, Arctic Queen, Delianne White, Reagan White Eli, Balloon \\
\hline & & Tamarinda White, Tamarinda Violet, Margarita Dark Pin, Margarita Helena \\
\hline & & Hypnotica Red, Carolina Orange, Juventa, lrmon, Bromo, Margarita Lilac \\
\hline
\end{tabular}

mainly at different flower patches alongside transects. In this study, flower patches were isolated groups of blooming plants; the group was composed of various plants of same or various species associated in a given site. Flowers were composed of either natural vegetation or crop plants and in some cases both.

While walking along transect, at each flower patch, data was collected on bee populations using field observations, hand-nets, and transect-count methods. Observations were also made on other pollinators, such as butterflies, moth, and hover flies; although detailed data is not presented since the focus was on bees.

Within each plot, bee species within the plots were counted and their visitation intensity was measured and recorded on datasheets. Parallel to bee surveys, habitat/landuse variables were also recorded such as the percentage cover and number of seminatural habitats. When needed (in some few cases), nests of solitary bees were recorded using subjective (focused) searches in particular habitats (nesting habitats). The different nests were also located either by chance during random searches or by inspecting tree-holes/ termite mounds located alongside established belt transects of width $20 \mathrm{~m}$ and length $1.1 \mathrm{~km}$ per transect.
Bee collections/censuses were conducted from morning to evening hours (07:00 h to 17:00 h, local time). Pesticides applications inside greenhouses are commonly conducted at different interval of times: 5:00 h-7:30 h, 7:30 h-10:30 h, 15:30 h-18:30 h. Therefore, some bee collections coincided with periods of pesticides application.

2.2.3. Censuses of Bee-Visitations. Visitations are part of four measures of pollination services delivery by pollinators to plants/crops: (a) pollination rate (number of pollinators visiting flowers/min), (b) proportion of visited flowers (number of flowers visited by pollinators/total number of flowers in a plot), (c) flower handling time (seconds) or the mean time pollinators spent on individual flowers in a plot, and (d) pollination efficiency (\% fruit set after single visit by a $\mathrm{p}$ ). These four parameters of pollination services can be used to forecast high reproductive success of plants/crops after visitation of crops/plants as compared to those that were not visited. Thus, pollinator visitations (number of bee individuals landing on flower reproductive parts and moving/ collecting floral resources such as pollen/nectar for at least 0.1-1 minute before flying away) to plants/crops species in 
flower patches were conducted from morning to evening hours each sampling day.

All floral visitors, pollinators and nonpollinators to male and female flowers and inflorescences of all flowering plant species were collected at the time of their greatest activity. The pollinator censuses were conducted for 2 full years (2010-2012 and for each year, data was collected during four consecutive sampling rounds (R1: December-February, R2: March-May, R3: June-August, R4: September-November)). The pollinator censuses were conducted within permanent plots $(20 \mathrm{~m} \times 100 \mathrm{~m})$ that were placed in a systematic way (along line transects of $20 \mathrm{~m} \times 1100 \mathrm{~m}$ ) and separated by $10 \mathrm{~m}$. Pollination information was basically collected on transects. Overall, data recorded was based on an observable number of bees per flower patch per $25 \mathrm{~m}^{2}(5 \mathrm{~m} \times 5 \mathrm{~m})$ from each sampling unit (plot). The data recorded and stored in datasheets was expressed as number of bee-visits per bee species per 100-500 flowers/15-20 min observations per flower patch of $25 \mathrm{~m}^{2}(5 \mathrm{~m} \times 5 \mathrm{~m})$.

While walking along transect, censuses of bees were performed during 15-30 min at each flowering patch met along the transect. In each census, several floral stems with 1005000 flowers were observed. A total of 10 to 50 flower patches were met and censured each study visit. Minimum observation distance from the flowers was $2 \mathrm{~m}$. In each census, the number and identity of visitors were recorded, including the number of flowers visited, the visitation intensity of each bee species, and the behavior of these visitors on the flowers. The abundance, diversity, and composition of the flower visitor assemblage of the focal populations were determined by counting the number of insects visiting the flowers by means of point-centered 30 min surveys. Sampling took place during full bloom of plants. Thus, fully blooming inflorescences/ flowers were monitored during the entire foraging period of the day including the period of peak insect visitation activity (9:00 h-15:00 h).

Flower-visiting insects were identified, and buzz-pollinating ability (based on observation of sonication and pollen release by some bees such as Xylocopa) was recorded for each visit whenever possible. During bee counts, local temperature and wind speed were recorded at the start of each transect as these can affect pollinator behavior, although counting was conducted only at temperatures above $18^{\circ} \mathrm{C}$ to eliminate the impact of low temperatures on counts. Censuses were conducted along the day from 6:30 h to 17:30 h local time. Each study visit, surveys were carried out across the five transect.

Duration of flower visits to individual inflorescences/ flowers of each plant species was recorded for several individual bees and rounded up to full minutes. A flower visit was defined as the period between the first landing on the inflorescence and final departure (irrespective of short hovering flights for scent transfer). More specifically, a visit was defined to have occurred when the visitor's body contacted the reproductive organs (stigma or anther) of any available fresh flower. The bee observations were conducted each day that weather conditions allowed pollinator activities. The order of observation of plots alongside transect was random, each plot being observed only once per day. During each observation period on flowering patches in sampling plots, the number and identity of flower visitors to flowers or inflorescences (depending on the species) of all species blooming in the plots were noted.

The identification of some flower visitors was done in the field with the experience of the researcher. For species that could not be identified in the field during foraging observations, the visitor was given a morpho-species name and immediately after finishing foraging observation data collection on datasheets, a handnet was used to collect specimens. Voucher specimens of visiting bees were collected from flowering plants on separate moments to avoid disturbance to pollinator activity. The specimens were saved in alcohol $70 \%$ and later the identification confirmed in the laboratory using available collection of bees of Uganda. The bees were identified using the author's reference collection of bees that is located at Makerere University zoology museum.

2.2.4. Assessment of Floral Resources. To account for the floral abundance of the plant species, after each observation period, each species' number of open attraction units to bees which could be flowers or inflorescences was counted. The data recorded was expressed as number of fresh flowers (all plant species combined) per flower patch per $25 \mathrm{~m}^{2}$. In addition, the number of flowering plant species was recorded per sampling plot alongside transect walks.

\subsection{Field Surveys and Farmer's Interviews on Pollination} Knowledge and on Causes of Pollinators Decline in Relationship to Activities Carried Out at Flower Farms. In the surrounding of each flower farm, four directions were followed. In each direction, 2 villages were selected in the north, south, east, and western directions of the flower farm. In each direction, the first village was selected between $0 \mathrm{~m}$ and $1 \mathrm{~km}$ far from the edge of the flower farm; the second village was selected between 2 and $3 \mathrm{~km}$ far from the flower farm. These villages were selected to cover the range of space at which a farmer could smell and could not smell the scent of the chemicals from the flower farms. In each village 20 people (10 men and 10 women) were randomly selected while walking alongside main trucks in the village. In total, 160 people were interviewed from 4 villages from the four directions in the surrounding of the 4 flower farms, making them 640 people interviewed in total from the surroundings of the four flower farms. Farmers interviewed were those met in their gardens busy farming. During interviews, after finishing the dialogue with farmers, the researcher conducted field inspection under their guidance. Field visit and inspection were conducted to enable scientists/researchers to verify whatever farmers were reporting when interested in gathering information about their ecological knowledge of pollination process.

Primary data were collected by administering a questionnaire to production managers of different flower farms and to small-scale farmers living in the surroundings of the flower farms. In addition, a separate datasheet was used to gather data on bee species diversity and populations. The questionnaire captured information on agrochemicals used, bee diversity, landscape/terrain, weather conditions, especially at 
the time of bee surveys, farmers, and flower official perceptions and the impact of their activities on pollinators and crops.

More specifically, the effects of farm management practices (agrochemical pesticides utilization intensity), landscape vegetation types, distance from the flower farm, and the flower farm location on bee communities foraging in environments surrounding flower farms were investigated. The investigation aimed at identifying factors that could help in understanding the potential role of agrochemical activities carried out inside flower farms on bee biodiversity living in the adjacent habitats. In addition, farmers' surveys were conducted in order to get an idea of the potential causes of decline of bees in the villages including the impact of flower farm activities (agrochemical applications).

The questionnaire was also administered to assess if farmers understood the meaning of pollinators, pollination, and pollination service and its importance in crop production activity. Villages where flower farm activities were not expected to impact agricultural production were identified (villages located at more than $5 \mathrm{~km}$ far away from the edge of the flower farms) and sampled to ascertain the differences in bee populations and species richness. Only farmers found doing some activities in their gardens were interviewed. Efforts were made to be gender sensitive during the course of interview. However, women were frequently found in the gardens than men.

The questionnaire consisted of a mixture of open and closed ended questions. The questionnaire was pretested by the researcher a few weeks prior to field surveys. Semistructured interviews that had a number of predefined starting questions were used. Thus, farmers were interviewed using a pretested structured questionnaire. The questionnaire was piloted by the researcher one week prior to the actual survey and the necessary corrections were made. Interviews were largely conducted in the local languages (Luganda, Runyakore) with translation into English whenever necessary.

Data collection related to interviews at the different sites took place from 9:00 am onwards, because most women started their agricultural activities by 6:00 am and were completed by midday. Prior to data collection, the researchers solicited informed consent from participants. The questionnaires took approximately 20-30 minutes to administer to each individual respondent. The questionnaire was filled using face to face interviews. Interviews were conducted either at the farmer's home or in the field, where such fields were within $0.5-1 \mathrm{~km}$ from a farmer's homestead and the farmer was willing to be interviewed on site (field or garden). Once conversation on a topic was initiated, it was allowed to roam freely until exhausted at which point a new topic was begun. It was ensured that interviewees had the opportunity to ask the researchers questions at the end.

Notes were taken on individuals' responses. The researcher visited every respondent's crop field in order to verify some of their responses. The questionnaire submitted to small-scale farmers focused mainly on crop production and the relevance of pollinators in crop production. The survey questionnaire comprised two main parts. The first section sought general sociodemographic information about respondents, including age, gender, household income, gender labour in crop production, marital status, number of children, and formal education levels. The second section gathered information relating to respondents' knowledge of crop pollination, pollinator types, perception of the importance of pollinators to crop yield, potential causes of decline of pollinators in the village, and potential role played by activities (application of agrochemicals) carried out by the flower farm located in the village. Specifically, farmers were asked to (i) describe/define their understanding of pollination, (ii) to name, identify, and differentiate between wild bees and honeybees and other insect pollinators they knew and indicate the area where they sleep (nesting site), (iii) mention the role of bees and other pollinators in crop fruit/seed set, (iv) to explain the importance of pollinators in their farming business, (v) to comment on the effects of pesticides application on wild bees and other pollinators, (vi) to list (and justify why they think so) the potential causes of decline/loss of pollinators in their village including describing the role played by activities carried out at the flower farm such as intensive application of agrochemicals, (vii) to comment on the linkage between crop yields reduction and bee decline in the village, (viii) to list advantages (benefits) they get by living near the flower farms, (ix) to propose sustainable solutions to resolve their conflicts with flower farms. Photographs of different bee species and different other pollinator species were presented to respondents to help in identification of different species of bees visiting crop flowers.

\subsection{Data Analysis}

2.4.1. Cumulative Analysis of Agrochemicals Application. From the raw data obtained during discussions with the flower farm managers, the total amount of agrochemicals applied on a daily basis was used to calculate the amount of agrochemicals used per annum in relationship to total amount of water used. Later on, the annual amount of pesticides used was cumulated based on the number of years since the flower has been in production. The cumulative analysis was undertaken using Microsoft Excel 2007.

2.4.2. Bee Visitation and Floral Resources Raw Data Files Pooling and Organizations. Data on bee counts and visitations that were recorded per each sampling plot were summed to obtain the total number of bee-visits and bee species per transect each study round. Similarly, the total number of fresh flowers and number of flowering plant species per transect was obtained by summing values obtained per sampling plot $(20 \mathrm{~m} \times 100 \mathrm{~m})$.

2.4.3. Variation in Bee Abundance, Visitation, Species Richness, and in Flower Density between Surrounding Habitats of the Different Flower Farms. Cross-tabulations with selected variables (number of species and individuals, visitation frequency) were undertaken using pivot table in Microsoft Excel 2007 , to verify anomalies and correct errors in raw data files before data analysis.

En ce qui concerne the diversity and numbers of bees, the abundance of flower visitors was estimated by standardizing 
the number of visits per time unit (expressed as visits per population per hour/flower patch). Flower visitor diversity was assessed by calculating species richness and evenness. Richness was calculated as the number of flower-visiting species found visiting flowers in flowering patches. Diversity of bee communities between the four flower farms was estimated using the Shannon-Wiener's diversity index $\left(H^{\prime}\right)$ and the similarity in bee communities among the four flower farms was estimated by the Sorensen similarity index according to Magurran [46] using raw data collected across four rounds of data collection over two years (2010-2012).

\subsubsection{Effects of Landscape/Habitat Types on Bee Abundance} and Species Richness. All variables were tested for normality and the strongly skewed variables were transformed prior to analyses if necessary to meet the assumption of normality and homogeneity of variances. Therefore, the percentage cover of flowering plants was arcsine-square-root $(+0.5)$ transformed and number of species or counts of bee individuals and beevisitations counts were $\ln (x+1)$ transformed. The differences in number of bee individuals and species and in number of fresh flowers between the 4 flower farms were tested with general linear model (GLM) analysis of variance (ANOVA) in Minitab release version 165. GLM analyses were fitted with pesticides application intensity (very high: 4, high: 3, medium: 2, and low: 1) landscape vegetation types, flower farms, and number of transects as treatment factors (predictors) and the abundance, visitation frequency, species richness of bees, and number of fresh flowers as the response variables. Where GLM test indicated significant differences, posthoc Tukey's test was used for means separations.

2.4.5. Farmers' Surveys. The survey data were entered into a spreadsheet and checked prior to analysis. Cross-tabulation with selected variables, percentages, and means were undertaken using pivot table in Microsoft Excel 2007. Percentages were based on either the total number of respondents or total responses, details of which are provided in the respective text or tables. Chi-square test was used to determine association between variables such as to determine the effects of farmers' sociodemographic profiles on their knowledge of pollinators, pollinator unfriendly farming practices, farmers' perceptions of crop yield reduction, and causes of decline of pollinators in their villages. During interviews of farmers about potential negative effects of agrochemicals applied by the flower farms on crop yields, decline of bees, and environmental pollution, most often a farmer could give more than one justification/statement (opinion). Therefore, both the summary of the statements made by farmers and the full statements were presented in separate tables/figures. The frequency of occurrence of the statements from the entire population interviewed was calculated and presented in respective tables.

\section{Results}

3.1. Agronomic and Socioeconomic Characteristics of Flower Farms Studied. The different farms studied were established with clear production objectives. For example, Mairye and
Pearl flower farms were found to be specialized in the production of cut flowers and roses whereas Fiduga flower farm was found to be specialized in the production and export of Crysantemum cuttings (stems). Hence, different companies grow different types of flower varieties (see Table 1). The land under production played a big role in the production potential for each farm.

The number of employed people was 800,485 , and 255 , respectively, at Mairye, Fiduga, and Pearl flower farms. Across flower farms, the proportion of employed females oscillated between 55 and $65 \%$. The monthly total production for export varied from one flower farm to another: 4 million cut-flowers for Mairye, 36 million cuttings for Fiduga, and 2 million cut flowers (including roses) for Pearl. Consequently, the declared total annual income obtained from sales of flower cuttings was US\$90,000, US\$47,000, and US\$7000 for Mairye, Fiduga, and Pearl flowers farms, respectively. The monthly cost for pesticides/fertilizers purchase oscillated between US $\$ 10,000$ and US\$53,000 across flower farms.

There was a positive correlation between the monthly total income obtained per flower farm after sales of flower cuttings and (i) the cost of general inputs $(y=0.2667 x+$ $\left.61421, R^{2}=0.4714, P<0.05\right)$, (ii) cost of labor $(y=$ $-0.7502 x+100423 ; R^{2}=0.4749, P<0.05$ ), (iii) the number of employed females by the flower farm $(y=51.036 x+59526$; $R^{2}=0.2035 ; P<0.05$ ), and (iv) total size of the flower farm in production $\left(y=3833.3 x+21000, R^{2}=0.306, P<0.05\right)$. On the other hand, there was no significant $(P>0.05)$ correlation between the monthly total income obtained per flower farm after sales of flower cuttings and (i) the number of employed males $\left(y=-61.626 x+89046 ; R^{2}=0.0966, P<\right.$ $0.05)$, (ii) the total number of workers $(y=13.314 x+67832$; $R^{2}=0.023, P>0.05$ ), (iii) the total farm size land ( $y=$ $1684.2 x+37053, R^{2}=0.0312, P>0.05$ ), and (iv) the cost pesticides/fertilizers $\left(y=0.1344 x+67049 ; R^{2}=0.0159, P>\right.$ $0.05)$. This last result indicated that it may not be necessarily rational for a flower farm to over spend on agrochemicals (pesticides/fertilizers) that are dangerous to the health of human beings and to the environment. In other words, it is still possible to have a flower company reaching high profitability while spending little on toxic pesticides. Different options of buying and using nontoxic and effective pesticides can still be adopted by a flower company and obtain good profitability.

3.2. Variation among Flower Farms in the Application of Agrochemicals (Pesticides, Fertilizers) inside Greenhouses. During field visits, information on agrochemicals used by the different flower farms was collected. A checklist of different fertilizers and pesticides used and dosages are given in Tables 3 and 4 , respectively. Long-term use of fertilizers for agricultural purposes has been an issue of concern to researchers. The presence of metals in some agricultural fertilizers raised fears that continued application of fertilizers may lead to accumulation of these metals to toxic levels in the soil for living organisms including plants. Prolonged fertilizers use is also a concern in sites where cut-flower industries are established in that it may affect neighboring small-scale lands. 
TABle 2: Types of fertilizers and pesticides used by different companies.

\begin{tabular}{|c|c|}
\hline Fertilizers applied & $\begin{array}{c}\text { Quantity mixed in } \\
1000-2000 \text { liters of water }\end{array}$ \\
\hline \multicolumn{2}{|l|}{ MAIRYE flower farm } \\
\hline \multicolumn{2}{|l|}{ Macroelements } \\
\hline Calcium nitrate & $600 \mathrm{~g}$ \\
\hline Potassium nitrate & $350 \mathrm{~g}$ \\
\hline Magnesium sulfate & $350 \mathrm{~g}$ \\
\hline Ammonium phosphate & $150 \mathrm{~g}$ \\
\hline Monopotassium phosphate & $150 \mathrm{~g}$ \\
\hline \multicolumn{2}{|l|}{ Microelements } \\
\hline Iron & $10 \mathrm{~g}$ \\
\hline Zinc & $5 \mathrm{~g}$ \\
\hline Manganese & $5 \mathrm{~g}$ \\
\hline Boran & $5 \mathrm{~g}$ \\
\hline \multicolumn{2}{|l|}{ PEARL flower farm } \\
\hline \multicolumn{2}{|l|}{ Macroelements } \\
\hline Calcium nitrate & $86 \mathrm{Kg}$ \\
\hline Potassium nitrate & $77 \mathrm{Kg}$ \\
\hline Magnesium nitrate & $27 \mathrm{Kg}$ \\
\hline Monopotassium phosphate & $30 \mathrm{Kg}$ \\
\hline Urea & $29 \mathrm{Kg}$ \\
\hline Microfeed & $2.2 \mathrm{Kg}$ \\
\hline Librel & $3.4 \mathrm{Kg}$ \\
\hline \multicolumn{2}{|l|}{ Trait-elements } \\
\hline Nitric acid & $15 \mathrm{Kg}$ \\
\hline Phosphorc acid & $12 \mathrm{Kg}$ \\
\hline Zinc sulphate & $0.2 \mathrm{Kg}$ \\
\hline Borate & $0.2 \mathrm{Kg}$ \\
\hline \multicolumn{2}{|l|}{ FIDUGA flower farm } \\
\hline \multicolumn{2}{|l|}{ Macroelements } \\
\hline Lime & $25 \mathrm{Kg}$ \\
\hline TSP (triple super phosphate) & $2.5 \mathrm{Kg}$ \\
\hline Calcium Nitrate & $3.5 \mathrm{Kg}$ \\
\hline N-P-K ( 12-10-18) & $3.5 \mathrm{Kg}$ \\
\hline Magnesium sulfate & $150 \mathrm{Kg}$ \\
\hline Type of pesticides applied & $\begin{array}{c}\text { Quantity mixed per liter of } \\
\text { water }\end{array}$ \\
\hline \multicolumn{2}{|l|}{ MAIRYE flower farm } \\
\hline \multicolumn{2}{|l|}{ Fungicides } \\
\hline Ortiva & $1 \mathrm{~g} / \mathrm{liter}$ \\
\hline Nimrod & $2.5 \mathrm{~g} / \mathrm{liter}$ \\
\hline Meltatox & $2.5 \mathrm{~g} /$ liter \\
\hline Previcur & $2 \mathrm{~g} / \mathrm{liter}$ \\
\hline Ridonil & $2.5 \mathrm{~g} / \mathrm{liter}$ \\
\hline Daconil & $2 \mathrm{~g} / \mathrm{liter}$ \\
\hline Ravaral & $2 \mathrm{~mL} / \mathrm{liter}$ \\
\hline
\end{tabular}

TABLE 2: Continued.

\begin{tabular}{lc}
\hline Insecticide & $1 \mathrm{~g} /$ liter \\
Methomex & $1.5 \mathrm{~g} /$ liter \\
Confidor & $0.8 \mathrm{~g} /$ liter \\
Duduthrin & $1 \mathrm{~g} /$ liter \\
Othane & \\
Miticide/Nematicides & $1.1 \mathrm{~mL} /$ liter \\
Nemacin & $1.5 \mathrm{~mL} /$ liter \\
Vydate & \\
Herbicide & $2 \mathrm{~mL} /$ liter \\
Lalad Master & $3 \mathrm{~mL} /$ liter \\
Round-up & \\
PEARL flower farm & \\
Insecticides & $2.5 \mathrm{~mL} / \mathrm{liter}$ \\
Meltaton & $2 \mathrm{~mL} /$ liter \\
Milraz & $0.4 \mathrm{~mL} /$ liter \\
Equation & $1 \mathrm{~g} /$ liter \\
Teldor & $1.5 \mathrm{~mL} /$ liter \\
Roural & $0.8 \mathrm{~mL} /$ liter \\
Score & $1.5 \mathrm{~mL} /$ liter \\
Previcur & \\
Acaricide-Miticide & $0.5 \mathrm{~mL} /$ liter \\
Silwet & $2 \mathrm{~mL} /$ liter \\
Fedion & $0.7 \mathrm{~mL} /$ liter \\
Floxelle & $0.6 \mathrm{~mL} /$ liter \\
Nissuron & \\
\hline & \\
\hline &
\end{tabular}

In these flower farms, spraying of pesticide is done manually by male workers provided with almost no means of protection apart from gumboot. There was a high variability in quantity of pesticides and fertilizers applied daily among the different flower farms visited (Tables 3 and 4). In the pesticide class, fungicides, miticide-nematicide, insecticides, and herbicides were applied by the different flower farms at different levels.

Types (herbicides, insecticides nematicides, miticides, and fungicides) and number of pesticide applications on flowers were retained as a surrogate variable for agricultural practice intensity inside the flower farm. Indeed, this variable reflected both the amount of inputs in field greenhouse (to increase flower productivity) and disturbance of environment and human health caused by each spray session by farming pumps or spray machines. Overall, the intensity of pesticide application (that combines both the types and number of pesticides applied per month) was considered as a proxy of flower production practice intensity. This surrogate has a potential indirect impact on pollinator communities living in habitats surrounding flower farms. The intensity of pesticide application by the flower farm was measured at four levels (very high: 4 , high: 3 , medium: 2 , and low: 1). Based on quantity reported by the production mangers and based on field experiences (observations, field impressions), Fiduga flower farm was classified as the flower farm with very high level of 
TABLE 3: General linear model (GLM) for exploring the effects of the flower farm type (location), the intensity of agrochemical (fertilizers/pesticides) applications per flower farm, landscape vegetation types, and the distance at which the sampling transect was set (spatial scale) in explaining the patterns of variability in bee biodiversity inhabiting habitats surrounding major flower farms found in central Uganda.

\begin{tabular}{|c|c|c|c|c|}
\hline Responses & Fixed factors & df & $F$ value & $P$ value \\
\hline \multirow{4}{*}{ Bee species richness } & Intensity of agrochemical applications & $(3,33)$ & 1.93 & 0.142 \\
\hline & Flower farm name (location) & $(3,33)$ & 2.94 & 0.048 \\
\hline & Landscape vegetation types & $(1,33)$ & 4.30 & 0.047 \\
\hline & Transects & $(4,33)$ & 3.88 & 0.012 \\
\hline \multirow{4}{*}{ Bee abundances } & Intensity of agrochemical applications & $(3,33)$ & 9.881 & 0.000 \\
\hline & Flower farm name (location) & $(3,33)$ & 13.94 & 0.000 \\
\hline & Landscape vegetation types & $(1,33)$ & 2.361 & 0.135 \\
\hline & Transects & $(4,33)$ & 4.07 & 0.009 \\
\hline \multirow{4}{*}{ Bee visitation frequency } & Intensity of agrochemical applications & $(3,33)$ & 8.02 & 0.000 \\
\hline & Flower farm name (location) & $(3,33)$ & 11.12 & 0.000 \\
\hline & Landscape vegetation types & $(1,33)$ & 0.09 & 0.773 \\
\hline & Transects & $(4,33)$ & 4.42 & 0.006 \\
\hline \multirow{4}{*}{ Blooming plants abundance } & Intensity of agrochemical applications & $(3,33)$ & 0.64 & 0.595 \\
\hline & Flower farm name (location) & $(3,33)$ & 1.69 & 0.190 \\
\hline & Landscape vegetation types & $(1,33)$ & 5.27 & 0.029 \\
\hline & Transects & $(4,33)$ & 13.80 & 0.000 \\
\hline \multirow{4}{*}{ Blooming plant species richness } & Intensity of agrochemical applications & $(3,33)$ & 0.711 & 0.598 \\
\hline & Flower farm name (location) & $(3,33)$ & 0.778 & 0.541 \\
\hline & Landscape vegetation types & $(1,33)$ & 2.415 & 0.018 \\
\hline & Transects & $(4,33)$ & 3.331 & 0.0016 \\
\hline \multirow{4}{*}{$\begin{array}{l}\text { Nests and nesting sites density } \\
\text { (abundance) on transects }\end{array}$} & Intensity of agrochemical applications & $(3,33)$ & 2.743 & 0.033 \\
\hline & Flower farm name (location) & $(3,33)$ & 2.568 & 0.044 \\
\hline & Landscape vegetation types & $(1,33)$ & 2.796 & 0.027 \\
\hline & Transects & $(4,33)$ & 23.12 & 0.000 \\
\hline
\end{tabular}

intensity of pesticide application; and Rosebud-II was classified as with high level of intensity of pesticide application whereas Mairye was classified as flower farm with medium level of intensity of pesticide applications. The flower farm that was classified as with low level of intensity of pesticide applications was Pearl flower farm.

It was not clear whether the quantity of pesticides had an effect on pollinators living in the surrounding habitats, since most of the agrochemicals were applied inside greenhouses of the flower farms. However, daily application of pesticides cannot be without effect on the surrounding environment with its living organisms. In the short term, the effects may not be visible or perceptible. However, in the long-term, the effects may be visible/perceptible given the fact that different types of pesticides have different characteristics of persistence in the environment. The more pesticides were applied from one focal point, the more they would accumulate in the environment with consequences of disturbing/disorganizing natural and ecological systems.

The results indicated that the amount of agrochemicals spent so far per flower varied with the number of years since the flower farm was established (Figure 2). Among the 3 flower farms for which data was available, Mairye is likely to have applied $250,000 \mathrm{~kg}$ (m.a) of fungicides; $1200000 \mathrm{~kg}$ (m.a.) of insecticides; $65000 \mathrm{~kg}$ of nematicide-maticide; $35000 \mathrm{~kg}$ of herbicides; and approximately 200,000,000 liters of water for a total land in production of 18 ha. This amount of pesticide application with high environmental persistence cannot be with any consequence to the local environment. There is a need to choose to apply less toxic pesticides by the flower firms.

3.3. Precautionary Measures Taken by Owners of Flower Farms for Containing Chemical Runoff from Flowers into the Surrounding Environment. When asked about the strategies/ measures taken by the flower farm to reduce negative effects of chemicals runoff into the environment, all production managers said they recycled and controlled well the quality of water before releasing it into the environment. Across all flower farms, greenhouses were set in such a way as to be always open to the outside; and this was suspected to have a great influence on pollinators and movement of pesticides into farmland habitats. 


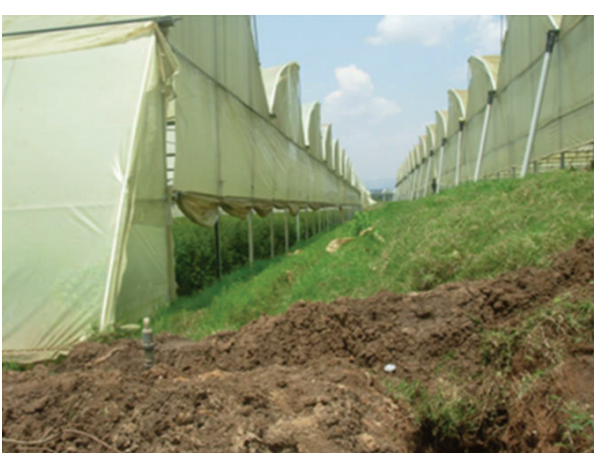

(a)

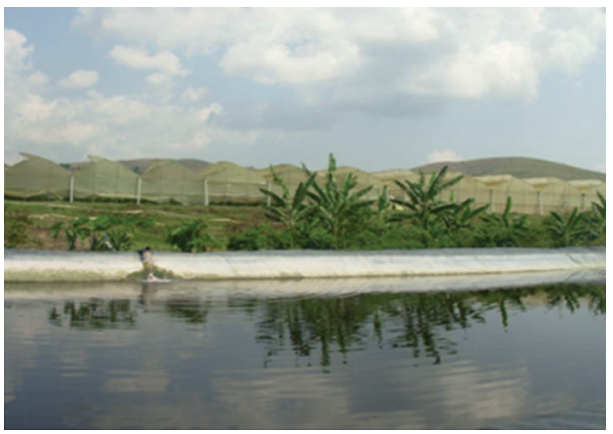

(c)

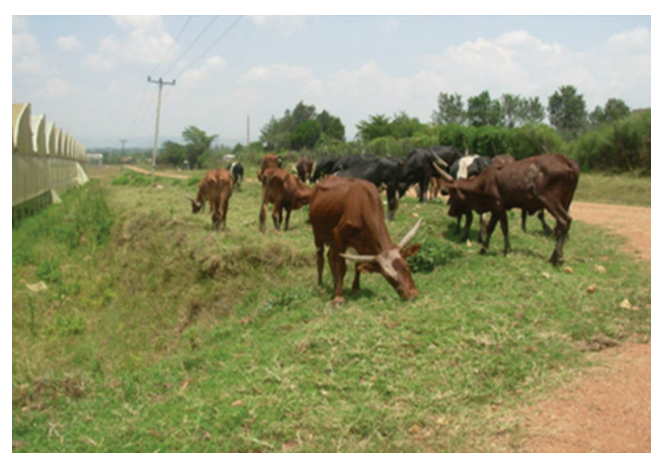

(b)

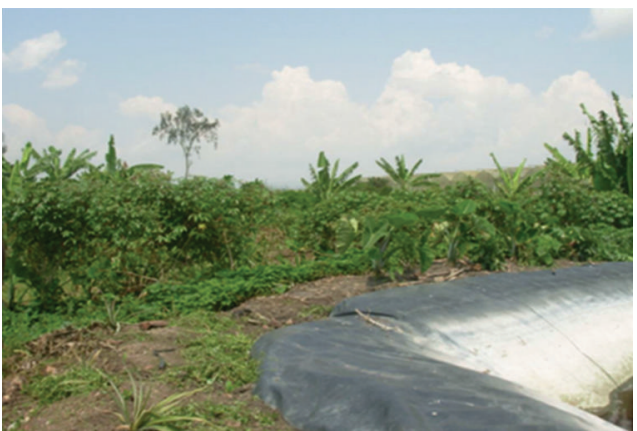

(d)

FIGURE 1: Plate showing greenhouses, cows grazing near the greenhouse, and crops grown near greenhouses and near water reservoirs at Pearl flower farm in Ntungsamo district, Western Uganda.

Production managers interviewed said management of agrochemicals and effluent from flower farms were a major concern by their companies. They also said that they were aware that pesticides, fertilisers, and herbicides can pollute river, lake, and wetland systems as a result of poor management of effluent from the flower farms and this constitutes a threat to aquatic life like fish and human health. Hence, they had to take measures that minimise soil and water pollution, such as constructing lagoons and planting papyrus to perform water purification (artificial wetlands). For example, production managers said that the water recycling system has enabled them to reduce water needs from 50,000 liters of water/day/ha to 13-20 liters/day/ha. However, during office discussion with the production managers, a question was asked about their perceptions/views in response to farmers' complaints of chemicals sprayed in the flower farms affecting their crops/livestock and their own health in the village nearby, some production managers said that they have never received complaints from the nearby communities, others said they control perfectly chemical runoff, and therefore accusations of farmers living nearby were not correct.

\subsection{Effects of the Types of Habitats Found in the Surrounding} Landscape of Flower Farms on Bee Abundance and Species Richness and on Availability of Floral Resources. Bee nests density, species richness, abundance, and visitation frequency to blooming plants in landscapes found in the villages surrounding the flower farms varied significantly (GLM test, $P<$ $0.05)$ across transects and locations of the flower farms. They also varied by the intensity of agrochemicals (pesticides, fertilizers) applications by the flower farms (Table 3) since flower farms that used more agrochemicals were also involved in regular (frequent) throwing (dumping) of agricultural wastes (agrochemical wastes) in the grasslands/croplands in the villages nearby the flower farms. However, the richness and the abundance of blooming plant species were not significantly $(P<0.05)$ affected by the intensity of application of agrochemicals (pesticides) nor by the flower farm location. But they varied significantly $(P<0.05$, GLM test $)$ across transects and according to landscape types/vegetation type. This result indicated that agrochemicals application during flower production process did not affect the richness of blooming plants in the neighborhood; few plant species managed to get adapted to such environment. Adapted plants were seen to be abundantly in bloom around the neighborhood of the flower farm (Table 3) even when there were few bees visiting such blossoms. Also, there was a significant positive correlation $(r=0.56, P<0.05)$ between the intensity of pesticides application by the different flower farms and the monthly net income from sales of cuttings.

Farmers living in the surrounding of different flower farms are engaged in the cultivation of different types of crop species in association. The average number of pollinatordependent crop species inventoried during the study survey was $5.1 \pm 0.9$ (Fiduga), $3.1 \pm 0.6$ (Mairye), $2.3 \pm 0.9$ (Pearl), and $4.6 \pm 0.85$ (Rosebud = Wagagai). The number of nonpollinator-dependent crop species grown was $3.3 \pm 0.35$ (Fiduga), $1.9 \pm 0.7$ (Mairye), $2.2 \pm 0.45$ (Pearl), and $2.3 \pm 1.12$ (Rosebud) (Table 4). 


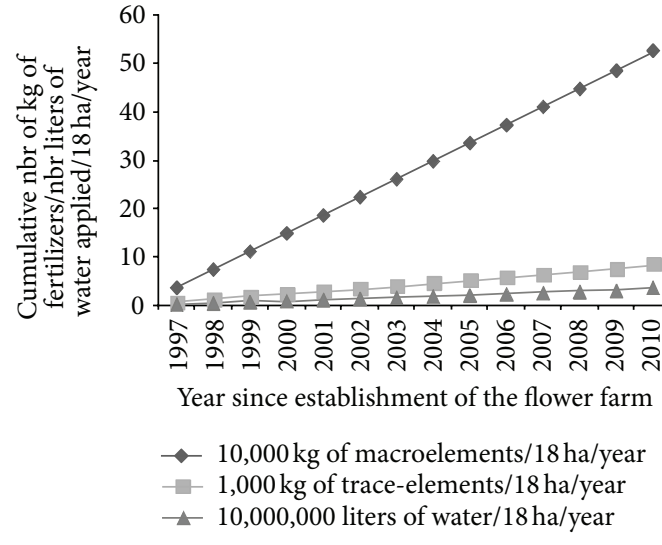

(a)

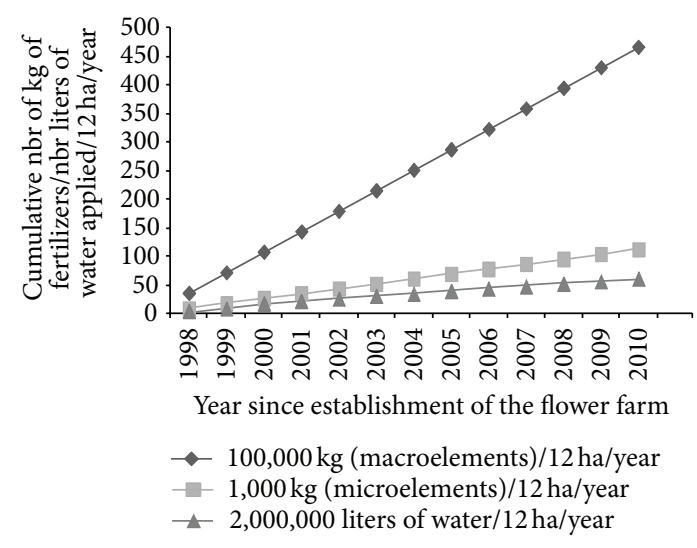

(e)

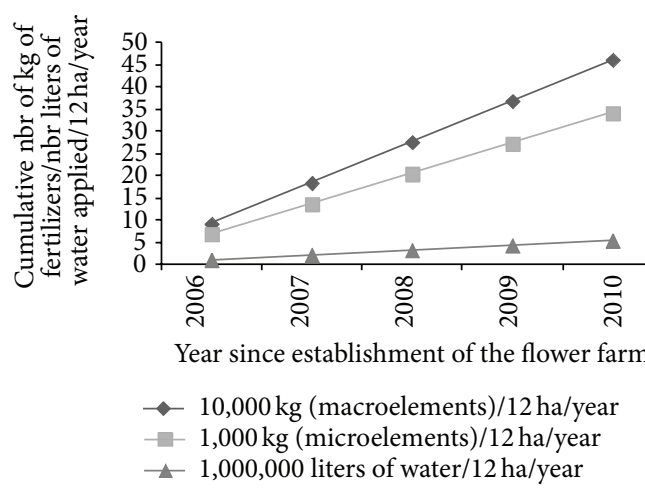

(c)

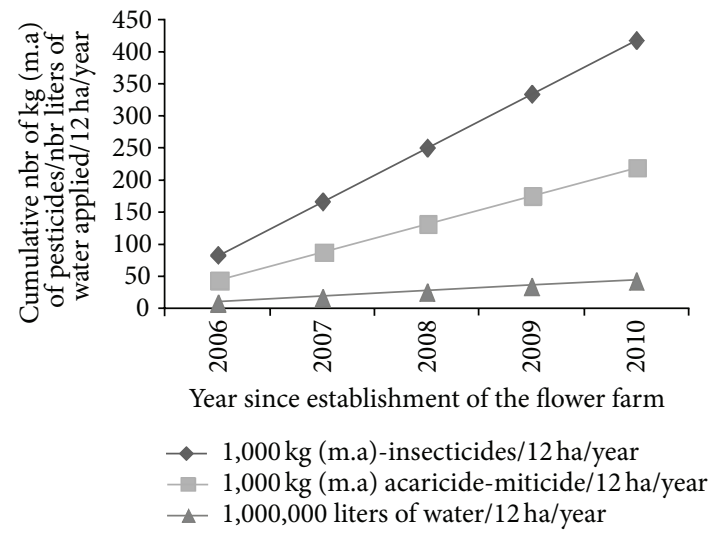

(d)

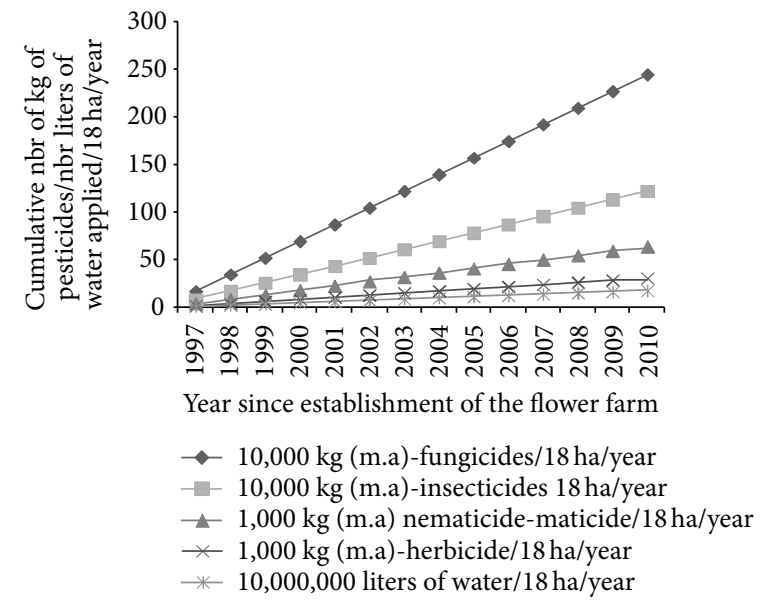

(b)

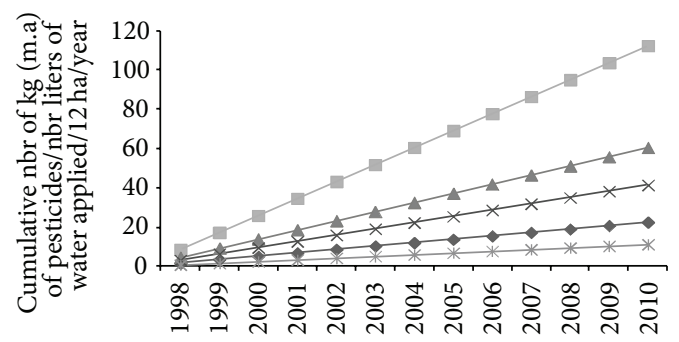

Year since establishment of the flower farm

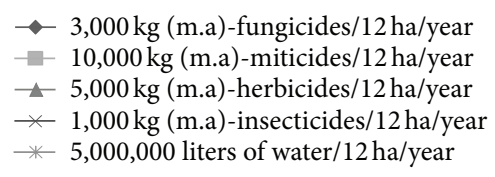

(f)

Figure 2: Long term application of (i) fertilizers ((a) = Mairye, (e) = Pearl, (c) = Rosebud-II) and (ii) pesticides ((d) = Mairye, (b) = Pearl, (f) = Rosebud-II) at different flower farms in Uganda. Table indicating the amount of each group of chemicals used at each farm is provided in the final year in Table 2 . 
TABLE 4: Common crop associations practiced by farmers interviewed from 2010 to 2012 .

\begin{tabular}{lc}
\hline \multicolumn{2}{c}{ Different types of crops grown in association by farmers } \\
Frequency of crop associations in & Freq. (\%) \\
non-pollinator-dependent crops & 14.06 \\
\hline Cassava-Banana & 1.56 \\
Cassava-Banana-Yams-Taro & 6.25 \\
Banana-Maize-Millet & 3.13 \\
Banana-Sweetpotato-Cassava-Maize & 7.81 \\
Banana-Sweetpotato-Maize & 10.94 \\
Cassava-Maize-Sweetpotato-Banana & 3.13 \\
Cassava-Sweetpotato-Banana-Maize & 17.10 \\
Maize-Cassava-Sweetpotato-Banana & 14.06 \\
Sweetpotato-Banana & 9.38 \\
Sweetpotato-Banana-Cassava & 10.94 \\
Sweetpotato-Banana-Maize-Cabbage & 1.56 \\
Sweetpotato-Maize-Cassava & \\
Frequeny of crop associations in pollinator-dependent & \\
crops & \\
Egg plant-Mango-Beans-Groundnut-Pepper-Pumpkin & 3.03 \\
Avocado-Mango-Pumpkin-Beans-Coffee & 15.15 \\
Avocado-Pumpkin-Beans-Tomato-Coffee & 12.12 \\
Beans-Egg plants-Tomato & 3.03 \\
Beans-Avocado-Mango & 22.73 \\
Beans-Groundnut-Pumpkin & 6.06 \\
Beans-Papaw-Watermelon-Pumpkin-Egg plant-Tomato & 6.06 \\
Beans-Tomato-Avocado-Papaya & 6.06 \\
Citrus-Papaw-Beans-Cowpea-Avocado-Mango & 1.52 \\
Coffee-Avocado-Passion fruit-Vanilla & 1.52 \\
Coffee-Tomato-Beans-Papaw-Vanilla & 9.09 \\
Pumpkin-Beans-Watermelon-Egg plant & 7.58 \\
\hline
\end{tabular}

In the surrounding of each flowering farm, there were significant $(P<0.05)$ differences in species richness, abundance, visitation frequency, and number of fresh flowers per transect at different distances $(0 \mathrm{~m}, 10 \mathrm{~m}, 50 \mathrm{~m}, 500 \mathrm{~m}$, $1500 \mathrm{~m}$ ) far away from the flower farm into farmland habitats. For example, for Pearl flower farm, there were significant differences between the 5 distances $(0 \mathrm{~m}, 10 \mathrm{~m}, 50 \mathrm{~m}, 500 \mathrm{~m}$, $1500 \mathrm{~m}, 2000 \mathrm{~m}$ ) in species richness (GLM: $F_{1,4}=3.14, P<$ 0.001 ), abundance (GLM: $F_{1,4}=7.85, P<0.001$ ), bee visitation frequency (GLM: $F_{1,4}=9.43, P<0.001$ ), and abundance of fresh flowers (GLM: $F_{1,4}=12.76, P<0.001$ ) (Figure 3). Similar trends in the results were observed at Mairye, Rosebud, and Fiduga flower farms (Figure 3).

In the surrounding of each flower farm and across sampling rounds (R1, R2, R3, R4), there were significant differences in the species richness and abundance of bees. In fact, for Pearl flower farm, there were significant differences in species richness of blooming plants in croplands (GLM: $\left.F_{1,3}=3.14, P<0.001\right)$ as well as in farmland habitats (GLM: $\left.F_{1,3}=7.14, P<0.001\right)$. Results of similar trends were observed for the percentage cover of mass blooming plants/ transects in both croplands (GLM: $F_{1,3}=12.3, P<0.001$ ) and grassland habitats (GLM: $F_{1,4}=9.13, P<0.001$; Figure 4).

The abundance of bees varied significantly $\left(P<0.05, \chi^{2}\right.$ test) across the different land-use types and seminatural habitats encountered on transects during transect counts of bees across the surroundings of the four flower farms (Table 5). The most visited land-use types were the banana + bean + cassava, followed by young fallows, field margins, and coffee + banana + cassava + beans + fruit trees + agroforestry trees. The most visited seminatural habitat among those encountered during transect counts of bees in grassland and rangeland habitats was "shrubby fallow", followed by unfenced grazing plot followed by pad-docking fenced grazing plot with live fence, unreclaimed papyrus swampy habitat, and hedgerow (Table 5). Different bee species made visits to blooming plants in these different habitats/land-uses at different periods of the day; most frequently, they made intense visits from 10:30 h to 15:30 h. The spray of chemicals in flower farms is generally conducted between $6: 30 \mathrm{~h}$ and $8: 30 \mathrm{~h}$ or between 15:30 $\mathrm{h}$ and 18:30 $\mathrm{h}$.

Different bee species were recorded significantly $\left(\chi^{2} 3 \mathrm{df}=\right.$ 7.87, $P<0.001)$ in the different cropland and grassland habitats in the surrounding of the flower farms. They occurred with different abundance. In total: 37, 26, 45, and 33 bee species were recorded in the surrounding of respectively, Fiduga, Mairye, Pearl, and Wagagai (Rosebud-II) flower farms. Landscape habitats surrounding Pearl flower supported more diverse bee communities (mean \pm SE of $H^{\prime}=$ $2.68 \pm 0.13)$ than Mairye (mean \pm SE of $\left.H^{\prime}=2.53 \pm 0.13\right)$, Fiduga (mean \pm SE of $H^{\prime}=2.17 \pm 0.11$ ), and Wagagai (mean \pm SE of $\left.H^{\prime}=1.91 \pm 0.09\right)$ flower farms (GLM-ANOVA: $F_{(4,37)}=$ $2.55, P=0.041)$. However, there were no significant differences $\left(\chi^{2}=3.24, P=0.198, \mathrm{df}=3\right)$ among flower farms in the average similarity index values of shared bee species. In other words, bee communities from these flowers were statistically similar in species composition. Common bee species were frequently recorded to be abundant on flowers than specialist bees. In the tropics, the structure of most bee communities is not different from that of other insects. There is always $1-5 \%$ of dominant bee species and $90-95 \%$ of species that are rare or appear as singletons or doubletons.

There was a significance ( $\chi^{2}$ test, $P<0.05$ ) in relative abundance of different bee species in the surrounding of different flower farms. The most abundant bee species in the surrounding habitats (croplands, grasslands) were Apis mellifera adansonii (14.08\%), followed by Meliponula ferruginea (10.90\%) and Nomia brevipes (9.03\%). The most abundant species in the farmland around Mairye were Apis mellifera adansonii (23.3\%), followed by Meliponula ferruginea (19.84\%) and Apis mellifera scutellata (8.67\%). The most abundant species in the surrounding of Pearl flower farm were Apis mellifera adansonii (23.67\%), followed by Apis mellifera scutellata (10.64\%) and Ceratina tanganyicensis (8.58\%). 
TABLE 5: Relative abundance of bees (\%) per habitat types encountered during transect counts across the surroundings of the 4 flower farms investigated from 2010 to 2012 in Uganda.

(a)

\begin{tabular}{lcc}
\hline Field types & Land-use types encountered during bee transect counts in croplands & Relative abundance (\%) \\
\hline Cultivated fields & Abandoned bushy gardens & 0.1 \\
Cultivated fields & Agroforestry trees + Banana + Beans + Maize + Fruit trees & 3.3 \\
Cultivated fields & Banana + Bean + Cassava crops & 29.7 \\
Cultivated fields & Banana + Beans + Sweetpotato + Agroforestry trees + Fruit trees & 4.8 \\
Cultivated fields & Banana + Cassava + Beans + Maize & 0.9 \\
Cultivated fields & Banana + Cassava + Beans + Sweetpotato + Maize + Mango + Avocado & 3.3 \\
Cultivated fields & Banana + Cassava + Groundnut + Fruit trees & 0.8 \\
Cultivated fields & Banana + Coffee + Beans + Maize + Mango + Avocado & 1.7 \\
Cultivated fields & Banana + Egg plant + Tomato + Bean + Sweetpotato & 1.6 \\
Cultivated fields & Banana + Groundnut + Casssava + Maize + Agroforestry trees & 2.8 \\
Cultivated fields & Banana + Maize + Beans + Sweetpotato + Fruit trees & 2.2 \\
Cultivated fields & Coffee + Banana + Cassava + Beans + Fruit trees & 2.0 \\
Cultivated fields & Coffee-Banana-Cassava-Beans-Fruit trees-Agroforestry trees & 7.1 \\
Cultivated fields & Coffee + Banana + Cassava + Groundnut + Maize + Fruit trees & 0.5 \\
Cultivated fields & Fruits orchards + Homegardens & 1.2 \\
Cultivated fields & Communal grazing fields & 1.3 \\
Cultivated fields & Field margins & 9.3 \\
Cultivated fields & Hedgerows (established in farmlands) \\
Cultivated fields & Swampy crops (Egg plant + Pumpkin + Watermelon + Tomato, etc.) \\
Cultivated fields & Herbaceous young fallows & 6.8 \\
\hline
\end{tabular}

Chi-square test: $\chi^{2}=179.61, N=100, \mathrm{DF}=19, P<0.0001$.

(b)

Field types Semi-natural habitat types encountered during transect-counts of bees in grasslands/rangelands

Relative abundance (\%)

Uncultivated fields

Uncultivated fields

Edge of natural wetlands (various plant species mixed)

0.22

Forest fallow (Vernonia sp.)

1.70

Forest fallows

1.00

$\begin{array}{ll}\text { Forested-swampy habitats } & 2.21\end{array}$

Grassy fallows $\quad 1.50$

Uncultivated fields

Uncultivated fields

Uncultivated fields

Uncultivated fields

Uncultivated fields

Uncultivated fields

Uncultivated fields

Uncultivated fields

Uncultivated fields

Uncultivated fields

Uncultivated fields

Uncultivated fields

Uncultivated fields

Uncultivated fields

Uncultivated fields

Uncultivated fields

Uncultivated fields

\begin{tabular}{cc} 
Forest fallow (Vernonia sp.) & 1.70 \\
Forest fallows & 1.00 \\
Forested-swampy habitats & 2.21 \\
Grassy fallows & 1.50 \\
Hedgerows (established rangelands) & 4.42 \\
Herbaceous/shrubby grasslands & 1.43 \\
Lake Victoria-edge vegetation (various species) & 5.88 \\
Lantana camara-Erlangeya tomentosa old fallows & 0.83 \\
Lantana camara-Erythrina sp. hedges on roadsides & 10.07 \\
Natural forest remnant patches & 0.44 \\
Old fallows (Lantana camara-Cassia sp.-Maesa lancelota) & 1.12 \\
Paddocking fenced grazing plots (with live fences) & 12.64 \\
Reclaimed wetlands (with crops + natural vegetations) & 0.99 \\
Shrubby old fallows & 25.29 \\
Swampy habitat vegetation (various plant species mixed) & 3.66 \\
Unfenced grazing plots & 19.97 \\
Unreclaimed-papyrus swampy habitats & 4.60 \\
Woodlands (Euphorbia sp.) & 0.15 \\
Woodlots (Eucalyptus-Pine) & 0.46 \\
Woodlots (native and exotic species mixed) & 1.42 \\
\hline
\end{tabular}

Chi-square test: $\chi^{2}=195.43, N=100, \mathrm{DF}=20, P<0.0001$. 

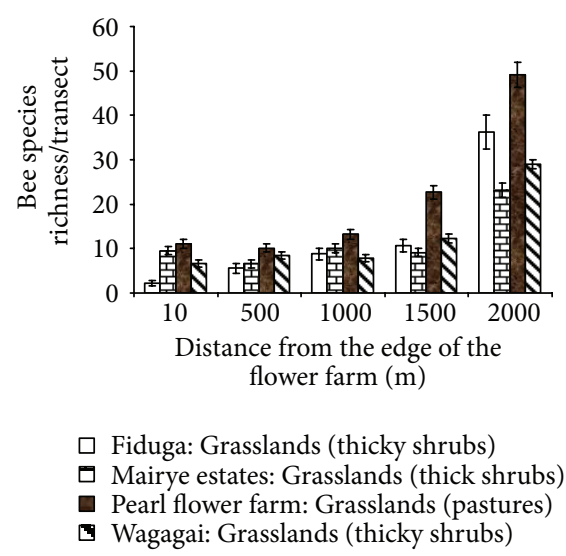

(a1)

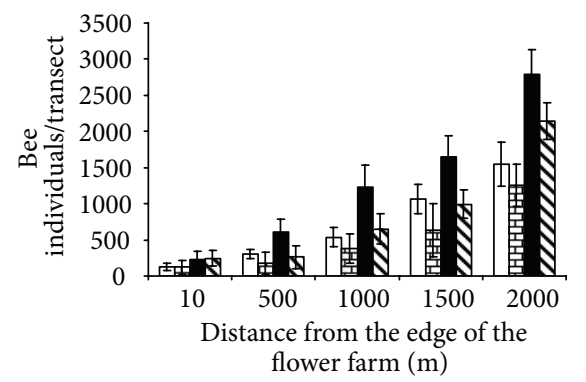

(b1)

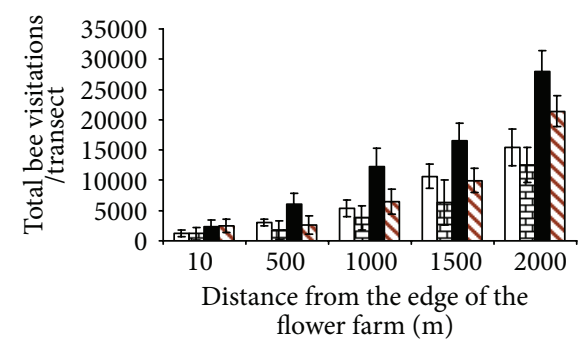

(c1)

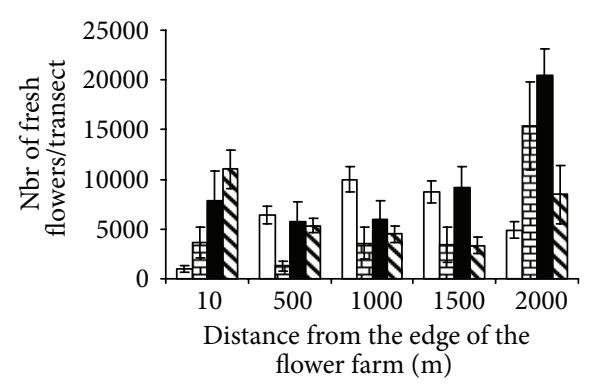

(d1)

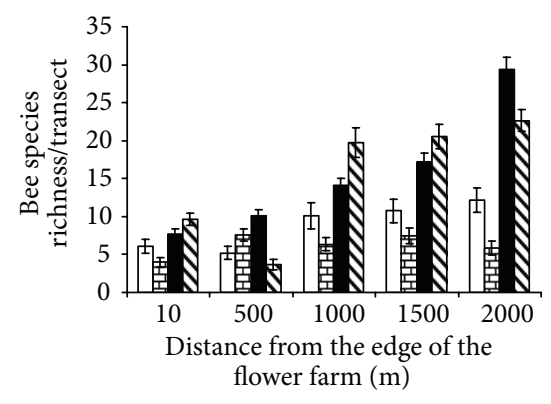

$\square$ Fiduga: Farmlands (croplands)

$\square$ Mairye estates: Farmlands (croplands)

- Pearl flower farm: Farmlands (croplands)

v Rosebud-II: Farmlands (croplands)

(a2)

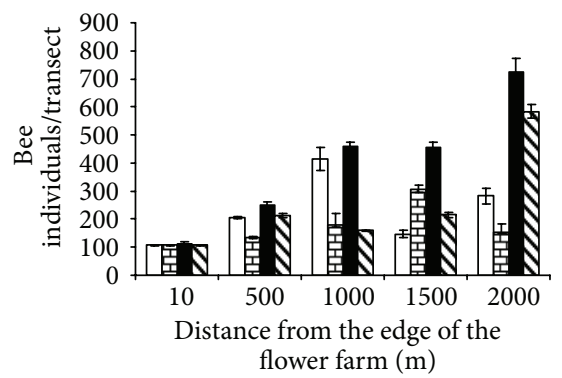

(b2)

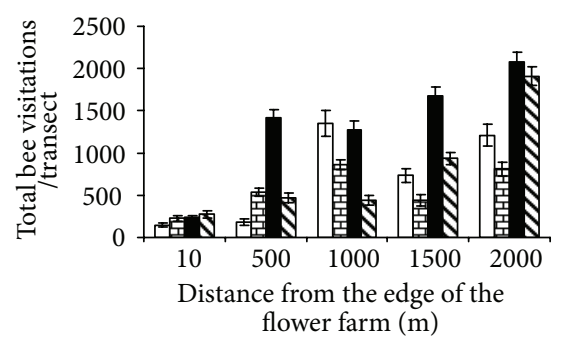

(c2)

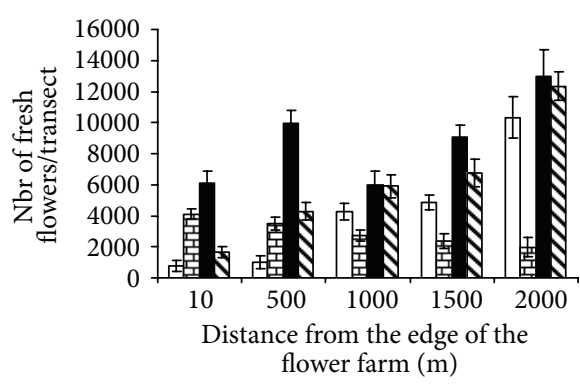

(d2)

FIGURE 3: (i) Variability in bee species richness (a1), bee abundance (b2), total visitation frequency (c1) and in number of fresh flowers (d1) countable per transect with the distance way from the edge of the flower farm into grassland habitat; (ii) variability in bee species richness (a2), bee abundance (b2), total visitation frequency (c2) and in Number of fresh flowers (d2) countable per transect with the distance way from the edge of the flower farm into farmland (cropland) habitat. [The data is the total from 10 focal observation plots $\left(25 \mathrm{~m}^{2}\right)$ per transect $(20 \mathrm{~m} \times$ $1 \mathrm{~km}$ ). For each sampling plot, data recorded was then number of bee-visits (number of bee coming and landing on the flowers) $/ 20$ min observations $/ 50-500$ flower patches $/ 25 \mathrm{~m}^{2}$ ). The flower patch was composed of diverse flowering plants.] Concerning the pattern (trend) in the raw data collected, it was observed that across the five distances (10,500, 1000, 1500, $2000 \mathrm{~m}$ ), there were significant differences (Tukey test at $P<0.05)$ in the number of bee individuals/species richness/transect and in the number of total bee visits/number of fresh flowers/transect. Either in cropland or in grassland habitats, within each distance, overlapping error bars indicate no significant differences (Tukey test at $P>0.05)$ between consecutive flower farms; Error bars are \pm SE. 


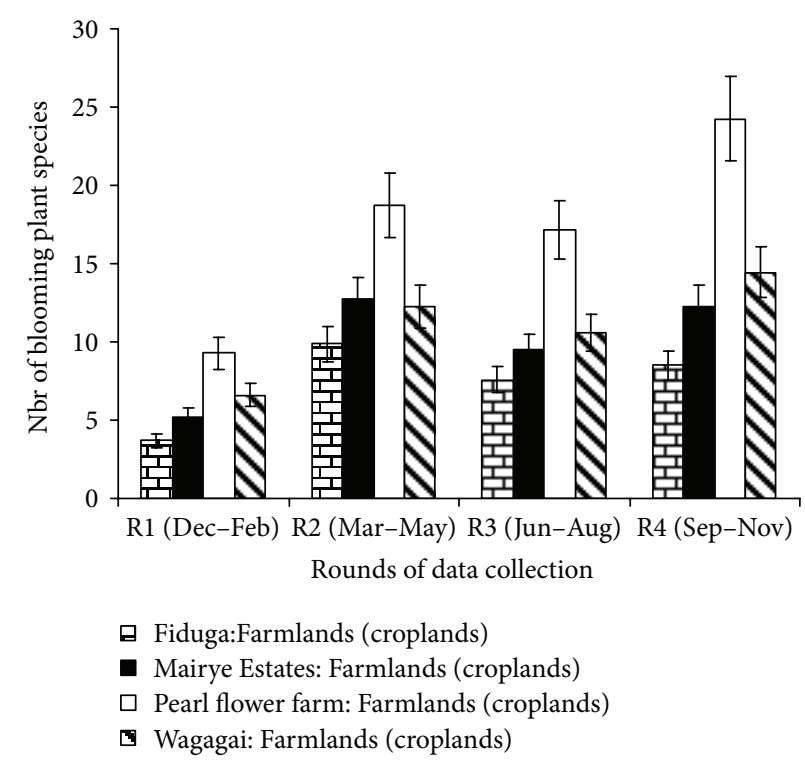

(a1)

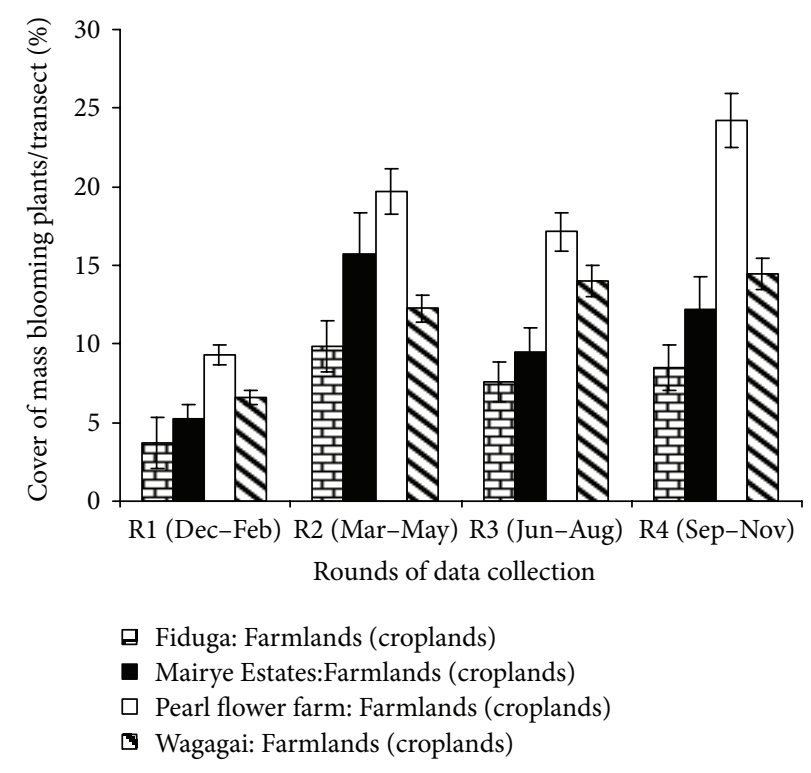

(a2)

(a)

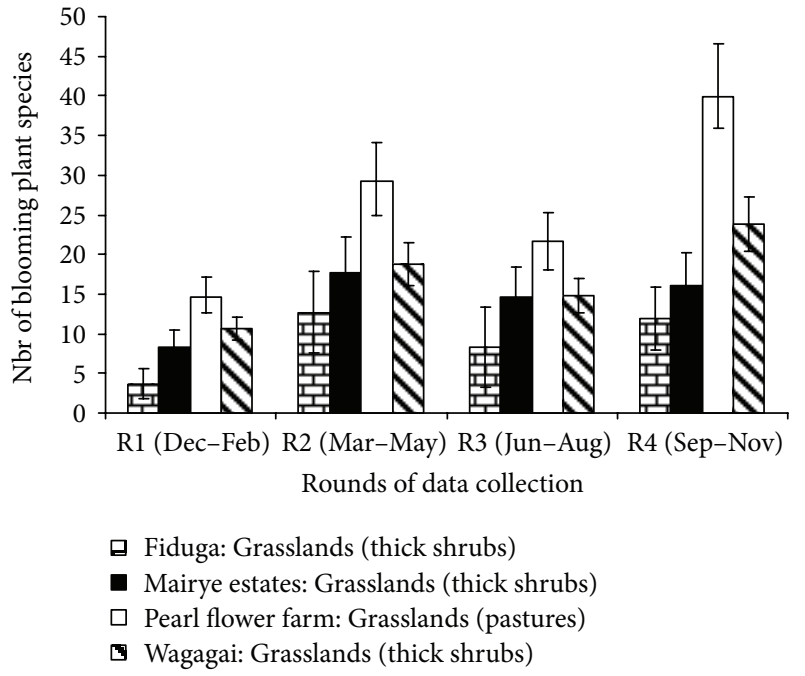

(b1)

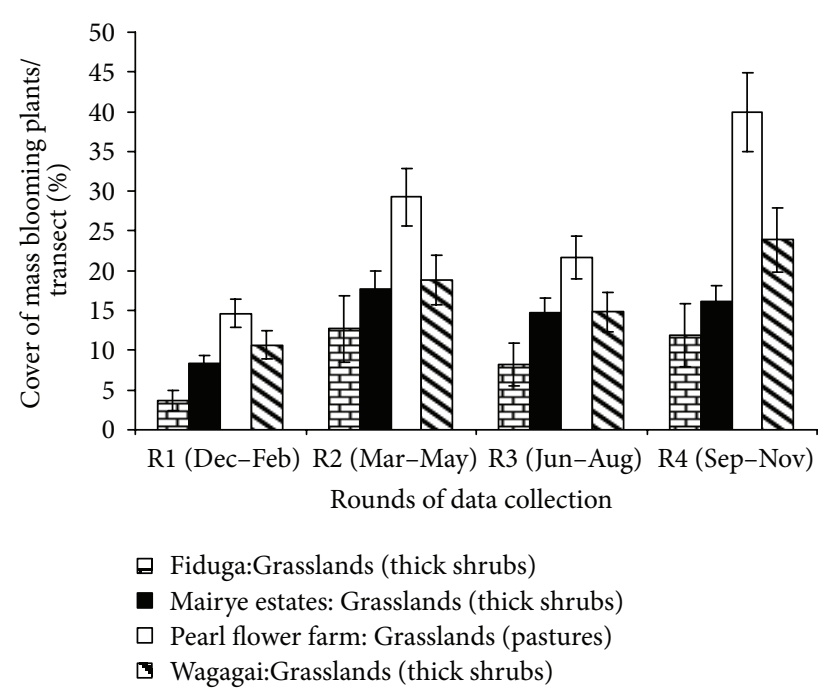

(b2)

(b)

FIGURE 4: (i) Variability in the richness of blooming plant species (a1) and in the abundance of blooming plants (a2) in cropland habitats (a) during each of the four rounds of data collection conducted across the four flower farms (data are means of five transects); (ii) variability in the richness of blooming plant species (a1) and in the abundance of blooming plants (a2) in grassland habitats (b) during each of the four rounds of data collection conducted across the four flower farms (data are means of five transects) during four rounds of data collection from 2010 to 2012. Concerning the pattern (trend) in the raw data collected, it was observed that across the four sampling rounds (R1 to R4), there were significant differences (Tukey test at $P<0.05$ ) in the number of blooming plant species and in the \% cover of mass blooming plants/transect. Either in cropland or in grassland habitats, within each sampling round, overlapping error bars indicate no significant (Tukey test at $P>0.05$ ) differences between consecutives flower farms; Error bars are \pm SE.

The most abundant species in the surrounding habitats of Wagagai (Rosebud-II) were Apis mellifera adnasonii (37.25\%), followed by Apis mellifera scutelatta (15.7\%) and Halictus orientalis $(9.59 \%)$ (Table 6).

Overall, high bee species richness was associated with different habitats (land-uses) found around Pearl flower farm, probably because the flower farm was young (recently established). There may be little accumulation in the environment of chemicals applied at Pearl flower farm to affect bee populations. The majority of bee species recorded were characterized by different ecological requirements. They belonged to different functional groups, but on overall most species 
TABLE 6: List of bee species recorded in different habitats around flower farms from 2010 to 2012 (data include relative abundance of the species over the five rounds of data collection conducted on five transect from 2010 to 2012. The abundance is the average visitation frequency (number of individual bee-visits counted on flowers patches met while walking along transect). The data are means of data collected in transects set in farmlands and in grasslands.

\begin{tabular}{|c|c|c|}
\hline Name of the flower farm & Bee species recorded around & $\begin{array}{c}\text { Relative abundance (\%) } \\
(n=3638 \text { individuals) }\end{array}$ \\
\hline Fiduga & Apis mellifera adansonii (Linnaeus, 1758) & 14.08 \\
\hline Fiduga & Meliponula ferruginea (Lepeletier, 1836) & 10.90 \\
\hline Fiduga & Nomia brevipes (Friese, 1914) & 9.03 \\
\hline Fiduga & Lassioglossum kampalense (Cockerell, 1945) & 6.92 \\
\hline Fiduga & Scrapter armatipes (Friese, 1913) & 5.62 \\
\hline Fiduga & Ceratina rufigastra (Cockerell, 1937) & 5.13 \\
\hline Fiduga & Halictus jucundus (Smith, 1853) & 4.98 \\
\hline Fiduga & Apis mellifera scutellata (Latreille, 1804) & 3.69 \\
\hline Fiduga & Ceratina whiteheadi (Eardley and Daly, 2007) & 3.47 \\
\hline Fiduga & Pseudoheriades moricei (Friese, 1897) & 3.19 \\
\hline Fiduga & Patellapis flavorufa (Cockerell, 1937) & 3.11 \\
\hline Fiduga & Megachile torrida (Smith, 1853) & 2.64 \\
\hline Fiduga & Megachile rufipennis (Fabricius, 1793) & 2.48 \\
\hline Fiduga & Anthophora armata (Friese, 1905) & 2.30 \\
\hline Fiduga & Xylocopa inconstans (Smith, 1874) & 2.09 \\
\hline Fiduga & Ctenoplectra ugandica (Cockerell, 1944) & 2.03 \\
\hline Fiduga & Scrapter flavipes (Friese, 1925) & 1.95 \\
\hline Fiduga & Scrapter flavostictus (Cockerell, 1934) & 1.55 \\
\hline Fiduga & Braunsapis angolensis (Cockerell, 1933) & 1.49 \\
\hline Fiduga & Megachile rufiventris (Guérin-Méneville, 1834) & 1.37 \\
\hline Fiduga & Xylocopa caffra (Linnaeus, 1767) & 1.37 \\
\hline Fiduga & Ceratina tanganyicensis (Strand, 1911) & 1.19 \\
\hline Fiduga & Amegilla calens (Lepeletier, 1841) & 1.18 \\
\hline Fiduga & Nomia bouyssoui (Vachal, 1903) & 1.14 \\
\hline Fiduga & Patellapis neavei (Cockerell, 1946) & 1.12 \\
\hline Fiduga & Amegilla velutina (Friese, 1909) & 1.02 \\
\hline Fiduga & Tetraloniella braunsiana (Friese, 1905) & 0.77 \\
\hline Fiduga & Nomia atripes (Friese, 1909) & 0.68 \\
\hline Fiduga & Tetralonia macrognatha (Gerstäcker, 1870) & 0.60 \\
\hline Fiduga & Tetralonia caudata (Friese, 1905) & 0.59 \\
\hline Fiduga & Lipotriches dentipes (Friese, 1930) & 0.57 \\
\hline Fiduga & Megachile acraensis (Friese, 1903) & 0.52 \\
\hline Fiduga & Lasioglossum ugandicum (Cockerell, 1937) & 0.43 \\
\hline Fiduga & Patellapis vittata (Smith, 1853) & 0.42 \\
\hline Fiduga & Lithurgus rufipes (Smith, 1853) & 0.39 \\
\hline Name of the flower farm & Bee species recorded around & $\begin{array}{c}\text { Relative abundance (\%) } \\
(n=4492 \text { individuals) }\end{array}$ \\
\hline Mairye Estates & Apis mellifera adansonii (Linnaeus, 1758) & 22.30 \\
\hline Mairye Estates & Meliponula ferruginea (Lepeletier, 1836) & 19.84 \\
\hline Mairye Estates & Apis mellifera scutellata (Latreille, 1804) & 8.67 \\
\hline Mairye Estates & Halictus jucundus (Smith, 1853) & 4.44 \\
\hline Mairye Estates & Ceratina braunsi (Eardley and Daly, 2007) & 4.25 \\
\hline Mairye Estates & Amegilla calens (Lepeletier, 1841) & 4.17 \\
\hline Mairye Estates & Patellapis terminalis (Smith, 1853) & 4.17 \\
\hline Mairye Estates & Patellapis schultzei (Friese, 1909) & 4.12 \\
\hline Mairye Estates & Lithurgus pullatus (Vachal, 1903) & 3.75 \\
\hline Mairye Estates & Braunsapis angolensis (Cockerell, 1933) & 3.24 \\
\hline
\end{tabular}


TABLE 6: Continued.

\begin{tabular}{|c|c|c|}
\hline Mairye Estates & Nomia bouyssoui (Vachal, 1903) & 3.21 \\
\hline Mairye Estates & Lassioglossum kampalense (Cockerell, 1945) & 2.60 \\
\hline Mairye Estates & Nomia rozeni (Pauly, 2000) & 1.79 \\
\hline Mairye Estates & Xylocopa caffra (Linnaeus, 1767) & 1.57 \\
\hline Mairye Estates & Tetraloniella junodi (Friese, 1909) & 1.35 \\
\hline Mairye Estates & Allodape friesei (Strand, 1915) & 1.28 \\
\hline Mairye Estates & Nomia lutea (Warncke, 1976) & 1.23 \\
\hline Mairye Estates & Scrapter algoensis (Friese, 1925) & 1.20 \\
\hline Mairye Estates & Megachile hopilitis (Vachal, 1903) & 1.01 \\
\hline Mairye Estates & Tetralonia caudata (Friese, 1905) & 1.01 \\
\hline Mairye Estates & Stenoheriades braunsi (Cockerell, 1932) & 0.91 \\
\hline Mairye Estates & Megachile torrida (Smith, 1853) & 0.78 \\
\hline Mairye Estates & Meliponula nebulata (Smith, 1854) & 0.71 \\
\hline Mairye Estates & Megachile rufipennis (Fabricius, 1793) & 0.79 \\
\hline Mairye Estates & Ctenoplectra armata (Magretti, 1895) & 0.64 \\
\hline Mairye Estates & Amegilla acraensis (Fabricius, 1793) & 0.61 \\
\hline Mairye Estates & Thyreus bouyssoui (Vachal, 1903) & 0.59 \\
\hline Name of the flower farm & Bee species recorded around & $\begin{array}{l}\text { Relative abundance (\%) } \\
(n=12454 \text { individuals })\end{array}$ \\
\hline Pearl & Apis mellifera adansonii (Linnaeus, 1758) & 23.67 \\
\hline Pearl & Apis mellifera scutellata (Latreille, 1804) & 10.64 \\
\hline Pearl & Ceratina tanganyicensis (Strand, 1911) & 8.58 \\
\hline Pearl & Ceratina rufigastra (Cockerell, 1937) & 4.12 \\
\hline Pearl & Nomia senticosa (Vachal, 1897) & 5.75 \\
\hline Pearl & Nomia theryi (Gribodo, 1894) & 5.43 \\
\hline Pearl & Ceratina lineola (Vachal, 1903) & 3.33 \\
\hline Pearl & Halictus jucundus (Smith, 1853) & 2.57 \\
\hline Pearl & Halictus niveocinctulus (Cockerell, 1940) & 2.24 \\
\hline Pearl & Amegilla velutina (Friese, 1909) & 2.20 \\
\hline Pearl & Lasioglossum aethiopicum (Cameron, 1905) & 2.00 \\
\hline Pearl & Meliponula ferruginea (Lepeletier, 1836) & 1.80 \\
\hline Pearl & Braunsapis angolensis (Cockerell, 1933) & 1.79 \\
\hline Pearl & Anthophora armata (Friese, 1905) & 1.73 \\
\hline Pearl & Megachile rufiventris (Guérin-Méneville, 1834) & 1.68 \\
\hline Pearl & Nomia bouyssoui (Vachal, 1903) & 1.55 \\
\hline Pearl & Braunsapis facialis (Gerstäcker, 1857) & 1.39 \\
\hline Pearl & Megachile junodi (Friese, 1904) & 1.18 \\
\hline Pearl & Patellapis vittata (Smith, 1853) & 1.18 \\
\hline Pearl & Megachile felina (Gerstäcker, 1857) & 1.15 \\
\hline Pearl & Megachile eurymera (Smith, 1864) & 1.03 \\
\hline Pearl & Lipotriches digitata (Friese, 1909) & 1.02 \\
\hline Pearl & Andrena africana (Friese, 1909) & 1.01 \\
\hline Pearl & Patellapis disposita (Cameron, 1905) & 0.99 \\
\hline Pearl & Allodape stellarum (Cockerell, 1916) & 0.96 \\
\hline Pearl & Afromelecta bicuspis (Stadelmann, 1898) & 0.95 \\
\hline Pearl & Megachile niveofasciata (Friese, 1904) & 0.79 \\
\hline Pearl & Amegilla acraensis (Fabricius, 1793) & 0.77 \\
\hline Pearl & Thyreus somalicus (Strand, 1911) & 0.73 \\
\hline Pearl & Megachile rufipennis (Fabricius, 1793) & 0.70 \\
\hline Pearl & Lithurgus rufipes (Smith, 1853) & 0.67 \\
\hline Pearl & Macrogalea candida (Smith, 1879) & 0.63 \\
\hline Pearl & Megachile nasalis (Smith, 1879) & 0.63 \\
\hline
\end{tabular}


TABle 6: Continued.

\begin{tabular}{|c|c|c|}
\hline Pearl & Halictus obscurifrons (Cockerell, 1945) & 0.59 \\
\hline Pearl & Lipotriches tanganyicensis (Strand, 1913) & 0.59 \\
\hline Pearl & Melitta whiteheadi (Eardley, 2006) & 0.58 \\
\hline Pearl & Plebeiella lendliana (Friese, 1900) & 0.51 \\
\hline Pearl & Melitta arrogans (Smith, 1879) & 0.31 \\
\hline Pearl & Amegilla niveata (Friese, 1905) & 0.27 \\
\hline Pearl & Melitta danae (Eardley, 2006) & 0.27 \\
\hline Pearl & Megachile natalica (Cockerell, 1920) & 0.26 \\
\hline Pearl & Amegilla rufipes (Lepeletier, 1841) & 0.26 \\
\hline Pearl & Plebeina hildebrandti (Friese, 1900) & 0.23 \\
\hline Pearl & Allodape friesei (Strand, 1915) & 0.23 \\
\hline Pearl & Ctenoplectra terminalis (Smith, 1879) & 0.20 \\
\hline Pearl & Ceratina viridis (Guérin-Méneville, 1844) & 0.18 \\
\hline Pearl & Nomia rozeni (Pauly, 2000) & 0.18 \\
\hline Pearl & Tetralonia macrognatha (Gerstäcker, 1870) & 0.18 \\
\hline Pearl & Xylocopa caffra (Linnaeus, 1767) & 0.18 \\
\hline Pearl & Megachile torrida (Smith, 1853) & 0.11 \\
\hline Name of the flower farm & Bee species recorded around & $\begin{array}{l}\text { Relative abundance (\%) } \\
(n=11038 \text { individuals) }\end{array}$ \\
\hline Wagagai & Apis mellifera adansonii (Linnaeus, 1758) & 37.25 \\
\hline Wagagai & Apis mellifera scutellata (Latreille, 1804) & 15.76 \\
\hline Wagagai & Halictus orientalis (Lepeletier, 1841) & 9.59 \\
\hline Wagagai & Meliponula ferruginea (Lepeletier, 1836) & 6.63 \\
\hline Wagagai & Hypotrigona gribodoi (Magretti, 1884) & 8.23 \\
\hline Wagagai & Braunsapis bouyssoui (Vachal, 1903) & 3.04 \\
\hline Wagagai & Ceratina tanganyicensis (Strand, 1911) & 2.63 \\
\hline Wagagai & Nomia atripes (Friese, 1909) & 1.89 \\
\hline Wagagai & Allodape friesei (Strand, 1915) & 1.88 \\
\hline Wagagai & Allodape ceratinoides (Gribodo, 1884) & 1.81 \\
\hline Wagagai & Allodapula acutigera (Cockerell, 1936) & 1.78 \\
\hline Wagagai & Braunsapis angolensis (Cockerell, 1933) & 1.70 \\
\hline Wagagai & Nomia bouyssoui (Vachal, 1903) & 1.51 \\
\hline Wagagai & Tetralonia caudata (Friese, 1905) & 0.84 \\
\hline Wagagai & Megachile eurymera (Smith, 1864) & 0.74 \\
\hline Wagagai & Patellapis disposita (Cameron, 1905) & 0.64 \\
\hline Wagagai & Megachile rufipes (Fabricius, 1781) & 0.63 \\
\hline Wagagai & Scrapter whiteheadi (Eardley, 1996) & 0.64 \\
\hline Wagagai & Thyreus neavei (Cockerell, 1933) & 0.55 \\
\hline Wagagai & Macrogalea candida (Smith, 1879) & 0.54 \\
\hline Wagagai & Lasioglossum ugandicum (Cockerell, 1937) & 0.45 \\
\hline Wagagai & Amegilla calens (Lepeletier, 1841) & 0.40 \\
\hline Wagagai & Tetralonia macrognatha (Gerstäcker, 1870) & 0.31 \\
\hline Wagagai & Megachile rufipennis (Fabricius, 1793) & 0.30 \\
\hline Wagagai & Xylocopa inconstans (Smith, 1874) & 0.25 \\
\hline
\end{tabular}

recorded were solitary, polylectic, multivoltine, and ground nesting bees. However, high population density was observed in the less rich functional groups of species: social bees (Apini, Meliponini). In addition, a high number of nesting sites and nests was counted for various solitary bee species in the landscapes. On average, nest density (10.98 to 183.91 nests/transect) was high in rangelands/pasturelands than in agroforestry landscapes around Pearl flower farm. Few (2.5 to 5.89/transect) stingless bee nests were counted in croplands, indicating the fact that most managed and wild bee species found in the surrounding of flower farms used natural and seminatural habitats as preferential nesting sites (reservoirs). However, the different bee species used different foraging habitat types. While walking in croplands, "banana + beanscassava" and "young fallows" were found to harbor a high number of bee foragers, whereas frequency of visitations by 
TABLE 7: Social, economic, environmental, and pollination attitudes of farmers towards activities of bees on flowers of their gardens.

\begin{tabular}{|c|c|c|}
\hline $\begin{array}{l}\text { Statement } \\
\text { no. }\end{array}$ & Question: What do you think bees are doing while visiting crop flowers? & $\begin{array}{c}\text { Freq. (\%) of the } \\
\text { statements among } \\
\text { interviewed people }\end{array}$ \\
\hline 1 & $\begin{array}{l}\text { Bees come and urinate on flowers of my crops; that urine makes fruits/seeds to come, a blessing from } \\
\text { God carried out by bees }\end{array}$ & 4.6 \\
\hline 2 & Bees come to facilitate marriage of my crops & 0.8 \\
\hline 3 & Bees and other pollinators facilitate the marriage of flowers & 2.3 \\
\hline 4 & Bees are just visiting my crops to get nectar only & 1.5 \\
\hline 5 & $\begin{array}{l}\text { Bees bring wild pollen ("Ngwaso"), drop them onto flowers to enable flower to open and give } \\
\text { fruits/seeds }\end{array}$ & 3.8 \\
\hline 6 & Bees come to drink water and collect other foods I do not know & 11.5 \\
\hline 7 & Bees come to my crops to do the natural job of fertilizing my crops as God created them for that job & 5.4 \\
\hline 8 & Bees come, bust, and later fertilize the flowers of my crops & 3.1 \\
\hline 9 & $\begin{array}{l}\text { Bees comes to take pollen/nectar from crops to their hives because they are pests (thieves), and of } \\
\text { what they take, my crop miss it }\end{array}$ & 0.8 \\
\hline 10 & Bees fall on flower of my crops, eating from there and later I get fruits/seeds & 1.68 \\
\hline 11 & Bees fertilize my crops by transporting pollen between male and female flowers & 3.1 \\
\hline 12 & Bees fertilize my crops, but wind can also fertilize my crops if bees do not come, so I am not bothered & 5.4 \\
\hline 13 & Bees get nectar from my crops, they help us to get better yield and help themselves & 2.3 \\
\hline 14 & Bees just come to drink juice from my crops but they do nothing good or bad on my crops & 2.3 \\
\hline 15 & $\begin{array}{l}\text { Bees just take pollen ("ebivu”) from flowers, go away, and disseminate these pollen on other plants in } \\
\text { forests }\end{array}$ & 8.5 \\
\hline 16 & Bees must visit flowers of my crops to get good yield (seeds/fruits): rules of Nature and God & 0.8 \\
\hline 17 & Bees pollinate on my crop for good growth and good seeds/fruit & 1.5 \\
\hline 18 & Bees provide a two-way benefit (collect nectar for their hives and bring pollen to my crops) & 0.8 \\
\hline 19 & I do not know (I cannot tell) & 1.5 \\
\hline 20 & I do not know but was told in a workshop that bees have to pollinate my crops for good yield & 1.5 \\
\hline 21 & I see bees visiting flowers of my crops but I do not know what they are after on my crops & 2.3 \\
\hline \multirow[t]{5}{*}{22} & I still do not know/understand what bees bring to my flowers to enable me to get better fruits/seeds & 0.8 \\
\hline & If bees fall on flowers of my crops, I will see fruits/seeds coming in 1 to 3 weeks & 14.6 \\
\hline & Just playing (they do nothing valuable) & 3.8 \\
\hline & They pollinate most of the crops I grow & 5.4 \\
\hline & They come to fertilize crop flowers & 3.8 \\
\hline
\end{tabular}

Chi-square test for difference in knowledge of what bees are after on crop flowers: $\chi^{2}=85.92, N=93.8, \mathrm{DF}=26, P<0.0001$.

individual bees belonging to different bee species was intense in old and bushy fallows and in hedgerows. This indicated that the conservation of bees in the flower producing zones has to involve the conservation of seminatural habitats (hedgerows, fallows) in the surrounding of flower farms. It may be relevant to say here that both flower farm managers and small-scale farms should be sensitized about the value of conserving seminatural habitats for the maintenance of pollinators in the habitats surrounding their flower farms.

\subsection{Farmers' Surveys Results}

3.5.1. Characteristics of Interviewed Farmers. Several farmers from Baganda, Bakiga, and Banyankore tribes were interviewed. Across flower farm location, the majority of respondents were females (62\%), aged between 35-60 years. The main lucrative activity of these farmers was crop production, although in Ntungamo, farmers interviewed were cattle keepers (cattle keeping being the main lucrative activity and crop production being the secondary subsistence activity). The majority of small-scale farmers interviewed had a total land allocated to crop production of 0.1 to 10 ha maximum. The majority of these farmers hired or paid 1 to 2 workers and this result indicated that they had almost no labour cost. Interviewed farmers did grow various crop species in association. Most frequently, it was common to find a mixture of pollinator-dependent crops with non-pollinator-dependent crops (Table 7).

3.5.2. Farmers' Knowledge of Pollination, Pollinator Groups, Pollination Processes, and Value of Pollinating Services to Their Crops. The percentage of farmers understanding the word pollination (those knowing different pollinators of their crops) increased and was significantly $(P<0.05)$ positively related to (a) the education level of the farmer (number 
TABLE 8: Perception of the importance of pollinators by bees in farming business.

\begin{tabular}{|c|c|c|}
\hline Statement no. & Question: Why do you think crop pollination by bees is important in your farming business? & $\begin{array}{c}\text { Freq. } \\
(\%)\end{array}$ \\
\hline 1 & Bees are important for honey production and for pollinating flowers of my crops & 1.48 \\
\hline 2 & I know bees collect only their nectar but I am not sure if they do anything beneficial to my crops & 1.48 \\
\hline 3 & I know no bee-visits, no yields. Please teach me how to make a home for them near my crops & 0.74 \\
\hline 4 & $\begin{array}{l}\text { I was told by extension workers and neighbours to care for bees because if no bee-visits, no fruit/seeds I will } \\
\text { harvest and sell, yet I need money to pay school fees }\end{array}$ & 8.15 \\
\hline 5 & If bees fall on flowers of my crops (avocado), I see a fruit coming; cropping is my business and bees help me free & 0.74 \\
\hline 6 & Bee visitation to coffee has no value; they add nothing, whether they come or not, my coffee will set fruits & 0.74 \\
\hline 7 & Bees are important because if no bee-visits, no yields I get at all & 7.41 \\
\hline 8 & Bees are important to get honey and also if no bee-visits, no fruit/seed I get from most of my crops & 8.15 \\
\hline 9 & Bees are important because I have seen that no bee-visits, no fruits on all crops I grow & 2.22 \\
\hline 10 & $\begin{array}{l}\text { Bees are important and visit my commercial and vegetable crops; but I ask myself a question, where do they } \\
\text { sleep? }\end{array}$ & 2.96 \\
\hline 11 & Bees are important for my pulse crops, I need to know how to build a small house for them so that they stay near & 0.74 \\
\hline 12 & When building a house for wild bees, how should it look? Like a beehive or like a rat hole? & 0.74 \\
\hline 13 & Bees are important because all flowering plants/crops on this earth want bee-visits to perpetuate well & 2.96 \\
\hline 14 & Bees are important for honey production and for pollinating flowers of crops I feed on and make money from & 0.74 \\
\hline 15 & $\begin{array}{l}\text { Bees are important for honey production and for pollinating flowers of my crops, especially crops wanted at } \\
\text { market }\end{array}$ & 1.48 \\
\hline 16 & Bees are important for pollinating our crops and they provide honey, wax, propolis, candle & 5.19 \\
\hline 17 & Bees are important to help make my crops grow and get better yield;they do free work & 2.22 \\
\hline 18 & Bees get nectar from my crops, but they bring manure from the hive to make turn into seeds/fruits & 5.19 \\
\hline 19 & By field experience, I know no bee-visits, all flowers will die off, no fruits/seeds will come out & 1.48 \\
\hline 20 & Either bees visit my beans/peas or not, I will still get my 5 to 12 pods per plant (bees have no value to my crops) & 0.74 \\
\hline 21 & Either bees visit my beans or not, I will still get my 5 to 12 pods per plant (bees have no value to my crops) & 1.48 \\
\hline 22 & $\begin{array}{l}\text { Every time bees fall on flowers of my crops (avocado, mango), few days later, I see a beautiful fruit/seed/pod } \\
\text { coming; no hunger at home in the future }\end{array}$ & 0.74 \\
\hline 23 & If there are few or no visits of my crop flowers, I get no or poor yield & 0.74 \\
\hline 24 & $\begin{array}{l}\text { For most fruit crops (mango, avocado, papaw) I grow, they have to get pollinated by bees to get sweet fruits and } \\
\text { high yields competitive in the markets }\end{array}$ & 0.74 \\
\hline 25 & From my observations if no bees visit flowers in the village abundantly, no pods on my bean plants & 0.74 \\
\hline 26 & $\begin{array}{l}\text { I know without bee-visitations to flowers I can not harvest. However, I do not know where they come from or } \\
\text { sleep; with bee-visits, I get fruits most wanted at market by my customers }\end{array}$ & 2.96 \\
\hline 27 & I know, no bees, no harvest. However, I do not know how to rear and make them many in my crops & 2.22 \\
\hline 28 & I am not sure if bees are important in crop production business (for my crops) & 11.11 \\
\hline 29 & $\begin{array}{l}\text { I know from my grandparents that no bees (pollinators) visits, no single mango fruit I will get acceptable at } \\
\text { market }\end{array}$ & 0.74 \\
\hline 30 & I know they are important but can not explain why it is only after their visit that I see fruits/seeds coming? & 2.96 \\
\hline 31 & I see bees visit my coffee flowers but I do not know for which purpose apart from feeding there & 0.74 \\
\hline 32 & $\begin{array}{l}\text { I see bees visit my avocado/coffee flowers but I donot know what do they bring to my flowers to get exciting } \\
\text { fruits/seeds }\end{array}$ & 2.22 \\
\hline 33 & $\begin{array}{l}\text { I was told by my neighbours by extension service agents that if no bee-visits to my crops, no yield at all but I can } \\
\text { not explain why }\end{array}$ & 0.74 \\
\hline 34 & $\begin{array}{l}\text { If bees fall on flowers of my crops (avocado), I see a fruit coming later and that fruit is wanted at market and if } \\
\text { children feed on it, they grow well because it is rich in vitamins, hence no stunting of children in my family }\end{array}$ & 1.48 \\
\hline 35 & If no bee-visits, no yields; however, I do not know where they come from (sleep) & 0.74 \\
\hline 36 & Important because all the crops I grow need bee-visitations, even flowers of my cassava & 5.19 \\
\hline 37 & My crops have to get high bee-visitations, otherwise they will not yield properly well & 2.96 \\
\hline 38 & $\begin{array}{l}\text { No mango fruits or bean seeds I get if no abundant and diverse bees flying around in the village, if you feed on } \\
\text { fruits not visited by bees, you fall ill }\end{array}$ & 1.48 \\
\hline
\end{tabular}


TABLE 8: Continued.

\begin{tabular}{lll}
\hline Statement no. & Question: Why do you think crop pollination by bees is important in your farming business? & $\begin{array}{c}\text { Freq. } \\
(\%)\end{array}$ \\
\hline 39 & The more bees fall on my (avocado/watermelon/pumpkin/tomato) flowers, the more fruits I get in my bag & 1.48 \\
40 & Fruits/seeds that were obtained after bee-visits last longer and are attractive to customers at local market \\
41 & The more bees fall on my crop flowers, the more fruits/seeds I get \\
42 & Without bees, no farmer can harvest in our village & 1.48 \\
\hline
\end{tabular}

Chi-square test for difference in knowledge of what bees are after on crop flowers: $\chi^{2}=103.49, N=100, \mathrm{DF}=41, P<0.0001$.

of years schooling), (b) the age of the respondent, (c) the number of years the farmer has been growing pollinatordependent crops among those interviewed, (e) the total land allocated for crop production by a farmer, and (f) the proportion of rich farmers in the village (community) among those interviewed (Figure 5). Surprisingly, there was a negative relationship between the number of rich farmers and knowledge about pollination (Figure 5(f)).

When asked the question, do you know or understand what we mean by pollination?, the percentage of farmers saying they understand what pollination means was of $80 \%$ against $20 \%$ who said they did not understand or know what pollination means $\left(\chi^{2} 1 \mathrm{df}=36.56, P<0.0001\right)$. When asked to name 1 to 6 species of pollinators they knew and saw visiting the flower of their crops, approximately 5\%,37\%, $38 \%, 14 \%, 4 \%$, and $2 \%$ of farmers interviewed declared knowing (were able to name), respectively, at least $0,1,2,3,4$, and 6 bee species/groups $\left(\chi^{2} 1 \mathrm{df}=85.129, P<0.0001\right)$. But, when asked to describe the types of pollinator/bee groups (species) they see visiting flowers of their crops, interviewed farmers had significantly ( $\chi^{2}$ test, $P<0.05$ ) correct knowledge of more than 2 pollinator groups. Farmers (14.1-19.3\%) knew honeybees, Xylocopa ("Civuvumira" in local language: Luganda) and stingless bees ("Kadoma" in local language: Luganda) as the frequent flower bee species/groups of their crops (Figure 6).

There were significantly $\left(P<0.05, \chi^{2}\right.$ test $)$ different farmers' perceptions on roles played by bees in crop flowers. When asked about what they think bees are doing on flowers of their crops, farmers provided different responses. Most frequent statement $(14.6 \%)$ from farmers was that they believed that if "bees fall on flowers on their crops, they will see fruits/seeds coming in 1 to 3 weeks." Other farmers (11.5\%) believed that "bees come to drink water and collect other foods on their crops." In $0.8 \%$ of frequency of statements, some farmers believed that "bees come to facilitate marriage of their crops." However, some farmers believed that bees were just playing with flowers of their crops and doing nothing valuable for their crops (Table 7). When asked the question: "is crop pollination by bees important in your crop production?", $73.9 \%, 9.9 \%$, and $16.2 \%\left(\chi^{2} 2 \mathrm{df}=74.81, P<0.001\right)$ of farmers declared, respectively, that they believe (i) bees are important, (ii) they are not important, and (iii) they are not sure if bees are important in their crop production activities. More frequently, farmers reported that they "think crop pollination by bees is important in their farming business because they frequently believed $(8.15 \%)$ that "with bees, they will get honey and they are convinced that if no bee-visits, there is no yield from their crops" (Table 8). Farmers who grow vegetables and fruits had higher understanding of pollination than those who grow legume, cereals, root, and tubers. Other farmers said bees contribute little and for them they are aware that bees that visit their crops come from community hives and or from surrounding forests and lake edges/wetlands; but for them they are convinced that "if no bees visiting crop flowers, wind \& other insects will still pollinate and they will still harvest something."

When asked "how much do you think bee-visitations to flowers of your crops contribute to crop yields?", approximately 23 to $28 \%$ of farmers perceived significantly ( $\chi^{2}$ test, $P<0.05)$ that bees contributed, respectively, to half $(41-50 \%)$ or to third (26-40\%) of yield increase of crop yields in their villages (Figure 7$)$. In fact, there were significant differences $\left(\chi^{2}\right.$ test, $\left.P<0.05\right)$ between the average pollination experimental data $[21,22]$ and the farmers' perceived contribution of bees to yield of different crops such as beans, citrus, coffee, cowpea, mangoes, passion fruit, and pepper (Table 10). In most cases, farmers guessed little value as compared to the pollination experimentally derived data [21-23]. For other crops (avocado, egg plant, watermelon, tomato, etc.) farmers perceived the value of the contribution of bees to yield that was statistically ( $\chi^{2}$ test, $P>0.05$ ) similar to the one that was derived empirically after conducting field pollination experiments (Table 9) by the author.

3.5.3. Farmers' Knowledge and Perception of Drivers of Bees in Villages Immediately Surrounding Flower Companies. When farmers were asked to explain where do they think bees are abundant between the edge of the flower farm $(0.01-0.2 \mathrm{~km})$ and far away $(>2 \mathrm{~km})$ in the village, most $(90 \%)$ farmers believed that bees should be abundant in their villages since the "fumes" or chemicals sprayed daily inside greenhouses of the flower farms will not reach at such distance $(>2 \mathrm{~km})$ (Table 10). Some villagers frequently stated that bees were many in the village ( $>2 \mathrm{~km}$ far away from flower farm) because "bees cannot survive where they spray daily toxic chemicals." However, the answer "I do not know, I am not sure, I cannot tell" was frequently given by farmers $(18.3 \%$ of frequency) and this indicated that some farmers were not good naturalists or had almost no interest in understanding the work of bees in their farming business. Different justifications (reasons) for getting higher yields far away from 
TABLE 9: Farmers' perception of the importance and value of pollinating services delivered by bees to their crops.

\begin{tabular}{|c|c|c|c|c|c|c|c|c|}
\hline \multirow[t]{2}{*}{$\begin{array}{l}\text { Crop } \\
\text { categories }\end{array}$} & \multirow[t]{2}{*}{$\begin{array}{l}\text { Crops } \\
\text { reported }\end{array}$} & \multirow[t]{2}{*}{$\begin{array}{c}\text { Yield } \\
\text { parameters }\end{array}$} & \multirow[t]{2}{*}{$\begin{array}{c}\text { YNFBV } \\
(\text { Mean } \pm \text { SD })\end{array}$} & \multirow[t]{2}{*}{$\begin{array}{c}\text { YHBV } \\
(\text { Mean } \pm \text { SD) }\end{array}$} & \multirow[t]{2}{*}{$\begin{array}{c}\mathrm{A}=\text { Fruit } / \text { Seed } \\
\text { set }(\%)\end{array}$} & \multirow{2}{*}{$\begin{array}{l}\mathrm{B}=\text { Fruit set }(\%) \\
\text { Experimental data } \\
\quad(2007)\end{array}$} & \multicolumn{2}{|c|}{$\begin{array}{l}\text { Statistics for difference } \\
\text { in fruit set between A } \\
\text { and B }\end{array}$} \\
\hline & & & & & & & $\chi^{2}(\mathrm{df}=1)$ & $P$ \\
\hline Fruits & Avocado & $\begin{array}{c}\mathrm{Nbr} \\
\text { fruits/branch }\end{array}$ & $4.037 \pm 3.76$ & $9.49 \pm 6.14$ & 57.45 & 82.67 & 4.53931 & 0.033 \\
\hline Pulses & Beans & Nbr pods/plant & $1.33 \pm 1.14$ & $6.05 \pm 4.53$ & 77.95 & 27.11 & 24.6022 & $<0.001$ \\
\hline Fruits & Citrus-lemon & $\begin{array}{l}\mathrm{Nbr} \\
\text { fruits/branch }\end{array}$ & $0.71 \pm 0.29$ & $4.31 \pm 0.82$ & 83.43 & 24.65 & 31.9679 & $<0.001$ \\
\hline Fruits & Citrus-orange & $\begin{array}{l}\text { Nbr } \\
\text { fruits/branch }\end{array}$ & $2.45 \pm 0.57$ & $8.39 \pm 1.88$ & 70.47 & 32.23 & 14.2385 & $<0.001$ \\
\hline Industrial & Coffea arabica & $\begin{array}{l}\text { Nbr berry- } \\
\text { fruits/branch }\end{array}$ & $21.84 \pm 3.28$ & $53.62 \pm 7.35$ & 59.26 & 62.12 & 0.067389 & 0.795 \\
\hline Industrial & Coffee robusta & $\begin{array}{c}\text { Nbr bags of } \\
\text { coffee beans/ha }\end{array}$ & $4.16 \pm 0.99$ & $8.62 \pm 1.79$ & 51.75 & 68.71 & 2.387869 & 0.122 \\
\hline Industrial & Coffee robusta & $\begin{array}{l}\text { Nbr berry- } \\
\text { fruits/branch }\end{array}$ & $11.65 \pm 6.10$ & $25.23 \pm 4.52$ & 53.86 & 78.32 & 4.52634 & 0.033 \\
\hline Pulses & Cowpea & Nbr pods/plant & $1.61 \pm 0.45$ & $6.31 \pm 0.82$ & 74.51 & 45.43 & 7.05058 & 0.008 \\
\hline Vegetables & Egg plant & Nbr fruits/plant & $1.46 \pm 1.21$ & $3.62 \pm 0.63$ & 59.73 & 41.65 & 3.22437 & 0.073 \\
\hline Pulses & Groundnut & Nbr pods/plant & $2.34 \pm 0.70$ & $8.61 \pm 1.65$ & 72.85 & 68.55 & 0.130764 & 0.718 \\
\hline Fruits & Mangos & $\begin{array}{l}\text { Nbr sacs of } \\
100 \mathrm{Kg} / \text { tree }\end{array}$ & $8.53 \pm 1.76$ & $12.77 \pm 2.66$ & 33.21 & 83.87 & 21.9204 & $<0.001$ \\
\hline Fruits & Mangos & $\begin{array}{l}\mathrm{Nbr} \mathrm{Kg} \\
\text { fruits/branch }\end{array}$ & $3.71 \pm 3.48$ & $9.276 \pm 3.76$ & 60.05 & 29.34 & 10.5504 & $<0.001$ \\
\hline Fruits & Papaya & Nbr fruits/plant & $1.59 \pm 0.44$ & $5.25 \pm 0.89$ & 69.81 & 31.55 & 14.4419 & $<0.001$ \\
\hline Fruits & Passion fruit & Nbr fruits/plant & $8.57 \pm 0.150$ & $11.00 \pm 1.31$ & 22.10 & 78.98 & 32.0077 & $<0.001$ \\
\hline Pulses & Pigeonpeas & $\begin{array}{c}\text { Nbr } \\
\text { pods/branch }\end{array}$ & $2.13 \pm 1.56$ & $6.31 \pm 1.05$ & 66.28 & 65.72 & 0.002376 & 0.961 \\
\hline Pulses & Peas & Nbr pods/plant & $1.13 \pm 1.17$ & $4.07 \pm 0.73$ & 72.21 & 65.41 & 0.335998 & 0.562 \\
\hline Vegetables & Pepper & $\begin{array}{l}\text { Nbr } \\
\text { fruits/branch }\end{array}$ & $0.88 \pm 0.19$ & $2.75 \pm 0.47$ & 67.87 & 19.89 & 26.2315 & $<0.001$ \\
\hline Fruits & "Prune" & $\begin{array}{l}\mathrm{Nbr} \\
\text { fruits/branch }\end{array}$ & $0.00 \pm 0.00$ & $3.20 \pm 0.58$ & 100.0 & 76.54 & 3.11755 & 0.077 \\
\hline Fruits & Pumpkin & Nbr fruits/plant & $0.00 \pm 0.00$ & $3.92 \pm 0.88$ & 100.0 & 82.21 & 1.73692 & 0.188 \\
\hline Pulses & Simsim & Nbr pods/plant & $0.84 \pm 0.20$ & $5.19 \pm 1.12$ & 84.1 & 71.67 & 0.991878 & 0.319 \\
\hline Industrial & Sunflower & Nbr seeds/head & $290.5 \pm 71.9$ & $951.5 \pm 186.7$ & 69.47 & 69.77 & 0.000646 & 0.98 \\
\hline Vegetables & Tomato & Nbr fruits/plant & $12.56 \pm 10.3$ & $22.06 \pm 11.90$ & 43.06 & 37.54 & 0.378045 & 0.539 \\
\hline Fruits & Watermelon & Nbr fruits/plant & $0.00 \pm 0.00$ & $3.43 \pm 0.69$ & 100.0 & 79.43 & 2.35816 & 0.125 \\
\hline Fruits & Apple & $\begin{array}{c}\mathrm{Nbr} \\
\text { fruits/branch }\end{array}$ & $0.00 \pm 0.00$ & $6.20 \pm 2.58$ & 100.0 & 78.45 & 2.60242 & 0.107 \\
\hline
\end{tabular}

Legend:

YNFBV: When no/few; YNFBV: yields when very few or no bees visit my crop flowers (bad yield).

YHBV: When I receive high bee-visits to crops; YHBV: yields if bees came with high visitation frequency to flowers of my crop.

A: $($ Fruit/seed set in $\%)=[($ mean YHBV - mean YNFBV $) /$ mean YHBV $] * 100$.

B: (Fruit/seed set in \%); this is data obtained after conducting pollination experiments.

the flower farm were given, but must frequently, farmers believed that higher yields can only be due to difference in field management systems, fertility levels, types of varieties grown, and to difference in bee-visitations (Table 11) because bee-visitations are almost absent near the flower farm where they apply toxic chemicals.

When asked if they have ever observed any changes (reduction, increase) in crop yields in the village over the last 5 to 20 years, and if yes, this may be due to what farmers perceived as significant ( $\chi^{2}$ test, $P<0.001$ ) changes (reductions) in crop yields during the last 5-20 years for various reasons such as soil infertility of their lands (Table 11). The presence of the flower farm spraying chemical toxic pesticides nearby and environmental degradation were key reasons provided by farmers even when some farmers said that there has been little change (14.62\%) while most farmers $(20.10 \%)$ said they were not sure if change has ever happened or affected crop yields in their villages (Table 11). 


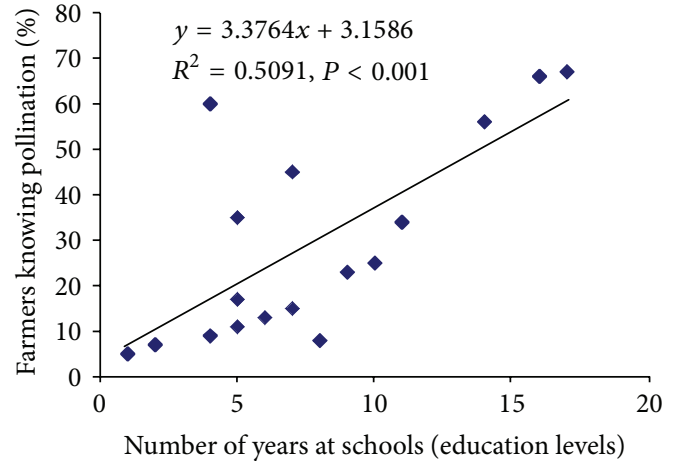

(a)

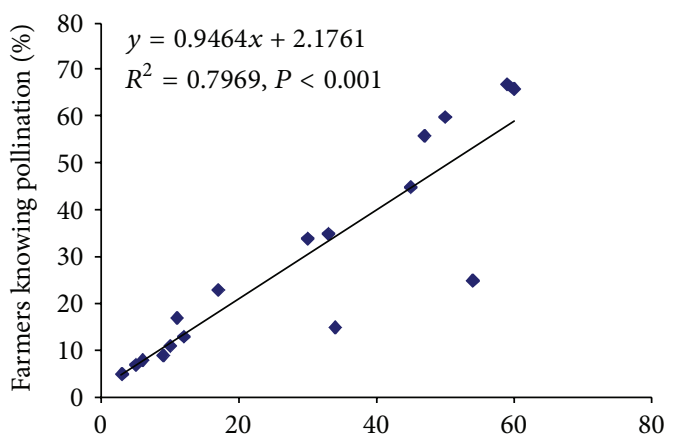

Number of years growing pollinator-dependent crops

(c)

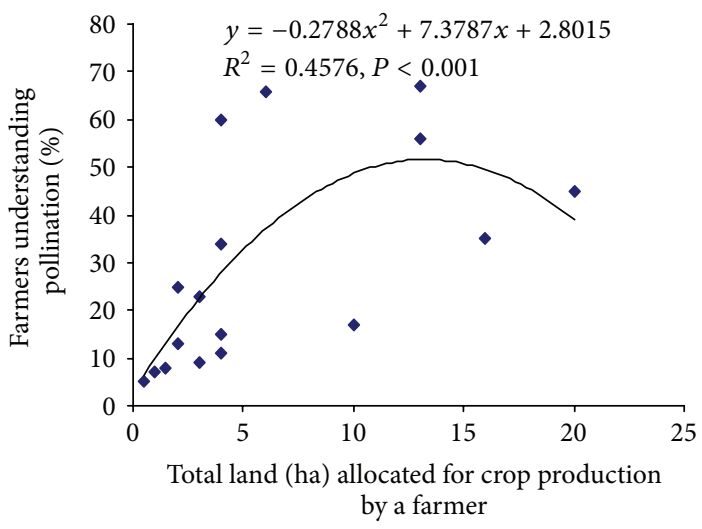

(e)

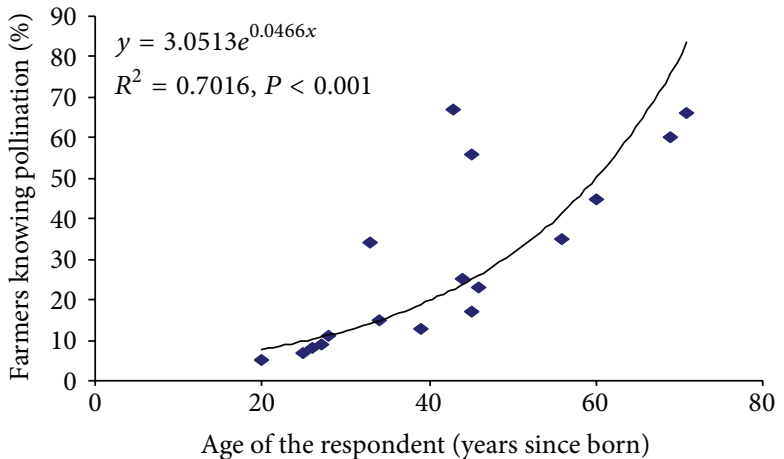

(b)

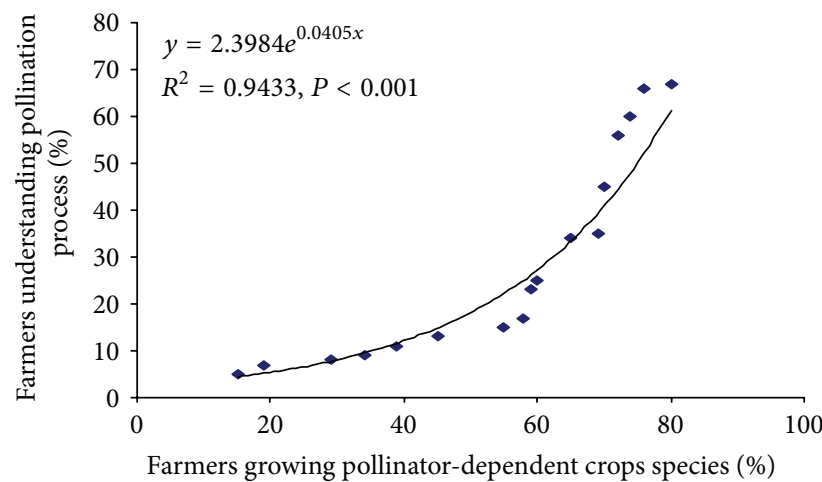

(d)

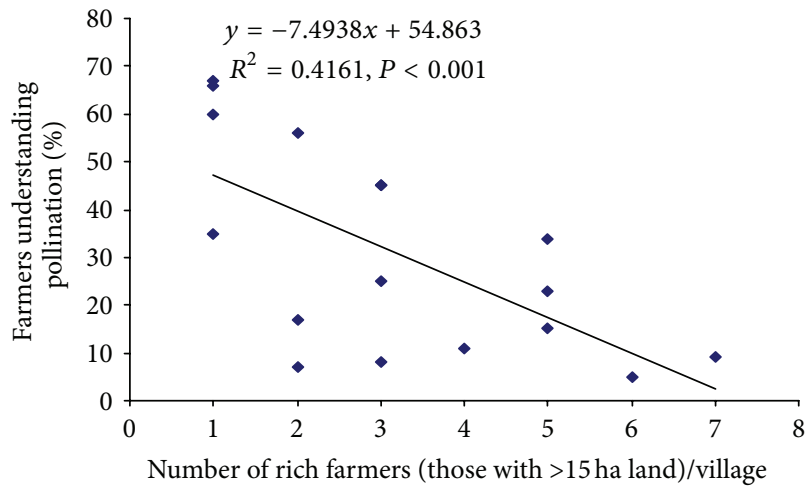

(f)

FIGURE 5: Trends in the influences of socioeconomic and demographic characteristics $((\mathrm{a})=$ level of education, $(\mathrm{b})=$ age; $(\mathrm{c})=$ crop production experience, $(\mathrm{d})=$ type of crops grown by the farmers, $(\mathrm{e})=$ land allocated to production of pollinator dependent crops, and $(\mathrm{f})=$ level of richness of the farmer) of the respondents on the level of knowledge/understanding of the word pollination by farmers interviewed from different villages surrounding flower farms.

When farmers were asked if they have seen any change in the population density (abundance) of bees in the village, most farmers were not sure if there has been change. Farmers who believed in changes attributed that to declining in beekeeping, "flower fumes", bad farming practices, or forest bush clear-cutting (Table 12). When asked if they felt that bee populations have been stable or changing (increasing/decreasing) over the last 5 to 15 years in their village landscapes, there were various answers (perceptions) among farmers. Most (45\%) of farmers perceived that bee populations have been reducing (declining) seriously in their villages in the last 5 to 15 years.
Some farmers (32.1\%) were not sure or had no idea (they did not know anything) whether changed has occurred or not. A few farmers (19.8\%) said they perceived no changes while only $3.1 \%$ of these respondents felt that there has been an increase of bee populations in the village over the last 5 to 15 years. The difference in perceptions among the four categories of respondents was significant $\left(\chi^{2} 3 \mathrm{df}=38.367, P<0.001\right)$.

Also, when asked if they felt that crop yields have been stable or changing (increasing/decreasing) over the last 5 to 15 years in their village landscapes, most (48.3\%) of the farmers perceived that crop yield has been reduced by $10-50 \%$ in their 


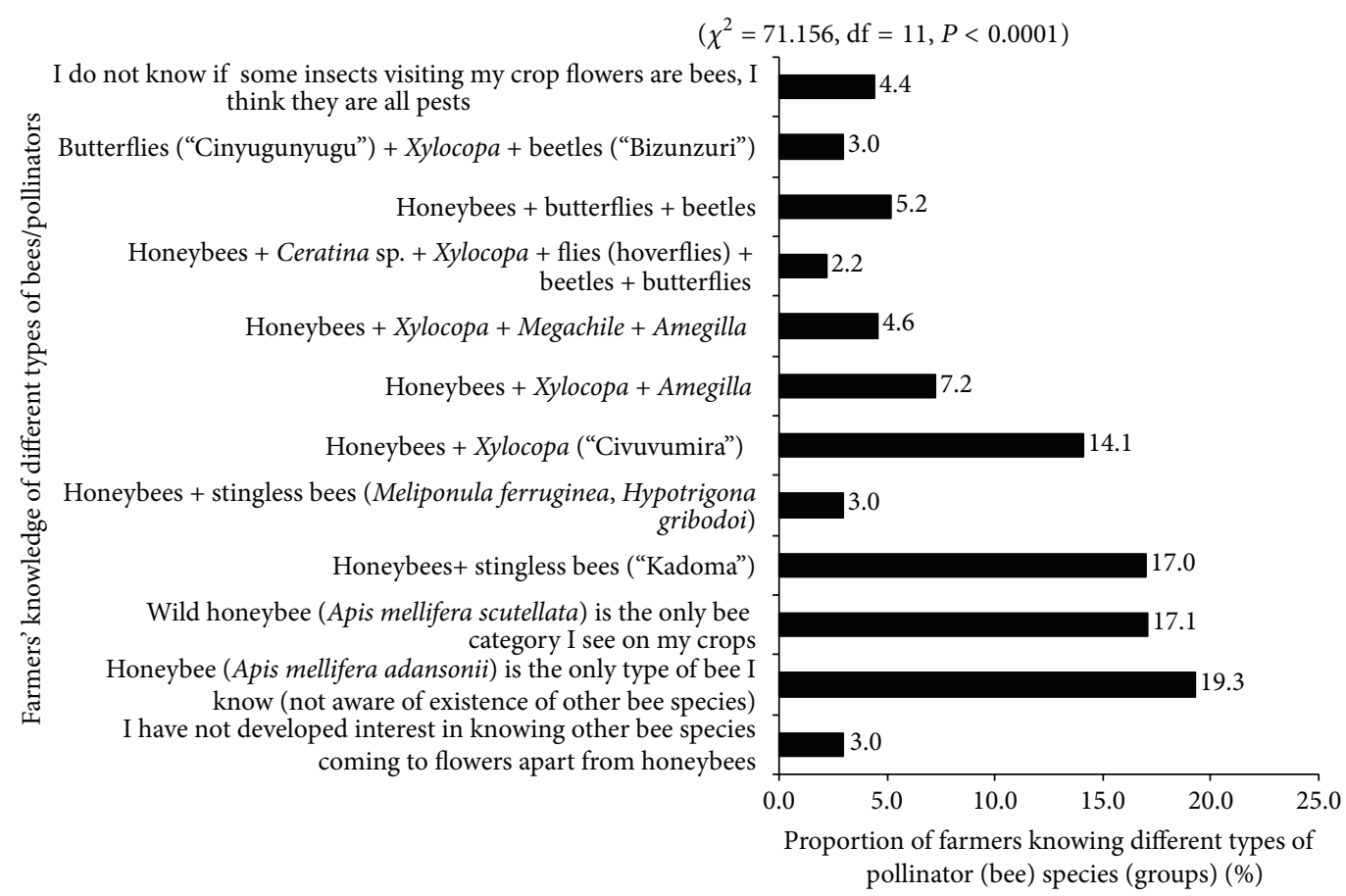

FIGURE 6: Type of species/functional group of pollinators farmers know pollinate their crops.

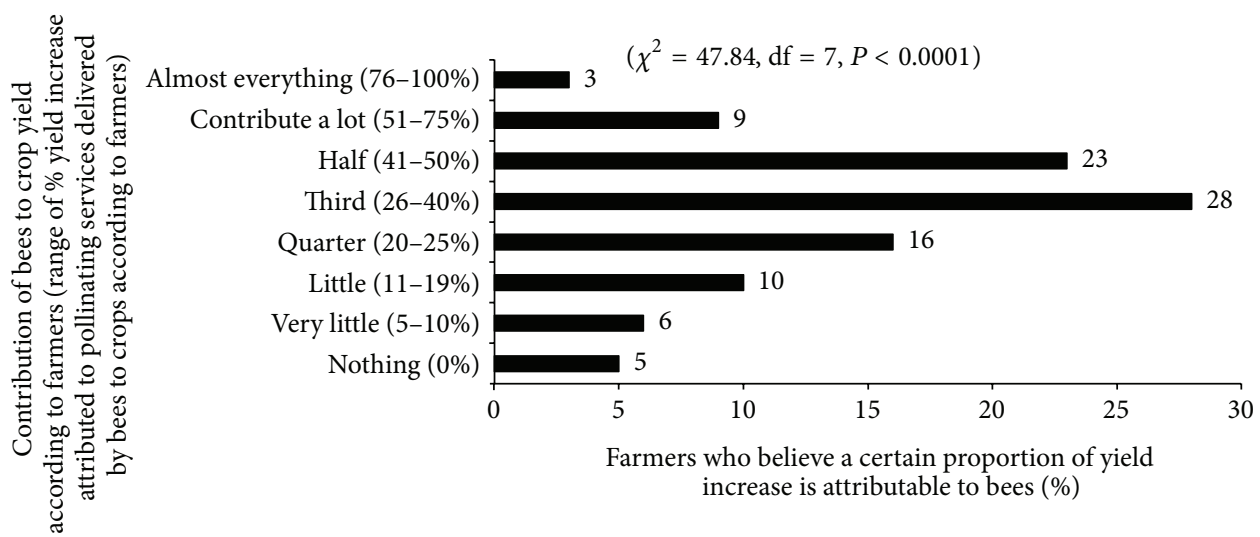

FiguRE 7: Farmers' perception of the general contribution of bees to crop yield.

villages in the last 5 to 15 years. Some farmers (17.8\%) felt that crop yield has been stable. Another group of respondents (18\%) perceived that they were not sure (they could not tell) if change has occurred or not. A small portion of respondents (6.1\%) perceived that crop yield has been increasing slightly in the 10 to $35 \%$ proportions. Approximately $3.8 \%$ of respondents perceived that crop yield has increased in the $40-85 \%$ proportion while another small group of respondents (6\%) perceived that crop has declined seriously by 50 to $85 \%$. The difference in views/perceptions among the 6 groups of respondents interviewed was significant $\left(\chi^{2} 5 \mathrm{df}=7.87, P<\right.$ $0.001)$. Overall, when asked if the currently observed changes (reductions) in crop yield are a consequence of reduction in bee populations in the villages, most farmers perceived that there has been a reduction in crop yield as a consequence of the decline in bee populations in the villages (Table 13).
When asked if they believed that if "crop yield reduction/ loss was linked to decline in bee populations in the village", there were different statements given by farmers (Table 14). Overall, 35.4\% of respondents were of neutral views, $39.2 \%$ disagreed, and $25.45 \%$ agreed. The difference in views between the 3 categories of respondents (neutral, disagreeing, agreeing) was significant $\left(\chi^{2} 2 \mathrm{df}=3.056, P<0.05\right)$. In fact, around $58 \%$ of farmers interviewed believed that growing crops far away $(>2 \mathrm{~km})$ from the flower farm was a better option to obtain higher yields even when some farmers $(22.9 \%)$ believed that it should be similar yields. Onlya few farmers $(1.5 \%)$ believed that the one growing crops at $(0.1-$ $0.3 \mathrm{~km}$ ) the edge of the flower farm could get better yield. A small proportion $(17.6 \%)$ of farmers stated that they were not sure (they did not know). The difference in views/perceptions of the 4 groups of respondents was statistically significant 
TABLE 10: Perception of farmers about the abundance of bees between the rural landscape and the neighborhood of a given flower farm.

\begin{tabular}{|c|c|c|}
\hline $\begin{array}{l}\text { Statement } \\
\text { no. }\end{array}$ & $\begin{array}{l}\text { Question: Where do you think bees are abundant, near the flower farm }(0.1-0.5 \mathrm{~km}) \text { or further }(>2 \mathrm{~km}) \text { in the } \\
\text { village? }\end{array}$ & $\begin{array}{c}\text { Freq. } \\
(\%)\end{array}$ \\
\hline & I have no idea but think bees should be many in the villages where there are abundant flowers for them & 11.5 \\
\hline 1 & Bee populations should be high up-country than near the flower farm with toxic chemical sprays they use & 2.3 \\
\hline 2 & Bees are many in the village ( $>2 \mathrm{~km}$ far from the flower farm) and no bees will stay near chemicals & 4.6 \\
\hline 3 & $\begin{array}{l}\text { Bees are many in the village ( }>2 \mathrm{~km} \text { far from the flower farm), everywhere where wild/crop flowers are } \\
\text { freshly/abundant }\end{array}$ & 3.8 \\
\hline 4 & Bees are many in the village because we have abundant flowers there than near the flower farm with toxic fumes & 2.3 \\
\hline 5 & Bees are many in the village compared to near (edge) the flower farm & 0.8 \\
\hline 6 & Bees are many in the village $(>2 \mathrm{~km})$ because they spray daily near the farm and bees can not survive there & 14.5 \\
\hline 7 & Bees are many in the villages (in every place where there are many flowers, bees will be there) & 3.1 \\
\hline 8 & Bees are many in the villages because they have no enemy there, they are free to go everywhere in the village & 2.3 \\
\hline 9 & Bees are many of course in the village ( $>2 \mathrm{~km}$ far from the flower farm) & 8.4 \\
\hline 10 & $\begin{array}{l}\text { Bees are no longer many in the village because the flower farm is killing them with the toxic sprays they make } \\
\text { every day }\end{array}$ & 1.5 \\
\hline 11 & $\begin{array}{l}\text { Bees are not strong like humans, if they smell the fumes from the flower farm when foraging, they end up dying } \\
\text { in their nests }\end{array}$ & 0.8 \\
\hline 12 & Bees are obviously many in the village with fresh air, not polluted by toxic chemicals of flower farms & 3.1 \\
\hline 13 & Bees are still many in the village compared to near the flower farm where nesting sites have been destroyed & 5.3 \\
\hline 14 & $\begin{array}{l}\text { Every bee flying for forage from the village to the edge of the flower farm will die there because of too many } \\
\text { pesticides there }\end{array}$ & 1.5 \\
\hline 15 & I am not sure (I cannot tell with confidence where exactly) & 5.3 \\
\hline 16 & $\begin{array}{l}\text { I am not sure if bees are many in the village }(>2 \mathrm{~km}) \text { than near the flower farm but I see few bees on gardens } \\
\text { located in the proximity of flower farm }(0.2 \mathrm{~km})\end{array}$ & 3.8 \\
\hline 17 & I cannot tell exactly but I think they should be many in the village where healthy-non-polluted wild flowers are & 3.1 \\
\hline 18 & I donot know; I cannot tell; I am not sure (I cannot even guess) & 18.3 \\
\hline 19 & Obviously bees are many in the village than near the flower farm where they spray a lot & 1.5 \\
\hline 20 & Pesticides have a long-persistence smell near the flower farm so bees will die there quickly & 1.5 \\
\hline
\end{tabular}

Chi-square test for differences in beliefs of farmers about area where bees are abundant: $\chi^{2}=93.1291, N=100, \mathrm{DF}=20, P<0.0001$.

$\left(\chi^{2} 3 \mathrm{df}=68.032, P<0.05\right)$. Overall the majority of farmers doubted negative effects of the proximity to the flower farm on yields of their crops.

When asked to guess the place where someone can get better yield between near the flower farm and far away $>2 \mathrm{~km}$ ) from the flower farm, most farmers were not sure $(10.9 \%)$, while others stated that there should be no difference in yield (11.6\%). A small proportion of farmers felt that yield will be higher in the villages ( $>2 \mathrm{~km}$ far away) because the fumes of the flower farms do not reach over there (Table 13).

When farmers were asked to say when they started observing changes (in bee populations/crop yields) in their villages the majority of farmers (22.3-44\%) believed there has been significant ( $\chi^{2}$ test, $P<0.05$ ) changes (reductions) occurring in either crop yields or bee populations. However, some farmers (29-30\%) believed that changes in bee populations started occurring some 5 to 10 years ago (Figure 8).

Several drivers of bees in farmlands have been identified worldwide. During discussion meetings, farmers were asked to name key factors likely leading to the current ongoing bee loss in their villages. These drivers were put together on a paper and farmers were again asked to rank them in terms of importance from the most important (dangerous) to the less important factors that may be associated directly/indirectly with bee loss in the village. There were variations in assessment (ranking) of drivers by farmers from the four study districts (where the 4 flower farms are located). However, on average, all farmers ranked as significant $(P<0.005$, Kruskal-Wallis test) primary drivers the following drivers: (i) fragmentation of national habitats such as forests/wetlands (average rank: $1.90 \pm 0.13$ ), (ii) forests/bush clear-cutting in the village (average rank: $1.26 \pm 0.002$ ), (iii) logging, charcoal burning, timber/poles/firewood collection (average rank: $1.26 \pm 0.02$ ), (iv) fires burning intensification (1.69 \pm 0.04$)$, and $(\mathrm{v})$ local climate change such as rainfall pattern changes $(1.84 \pm 0.002)$.

Some worldwide documented key drivers of bee biodiversity loss (road construction up-country, land-use change, global climate change, environmental/degradation, grazing intensification, and agriculture modernization plan by the government) were perceived by local farmers as factors playing a tertiary role or as factors playing no role in the decline process or as factors having nothing to do with bee decline in the villages. Most farmers said they were not sure if these factors could affect bees even when a few of them believed that these factors could be associated to some extent with bee 
TABLE 11: Perceptions of farmers about changes (reduction/increase) in crop yields in the village in the last 5-20 years.

\begin{tabular}{|c|c|c|}
\hline $\begin{array}{l}\text { Statement } \\
\text { no. }\end{array}$ & $\begin{array}{l}\text { Question: Have you observed any changes (reduction, increase) in crop yields in the village over the last } 5 \text { to } 20 \\
\text { years? }\end{array}$ & $\begin{array}{c}\text { Freq. } \\
(\%)\end{array}$ \\
\hline 1 & Yield of crop is also reducing in the last $10-20$ years. I think it is because; soil is old/currently infertile in our area & 5.38 \\
\hline 2 & Changes in crop yield may be due to infertility of the lands and to flowers fumes & 0.77 \\
\hline 3 & I have not yet observed changes (reduction/increase) in my yields of crops & 8.46 \\
\hline 4 & I have observed changes (reduction) in yields for the last 5-10 years & 5.38 \\
\hline 5 & I have seen some change these days (reduction) in yields of many crops although I donot know the exact causes & 8.46 \\
\hline 6 & No change, for me, yield is increasing because I live far from the flower farm and I manage well my gardens & 1.54 \\
\hline 7 & No changes (reduction), instead I see increase because I do fertilization with cow dung to increase my yield & 0.77 \\
\hline 8 & No changes (reduction) in yields apart from thieves in the villages & 2.31 \\
\hline 9 & Not sure (I can not tell) & 20.10 \\
\hline 10 & There has been change (reduction) and this may be linked to practice of bad farming methods & 1.54 \\
\hline 11 & There has been changes in yield of many crop species for unknown reasons of changes in the global system & 0.77 \\
\hline 12 & $\begin{array}{l}\text { There have been drastic changes (reduction of } 50 \text { to } 80 \% \text { compared to previous harvests) in most of the crop } \\
\text { yields I grow }\end{array}$ & 3.08 \\
\hline 13 & There is a general decrease in yield of all crops we grow but I think it may be due to soil/land infertility & 0.77 \\
\hline 14 & There is a change (reduction) and bad yields are due to soil infertility, excess sunshine/rains, and climate change & 4.62 \\
\hline 15 & There is a change (reduction) in crop yields but do not know what it is due to exactly & 3.08 \\
\hline 16 & $\begin{array}{l}\text { Yes, there is a change (reduction) in yields over time but I can not explain clearly the changes are due to what } \\
\text { exactly }\end{array}$ & 0.77 \\
\hline 17 & $\begin{array}{l}\text { There is a change in yields probably due to soil infertility because I have over-used the land to grown different } \\
\text { crops over years }\end{array}$ & 1.54 \\
\hline 18 & $\begin{array}{l}\text { There is a reduction in yield due to over-use of soils, growing crops/bad varieties in a wrong season, no respect of } \\
\text { growing seasons }\end{array}$ & 3.85 \\
\hline 19 & $\begin{array}{l}\text { There are changes (reduction) in yields probably due to soil infertility of my gardens and to fumes from flower } \\
\text { farms }\end{array}$ & 0.77 \\
\hline 20 & There is yield reduction because bees are disappearing in the village due to chemical sprays from the flower farm & 6.15 \\
\hline 21 & There is very little change (decrease)/to not much changes in yield of my crops & 14.62 \\
\hline 22 & Yield of crops has reduced in the village over the last 5-20 years but I do not know why & 5.38 \\
\hline
\end{tabular}

Chi-square test for difference in arguments (statements) frequency: $\chi^{2}=110.15, N=100, \mathrm{DF}=21, P<0.0001$.

disappearance in the villages (Table 16). There was a great variability in perception of farmers concerning the place (area) where to get better yield between the near and the far areas to the flower farm (Table 15).

Farmers were requested to relate the rate of disappearance of bees due to degradation of natural/seminatural habitats; and it was observed that only old farmers (aged 70-80 years) think/perceive that forests and other good seminatural habitats disappeared 10-50 years ago. Old farmers perceived also that in areas covered by forests, it is possible to observe visits of bees to crop flowers at the rate of 500 bee-visits/ $10 \mathrm{~min} / 50 \mathrm{~m}^{2}$ garden plot. Young people (20-35 years old) perceived that forests disappeared in the villages some 5-10 years ago and that bee-visits to crop do not exceed 20 beevisits/10 min observations $/ 50 \mathrm{~m}^{2}$ garden plots (Figure 9) even in regions covered by forests or plenty of seminatural habitats.

3.5.4. Farmers' Attitudes towards Flower Industry Growth and Development in the Surrounding of Their Villages: Perceptions of the Negative Effects of Flower Industries on Environmental, Human, and Agricultural Health. When asked about the benefit of living near the flower farm, most (66\%) respondents significantly ( $\chi^{2}$ test, $\left.P<0.05\right)$ declared (stressed) gaining no benefit (advantage) by having their homesteads established close to flower farms (Figure 10). However, the proportion of farmers declaring having no problem with the presence of the flower farm in their villages was of $86 \%$ against $14 \%$ of farmers who said they had a problem with the flower farm $\left(\chi^{2} 1 \mathrm{df}=\right.$ 51.46, $P<0.001)$. Those who had problems with the presence of the flower farm in their village raised several reasons for why they had problems with the presence of the flower farm in their village (Table 17).

When asked to propose durable solutions to the problems of the presence of the flower farms in their villages, more frequently $(47.4 \%)$ farmers stated that they had no power to propose what should be done because when these cut-flower industries were established, politicians were consulted and they ended up allowing theses industries to settle in our villages without the consent of communities (Table 18). Only a small proportion of farmers frequently (5.9\%) affirmed that if flower farms stop applying dangerous chemicals, then they can stay in the villages. Another group said the flower companies should use nontoxic dangerous chemicals (8.1\%). Other farmers said they wanted the flower farms to pay all land titles from the surrounding villages (22\%). Some other farmers 
TABLE 12: Perception of changes in the populations of bees in the villages over the last 5-20 years.

\begin{tabular}{|c|c|c|}
\hline $\begin{array}{l}\text { Statmenet } \\
\text { no. }\end{array}$ & $\begin{array}{l}\text { Question: Have you observed any changes in bee populations (abundances) in the village over the last } 5 \text { to } 20 \\
\text { years? It is because of what? }\end{array}$ & Freq. (\%) \\
\hline & $\begin{array}{l}\text { Not sure if there has been strong changes in bees, but I watch few bee-visits (I see few bees feeding) in my farm } \\
\text { these days }\end{array}$ & 8.40 \\
\hline 1 & $\begin{array}{l}\text { I have observed no reduction in bees in the village; there are enough hives, wild nest sites, and food plants for } \\
\text { bees }\end{array}$ & 5.34 \\
\hline 2 & $\begin{array}{l}\text { I think bees are reducing in the village because of too much pollutants and toxic chemicals applied in the flower } \\
\text { farm around there }\end{array}$ & 3.05 \\
\hline 3 & Not sure if any change has occurred because I donot know how many bees were there before compared to now & 6.11 \\
\hline 4 & $\begin{array}{l}\text { Bee populations are declining over years because many termite mounds and tree/stamps where bees used to } \\
\text { nest have been destroyed. }\end{array}$ & 0.76 \\
\hline 5 & $\begin{array}{l}\text { Bee populations are declining in the village over the years because beekeeping is also declining in the village } \\
\text { (few hives in the village) }\end{array}$ & 2.29 \\
\hline 6 & $\begin{array}{l}\text { Beekeeping attracts all wild bees to hives and concentrates them where the hives are placed, so they will visit } \\
\text { only that area, then we shall think bees have disappeared }\end{array}$ & 3.05 \\
\hline 7 & $\begin{array}{l}\text { Bees have been reducing in the village over the last 5-10 years, but I do not know why Maybe you can tell me } \\
\text { more about it }\end{array}$ & 0.76 \\
\hline 8 & Bees are increasing these days because we have planted many flowering trees and shrubs they are interested in & 1.53 \\
\hline 9 & Bees are increasing; they are many in all bushes in the village, even in crops, I see many these days & 1.53 \\
\hline 10 & Bees are no longer coming on my crops (beans) these days and I do not know why & 0.76 \\
\hline 11 & $\begin{array}{l}\text { Bees are reducing because many beehives/wild nests have been destroyed 5-10 years ago with crop production } \\
\text { intensification due to too many children we are producing these days }\end{array}$ & 0.76 \\
\hline 12 & Bees are reducing because the flower farms do not want bees, any insect around their flower farm is killed & 0.76 \\
\hline 13 & $\begin{array}{l}\text { Bees are reducing because the crop varieties we grow these days are noninteresting foods for bees anymore. No } \\
\text { good scents of flowers to attract bees }\end{array}$ & 0.76 \\
\hline 14 & $\begin{array}{l}\text { Bees are reducing because may be these days we are growing crops that produce noninteresting/attractive } \\
\text { flowers to bees }\end{array}$ & 0.76 \\
\hline 15 & $\begin{array}{l}\text { Bees are reducing because we have destroyed underground nests of wild bees and we are cutting trees to make } \\
\text { charcoal }\end{array}$ & 0.76 \\
\hline 16 & $\begin{array}{l}\text { Bees have been reducing in the village over the last 5-10 years, but do not know why May be you can tell me } \\
\text { more about it because you stay with people who know things than us }\end{array}$ & 0.76 \\
\hline 17 & Bees have been decreasing because no abundant hives in the village these days & 0.76 \\
\hline 18 & $\begin{array}{l}\text { Bees have drastically reduced; they are few these days because farmers are cuttingoff all flowering herbs/weeds } \\
\text { near fields (bad farming practices) }\end{array}$ & 3.05 \\
\hline 19 & $\begin{array}{l}\text { Bees have reduced because many of them are dying in the village after smelling the toxic fumes of the flower } \\
\text { farm }\end{array}$ & 3.05 \\
\hline 20 & $\begin{array}{l}\text { Bees have reduced because the flower farm has killed them with their toxic sprays from the flower farm in the } \\
\text { surroundings }\end{array}$ & 0.76 \\
\hline 21 & Bees have reduced because the flower farm sprayed everywhere at night and their fumes chased away all bees & 0.76 \\
\hline 22 & Bees have reduced ever since the flower farm came around here, no more bees come to my crop flowers & 1.53 \\
\hline 23 & $\begin{array}{l}\text { Bees number have drastically reduced (e.g., could count around } 100 \text { bees } / \mathbf{m}^{2} \text { in the bean field, these days I } \\
\text { count less than } 10 / \mathbf{m}^{2} \text { ) }\end{array}$ & 3.05 \\
\hline 24 & $\begin{array}{l}\text { Bees reduced because no abundant bees coming to the village these days compared to a previous time when I } \\
\text { was young }\end{array}$ & 0.76 \\
\hline 25 & Bees used to be many in the village (5-20 years ago), these days, they have reduced I do not know why & 0.76 \\
\hline 26 & $\begin{array}{l}\text { Changes (reductions) came with human population increasing (pressure), destroying nesting sites (habitats) of } \\
\text { bees to grow crops }\end{array}$ & 0.76 \\
\hline 27 & $\begin{array}{l}\text { Drastic reduction in bees occurred because people have cleared all bushes and forests for livestock/crop } \\
\text { productions intensification }\end{array}$ & 3.05 \\
\hline 28 & I am not sure if bees have reduced/increased in the village, I have no interest in bees & 2.29 \\
\hline 29 & I am not sure, I have never paid attention (no curiosity) to observe change in bee populations & 1.53 \\
\hline 30 & I cannot explain (do not know) why bee populations are reducing in the village these days & 0.76 \\
\hline 31 & I do not know, I think bees will be every where because there are tasty/fresh flowers in the village & 0.76 \\
\hline
\end{tabular}


TABLE 12: Continued.

\begin{tabular}{|c|c|c|}
\hline $\begin{array}{l}\text { Statmenet } \\
\text { no. }\end{array}$ & $\begin{array}{l}\text { Question: Have you observed any changes in bee populations (abundances) in the village over the last } 5 \text { to } 20 \\
\text { years? It is because of what? }\end{array}$ & Freq. (\%) \\
\hline 32 & $\begin{array}{l}\text { I have observed no changes in bee populations in the village since my childhood up to now, it is the same thing I } \\
\text { see }\end{array}$ & 3.82 \\
\hline 33 & I have never paid attention (no curiosity) to observe changes in bee populations & 4.58 \\
\hline 34 & $\begin{array}{l}\text { I have no idea if bees have reduced (declined) or not; I will start making my observations from today in many } \\
\text { gardens }\end{array}$ & 6.87 \\
\hline 35 & I have observed no changes in bee numbers these days; in fact, there are many coming to visit flowers as usual & 6.11 \\
\hline 36 & $\begin{array}{l}\text { I see no change in bees numbers in the village because we have even received beehives from NAADS; numbers } \\
\text { are increasing these days }\end{array}$ & 0.76 \\
\hline 37 & $\begin{array}{l}\text { I used to see 2-3 colonies moving (flying around/month) in the village, these days I see one colony flying-out } \\
\text { around our villages once a year }\end{array}$ & 0.76 \\
\hline 38 & $\begin{array}{l}\text { I used to see bees hovering cups, saucepans left outside, these days, no bees come to visit my cups left outside, } \\
\text { only flies and ants }\end{array}$ & 0.76 \\
\hline 39 & $\begin{array}{l}\text { I used to see many bees flying around/feeding on flowers in my fields; but since the flower farm came, I see few } \\
\text { or no bees at all }\end{array}$ & 1.53 \\
\hline
\end{tabular}

Chi-square test for differences in explanations about causes of changes in bee numbers: $\chi^{2}=72.07, N=87, \mathrm{DF}=39, P=0.001$.

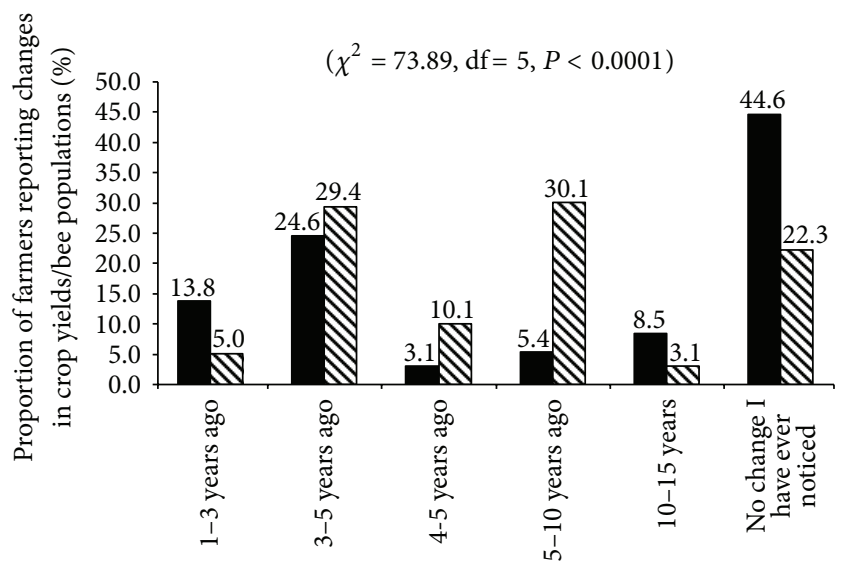

Number of year-intervals since changes (decrease) started occurring in the village

- Farmers reporting occurrence of change in crop yields (\%)

$\mathbf{v}$ Farmers reporting occurrence of change in bee populations $(\%)$

FIGURE 8: Perception of time since change (decrease in crop yields and bee populations) started occurring in the village.

perceived that leaders of flower companies should organize regular meetings with the surrounding communities (5.2\%). Some farmers requested that these flower companies should be requested to go away (14\%). Another small group of farmers said that flower companies should be allowed to continue their business (14\%). The difference in opinions among the respondent groups was significant $\left(\chi^{2} 5 \mathrm{df}=118.9\right.$, $P<0.001$; Table 18).

Overall, with regard to sustainable development of the flower industry in Uganda, farmers who were living within less than $1 \mathrm{~km}$ of the flower farm's boundaries indicated that they had a problem with the existence and operations of cutflower forms in their village. Various reasons were provided

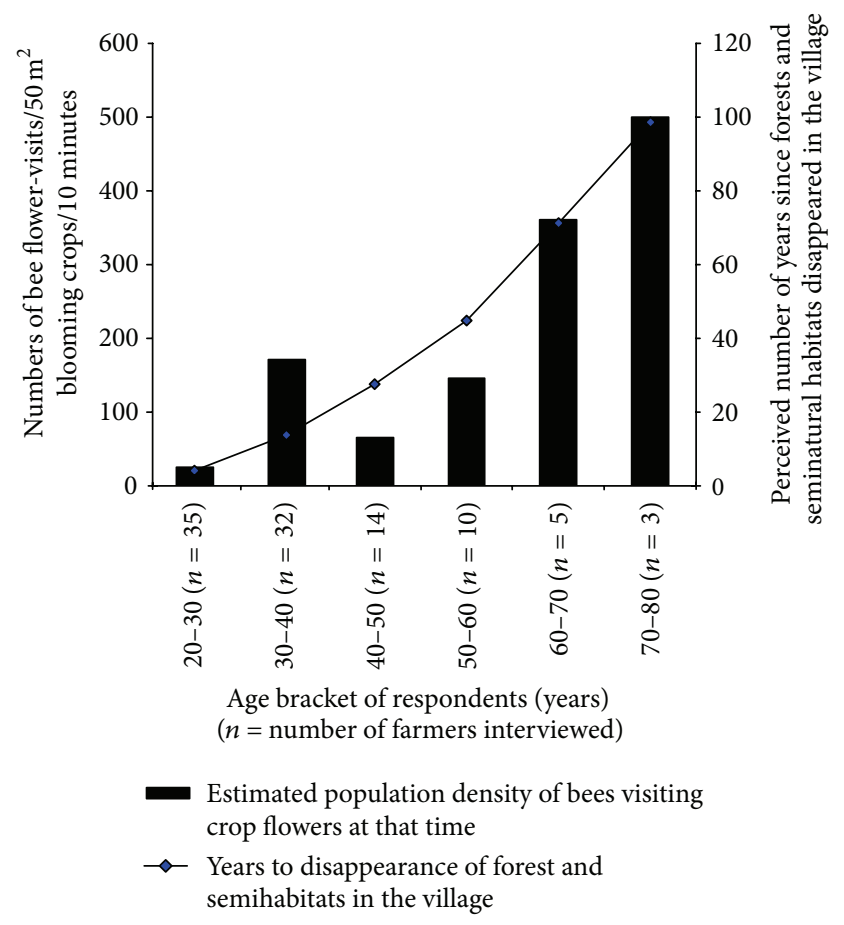

FIGURE 9: Farmers' perception/estimation of periods of disappearance of bee population visiting crop flowers in relationship to periods since disappearance of natural habitats (forests)/seminatural habitats in the village due to various drivers (grazing, fires, crop cultivation intensity, and demographic pressures).

for this dissatisfaction. More specifically, the following reasons were given among others: (i) rotting of fruits before fruit maturity from most cultivated fruit tree species such as avocado, mango, pawpaw, and jackfruit; (ii) for farmers practicing animal rearing, farmers accused the flower farms of being responsible for abortion when cattles drank from a water stream near the flower farms and yet was declared free of effluents; (iii) low yield of fish from fish ponds established 
TABLE 13: Farmers' perceptions of the changes in crop yield that have occurred in the last 5 to 20 years.

\begin{tabular}{|c|c|c|}
\hline $\begin{array}{l}\text { Statement } \\
\text { no. }\end{array}$ & $\begin{array}{l}\text { Question: Have you observed any changes (reduction, increase) in crop yields in the village over the last } 5 \text { to } 20 \\
\text { years? }\end{array}$ & $\begin{array}{c}\text { Freq. } \\
(\%)\end{array}$ \\
\hline 1 & Yield of crop is also reducing in the last $10-20$ years, we think it is because soil is old/infertile in our area & 5.38 \\
\hline 2 & However, changes in yield may be due to infertility of the lands and to flowers fumes & 0.77 \\
\hline 3 & I have not yet observed changes (reduction/increase) in my yields of my crops & 8.46 \\
\hline 4 & I have observed changes (reduction) in yields for the last 5-10 years & 5.38 \\
\hline 5 & I have seen these days some change (reduction) in yields of many crops although I donot know the exact causes & 8.46 \\
\hline 6 & No change, for me, yield is increasing because I live far from the flower farm and I manage well my gardens & 1.54 \\
\hline 7 & No changes (reduction), instead I see an increase because I do fertilization with cow dung to increase my yield & 0.77 \\
\hline 8 & No changes (reduction) in yields apart from thieves & 2.31 \\
\hline 9 & Not sure (I cannot tell) & 20.10 \\
\hline 10 & There have been a change (reduction) and this may be linked to practice of bad farming methods & 1.54 \\
\hline 11 & There have been changes in yield of many crop species for unknown changes in the global system & 0.77 \\
\hline 12 & $\begin{array}{l}\text { There has been drastic changes (reduction of } 50 \text { to } 80 \% \text { compared to previous harvests) in most of the crop yields I } \\
\text { grow }\end{array}$ & 3.08 \\
\hline 13 & There is a general decrease in yield of all crops we grow but I think it may be due to soil/land infertility & 0.77 \\
\hline 14 & There is a change (reduction) and bad yields are due to soil infertility, excess sunshine/rains, and climate change & 4.62 \\
\hline 15 & There is a change (reduction) in crop yields but do not know what it is due to exactly & 3.08 \\
\hline 16 & There is a change (reduction) in yields over time but we can't explain clearly the changes are due to what exactly & 0.77 \\
\hline 17 & $\begin{array}{l}\text { There is change in yields probably due to soil infertility because I have over-used the land to grow different crops } \\
\text { over the years }\end{array}$ & 1.54 \\
\hline 18 & There is areduction in yield due to over-use of soils, growing crops/bad varieties in a wrong season & 3.85 \\
\hline 19 & $\begin{array}{l}\text { There are changes (reduction) in yields probably due to soil infertility of my gardens and to fumes from flower } \\
\text { farms }\end{array}$ & 0.77 \\
\hline 20 & There is yield reduction because bees are disappearing in the village due to chemical sprays from the flower farm & 6.15 \\
\hline 21 & There has been very little change (decrease)/to not much changes in yield of my crops & 14.62 \\
\hline 22 & Yield of crops has reduced in the village over the last $5-10$ years but I do not know why & 5.38 \\
\hline
\end{tabular}

Chi-square test for difference in arguments (statements) frequency: $\chi^{2}=110.15, N=100, \mathrm{DF}=21, P<0.0001$.

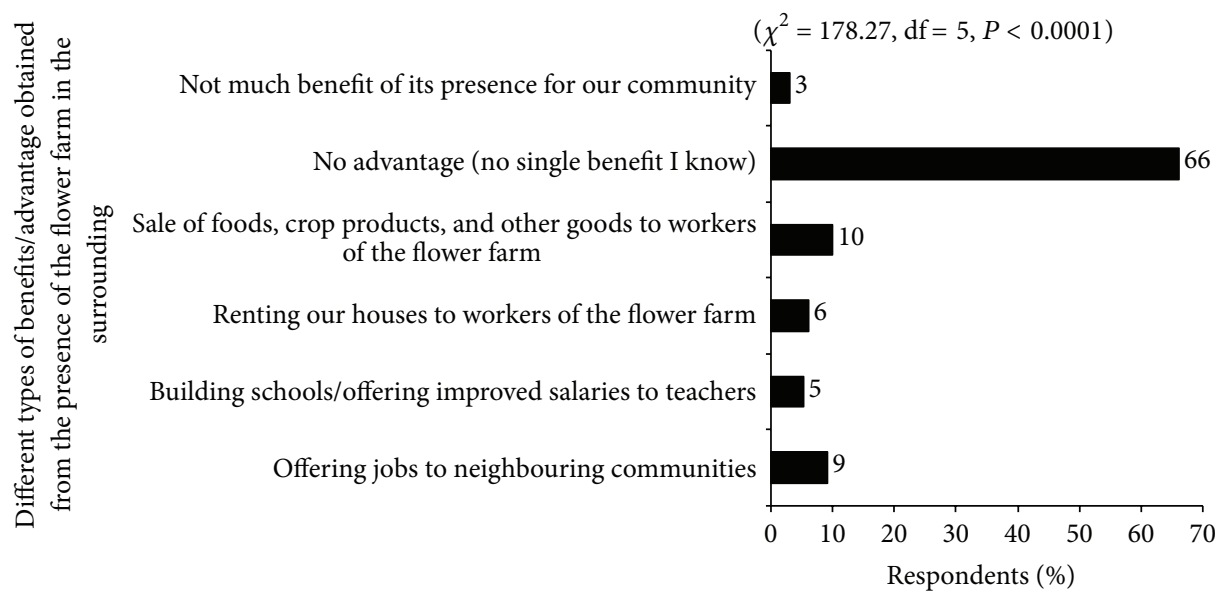

FIGURE 10: Perception of farmers about the benefits (advantages) they get from the presence of the flower farm in their village.

in the village and those around Lake Victoria resulted in fish dying and found floating on the lake in areas surrounding the flower farms (no evidence was gathered by the researchers on this); and (iv) low honey yield due to death of bees and they attributed this to agrochemicals used by the flower farms.
Farmers said they see no added advantage/benefit of the flower farm being in their locality, whereas some said that flower farms were offering jobs, building schools for their children, and improving road infrastructure (Figure 8). Farmers requested that the government should relocate 
TABLE 14: Views/beliefs of farmers' about crop yield reduction being linked or not to decline in bee-visitations to crop flowers in villages.

\begin{tabular}{|c|c|c|}
\hline St. no & $\begin{array}{l}\text { Question: Do you think (agree/disagree) that changes (reductions) in crop yields are associated with changes } \\
\text { (decline/loss) in bee-visitations? Why not? }\end{array}$ & Freq. $(\%)$ \\
\hline 1 & $\begin{array}{l}\text { I am not sure and do not know, someone should explain to me why there is too much yield reduction these days in } \\
\text { our village }\end{array}$ & 2.3 \\
\hline 2 & I am not sure (I have no idea at all and cannot even speculate or guess) & 8.5 \\
\hline 3 & Because most of our grown crops need bees, if bees are few in the village, then low yield obviously is due to that & 14.6 \\
\hline 4 & $\begin{array}{l}\text { Change (reduction) in crop yields over time is due to the fact that FIDUGA dumped toxic chemicals around our } \\
\text { villages }\end{array}$ & 1.5 \\
\hline 5 & Change (reduction) in yields can only be related to thieves of my harvests & 3.8 \\
\hline 6 & Changes in yield may be due to land infertility/degradation and fumes from the flower farms & 0.8 \\
\hline 7 & $\begin{array}{l}\text { Changes in yields are due to lack (reduction) in bee population in the village because all crops I grow need bees to } \\
\text { fertilize them }\end{array}$ & 1.5 \\
\hline 8 & $\begin{array}{l}\text { Changes in yields are due to lack (reduction) in bee population in the village because all crops I grow need bees to } \\
\text { fertilize them }\end{array}$ & 0.8 \\
\hline 9 & $\begin{array}{l}\text { Currently observed yield loss (reduction) in many crops is due to pests/diseases emergence but not at all to decline in } \\
\text { bees }\end{array}$ & 1.5 \\
\hline 10 & I am not sure if change in yield can be associated with decline in bees, I need someone to explain to me how & 8.5 \\
\hline 11 & I can't relate yield reduction to loss of bees because in the village, their habitats (nests) are still many & 3.1 \\
\hline 12 & $\begin{array}{l}\text { I do not think low yield is linked to reduction because theses days yield reduction is generalized in all crops even in } \\
\text { those } \\
\text { that don't need pollinators to yield better }\end{array}$ & 5.4 \\
\hline 13 & I don't agree/believe that low yield is due to lack (low) of numbers of bees in the village & 2.3 \\
\hline 14 & I don't think the changes (reductions) in yield are due to few bees currently seen in the villages & 0.8 \\
\hline 15 & I have no idea if they have changed or not & 11.5 \\
\hline 16 & $\begin{array}{l}\text { No, I think yield reduction is due to drought and climate change, but not to low bee-visitations or lack of bees in the } \\
\text { village }\end{array}$ & 1.5 \\
\hline 17 & Not sure (I donot believe low yield is due to absence or low bee-visitations to my crops) & 4.6 \\
\hline 18 & Reduction in coffee/beans yields may be due to climate change and to diseases/pests emergency & 3.1 \\
\hline 19 & $\begin{array}{l}\text { The change (reduction) in yield is due to change in rainfall pattern prevalence infertile soils, but not due to bees } \\
\text { reduction in the village }\end{array}$ & 3.1 \\
\hline 20 & $\begin{array}{l}\text { The change (reduction) in yields is only associated with low rainfall, these days, we receive little rainfall that can help } \\
\text { get good harvests }\end{array}$ & 3.8 \\
\hline 21 & $\begin{array}{l}\text { The change (reduction) in yield is due to chemical sprays of the flower farm that have killed bees and then we get little } \\
\text { yield }\end{array}$ & 5.4 \\
\hline 22 & There have been changes in yields of many crops but I don't believe low yields is due to lack of bees & 2.3 \\
\hline 23 & There is little harvest these days because there is not much rainfall coming these days & 1.5 \\
\hline 24 & $\begin{array}{l}\text { Yield reduction is due to interacting factors (including chemical, poor farming methods) leading to reduced } \\
\text { bee-visitations to flowers of our crops }\end{array}$ & 6.2 \\
\hline 25 & $\begin{array}{l}\text { Yield reduction is due to the fact that NARO (agricultural research institute) has released crop varieties that are very } \\
\text { susceptible or contain pests/disease germs in the village }\end{array}$ & 1.5 \\
\hline
\end{tabular}

Chi-square test for difference in statement frequency: $\chi^{2}=74.2604, N=100, \mathrm{DF}=24, P<0.0001$.

flower farms in areas that are not close to villages or to crop production and animal rearing. They alternatively suggested that flower farms should be encouraged to use nontoxic agrochemicals (if they exist on the market) if they have to stay for a longer period in their village (Figure 9).

When interviewing the four agronomic managers of the flower farms about pollination, most of them were aware of the word pollination and affirmed that they did not need pollinators to produce flowers inside their greenhouses. They also confirmed that as opposed to farmers' accusations they do not experience any problem of runoff of water or of waste chemicals into the environment. These agronomic managers suggested controlling well their wastes by setting some mechanisms such as pumping back the water and recycling/reusing the water from the flower farm. They also suggested not to dump wastes at night in villages (as claimed by farmers). However, field observations showed that infrastructures to control runoff in the environment were old and poorly constructed/managed. During field visits, it was easy to see waste running into water crossing neighboring villages. In other words, agronomic managers were at a defensive front but actually the complaints of farmers may be correct. In addition, while sampling bees, several dumping points of agrochemical wastes were observed in the landscape (grasslands 
TABLE 15: Perception of the place (area) where to get better yield between the near and the far areas to the flower farm.

Statement Question: Who can get higher yields between the one growing close to the flower farm compared to the one

No. growing crops far away $(>2 \mathrm{~km}$ ) and why? (all growing/environmental conditions are standards and similar)

I am not sure if the distance has an effect on yield but difference in yields can be due to varieties, age of plants, and fertility conditions

I know, I will get higher yield at $>2 \mathrm{Km}$ far from the flower than growing near it, but I still cannot explain why

No difference in yield and if there exist differences, it depends on good care and management of crops and fields

The same yield everywhere (I see no reason for difference in yields), there should be no difference in yields

Definitively, mangos/avocado will yield more in the village because bees have been killed near the flower farm

Even when the level of fertility of the soil is the same, yield will still differ (being high in the village) but I do not know why?

Growing crops near flower farm, no yield because no bees; but in the village there are some bees, flies, and wasps to pollinate my crops

Higher yields are in the village because we pose no harm to bees in the village but the flower spray alot to chase them away

Higher yields are in the village because soils are fertile there and people care more for their crops up there

I am not sure if someone who grows coffee faraway from the flower farm will harvest more than me

I can harvest more in the village than near the flower farms, I am sure

I think it should be the same yield if all variables and growing conditions (rainfall, management, bee-visits, soil, and fertility levels) remain the same over time

I think the one who grows far away will get higher yield even if I donot why

No difference in yields, but if it exists, it can only be due to bad weather, infertility of soils, management techniques, and planting bad varieties

The yields will be different since we have different levels of weed management system/soil fertility/bee-visitations and thus bee-visitations will be different and consequently yield different

Higher yields are in the village due to different levels of fertility, management, and bee-abundances compared to flower farm edge where bees are continuously killed

There will be higher yields in the village because there are many bees to enable getting better yields than near the flower farm

Yields near the flower farm cannot be similar to that in the village $(>2 \mathrm{~km})$ because growing conditions are not the same

Yields will be higher in the village because of high fertility levels in the village

Yields will be higher in the village probably due to difference in environmental conditions and not due to difference in bees 
TABLE 16: Farmers' perception of key drivers (factors) of the ongoing decline (loss/erosion) in wild and managed pollinators in villages in relationship to multiple drivers and pressures that act simultaneously/synergistically on pollinator communities in villages (farmers' rating of key drivers of bee diversity in their village). Among various interacting drivers (types of disturbances) of wild bee abundance and species richness, the most important factors likely being responsible for ongoing decline (loss/erosion) in wild and managed pollinators in the villages are ranked by order of importance.

\begin{tabular}{|c|c|c|c|c|c|c|c|c|}
\hline \multirow{2}{*}{$\begin{array}{l}\text { Type of drivers/pressures/disturbances of } \\
\text { pollinators }\end{array}$} & \multirow{2}{*}{$\begin{array}{c}\text { Wagagai } \\
\text { Mean } \pm \text { SE }\end{array}$} & \multirow{2}{*}{$\begin{array}{c}\text { Mairye } \\
\text { Mean } \pm \text { SE }\end{array}$} & \multirow{2}{*}{$\begin{array}{c}\text { Fiduga } \\
\text { Mean } \pm \text { SE }\end{array}$} & \multirow{2}{*}{$\begin{array}{c}\text { Pearl } \\
\text { Mean } \pm \text { SE }\end{array}$} & \multirow{2}{*}{$\begin{array}{l}\text { Overall mean } \\
\text { Mean } \pm \text { SE }\end{array}$} & \multicolumn{3}{|c|}{ Kruskal-Wallis test } \\
\hline & & & & & & DF & $\begin{array}{c}H \\
(\operatorname{adj})\end{array}$ & $P$ \\
\hline General land-use changes/shifts pat & $4.91 \pm 0.05$ & & & & & 3 & 81.71 & $<0.0001$ \\
\hline $\begin{array}{l}\text { Fragmentation of natural habitats } \\
\text { (forests, wetlands) }\end{array}$ & $2.93 \pm 0.03$ & $1.38 \pm 0.03$ & $1.29 \pm 0.05$ & $1.99 \pm 0.43$ & $1.90 \pm 0.13$ & 3 & 88.78 & $<0.0001$ \\
\hline $\begin{array}{l}\text { Loss/degradation of semi-natural habitats } \\
\text { (hedges, grasslands) }\end{array}$ & $4.24 \pm 0.05$ & $4.12 \pm 0.19$ & $2.97 \pm 0.07$ & $3.08 \pm 0.06$ & $3.60 \pm 0.09$ & 3 & 79.51 & $<0.0001$ \\
\hline Forest/bushes clear-cutting in the village & $1.03 \pm 0.01$ & $1.98 \pm 0.03$ & $0.99 \pm 0.03$ & $1.05 \pm 0.01$ & $1.26 \pm 0.02$ & 3 & 62.44 & $<0.0001$ \\
\hline $\begin{array}{l}\text { Logging, charcoal burning, } \\
\text { timber/poles/firewood collection }\end{array}$ & $1.07 \pm 0.02$ & $1.08 \pm 0.01$ & $0.95 \pm 0.03$ & $1.93 \pm 0.03$ & $1.26 \pm 0.02$ & 3 & 65.13 & $<0.0001$ \\
\hline $\begin{array}{l}\text { Forest habitats conversion into grazing } \\
\text { fields/crop fields }\end{array}$ & $3.35 \pm 0.06$ & $.12 \pm 0.02$ & $3.5 \pm 0.10$ & $5.09 \pm 0.01$ & & 3 & 88.82 & $<0.0001$ \\
\hline $\begin{array}{l}\text { Over-harvesting of specific resources in } \\
\text { the forests }\end{array}$ & $4.26 \pm 0.09$ & $1.07 \pm 0.01$ & $4.76 \pm 0.13$ & & & 3 & 76.48 & $<0.0001$ \\
\hline $\begin{array}{l}\text { Agriculture modernization plan by the } \\
\text { government }\end{array}$ & & $4.98 \pm 0.03$ & $5.31 \pm 0.04$ & $5.13 \pm 0.08$ & & 3 & 7 & 0.001 \\
\hline $\begin{array}{l}\text { Cultivation } \\
\text { intensificat }\end{array}$ & $4.50 \pm 0.07$ & $.22 \pm 0.06$ & $4.08 \pm 0.01$ & $4.27 \pm 0.06$ & $4.52 \pm 0.05$ & 3 & 3.92 & 0.0001 \\
\hline $\begin{array}{l}\text { ive trees } \\
\text { tion in villages }\end{array}$ & $3.24 \pm 0.04$ & $.31 \pm 0.04$ & $1.11 \pm 0.01$ & $2.10 \pm 0.01$ & $.44 \pm 0.03$ & 3 & 8.92 & 0.0001 \\
\hline $\begin{array}{l}\text { Intensification of farn } \\
\text { practices }\end{array}$ & $5.33 \pm 0.05$ & $5.49 \pm 0.07$ & $5.28 \pm 0.04$ & $4.17 \pm 0.06$ & $5.06 \pm 0.05$ & 3 & 89.07 & $<0.0001$ \\
\hline $\begin{array}{l}\text { Increasing application of pesticides/other } \\
\text { agrochemicals }\end{array}$ & $3.12 \pm 0.06$ & $1.25 \pm 0.04$ & $4.12 \pm 0.02$ & $3.21 \pm 0.05$ & $2.92 \pm 0.04$ & 3 & 74.56 & $<0.0001$ \\
\hline ensification & $5.38 \pm 0.06$ & $3.35 \pm 0.05$ & $5.22 \pm 0.04$ & $4.96 \pm 0.04$ & $4.73 \pm 0.05$ & 3 & 73.38 & $<0.0001$ \\
\hline Fires & & & & & & 3 & & $<0.0001$ \\
\hline $\begin{array}{l}\text { General environ } \\
\text { pollution/degrac }\end{array}$ & $5.25 \pm 0.03$ & $.24 \pm 0.04$ & $4.32 \pm 0.04$ & $5.22 \pm 0.04$ & $5.01 \pm 0.04$ & 3 & 1.61 & $<0.0001$ \\
\hline $\begin{array}{l}\text { Decreased/degradation of floral/nesting } \\
\text { resources diversity }\end{array}$ & $4.01 \pm 0.02$ & $34 \pm 0.05$ & $3.08 \pm 0.01$ & $3.34 \pm 0.05$ & $2.98 \pm 0.03$ & 3 & 1.04 & 0.0001 \\
\hline $\begin{array}{l}\text { Alien invasive species spread in the } \\
\text { village }\end{array}$ & $4.92 \pm 0.03$ & $.17 \pm 0.06$ & $4.24 \pm 0.05$ & $5.08 \pm 0.02$ & $1.85 \pm 0.04$ & 3 & 4.23 & $<0.0001$ \\
\hline $\begin{array}{l}\text { Cultivation of exotic high yielding } \\
\text { varieties/genotypes }\end{array}$ & $3.02 \pm 0.04$ & $1.24 \pm 0.03$ & $3.54 \pm 0.09$ & $5.20 \pm 0.04$ & $3.25 \pm 0.04$ & 3 & 90.85 & $<0.0001$ \\
\hline Bee diseases/parasites and predation & $4.92 \pm 0.02$ & $1.39 \pm 0.06$ & $4.09 \pm 0.08$ & $5.56 \pm 0.08$ & & 3 & 94.22 & $<0.0001$ \\
\hline Increasing urbanization of rural towns & $4.12 \pm 0.04$ & $4.06 \pm 0.03$ & $3.94 \pm 0.06$ & $5.38 \pm 0.06$ & & 3 & 83.85 & $<0.0001$ \\
\hline Road construction & $5.19 \pm 0.04$ & $5.08 \pm 0.03$ & $5.15 \pm$ & & & 3 & 6.89 & 0.075 \\
\hline $\begin{array}{l}\text { Demographic pressures (human } \\
\text { population increase, refugees migration) }\end{array}$ & $4.45 \pm 0.05$ & $4.10 \pm 0.01$ & $4.16 \pm 0.10$ & $4.31 \pm 0.04$ & $4.26 \pm 0.05$ & 3 & 14.67 & 0.02 \\
\hline $\begin{array}{l}\text { Natural calamities (landslide, river } \\
\text { floods) }\end{array}$ & $4.91 \pm 0.05$ & $1.93 \pm 0.03$ & $4.12 \pm 0.09$ & $4.06 \pm 0.08$ & $3.75 \pm 0.06$ & 3 & 76.73 & $<0.0001$ \\
\hline $\begin{array}{l}\text { Research and tourism (wildlife visits) } \\
\text { intensification }\end{array}$ & 5.1 & 0.30 & $5.15 \pm 0.06$ & $4.48 \pm 0.09$ & 0.00100 & 3 & 67.15 & 0.0001 \\
\hline $\begin{array}{l}\text { Local climate change (rainfall pattern } \\
\text { changes) }\end{array}$ & $2.18 \pm 0.03$ & $1.08 \pm 0.02$ & $2.14 \pm 0.06$ & $1.96 \pm 0.02$ & $1.84 \pm 0.03$ & 3 & 60.58 & $<0.0001$ \\
\hline Regional and global climate changes & $5.21 \pm 0.04$ & $4.99 \pm 0.04$ & $3.75 \pm 0.07$ & $4.34 \pm 0.10$ & $4.58 \pm 0.06$ & 3 & 77.20 & $<0.0001$ \\
\hline
\end{tabular}

Ranks: 1: very important (or primary causal) agent; 2: important causal agent; 3: associate (secondary) important causal agent, 4: playing tertiary role; 5: play very little or no role in the decline process; 6 : has nothing to do with bee decline (not sure this can affect bees). 
TABLE 17: Perceived problems of having a flower farm in the village.

\begin{tabular}{|c|c|c|}
\hline $\begin{array}{l}\text { Statement } \\
\text { no. }\end{array}$ & Question: Do you have any problem with the presence of the flower farm in the village? & $\begin{array}{c}\text { Frequency (\%) } \\
\text { of } \\
\text { reasons/statements }\end{array}$ \\
\hline 1 & $\begin{array}{l}\text { I doubt if a single animal/insect will survive where that chemically-enriched waste soil has been dumped } \\
\text { by flower farm }\end{array}$ & 2.31 \\
\hline 2 & My animals have been seek ever since the farm came around & 0.77 \\
\hline 3 & $\begin{array}{l}\text { Papaw/avocado/pumpkin/mango flowers are aborting; even the few that formed fruits started rotting on } \\
\text { the tree before the fruit is mature }\end{array}$ & 1.55 \\
\hline 4 & $\begin{array}{l}\text { People working for a long time ( } 2-5 \text { years) get contaminated by chemicals and eventually died when they } \\
\text { came out from work }\end{array}$ & 1.55 \\
\hline 5 & $\begin{array}{l}\text { Ever since this flower farm come around, we are experiencing yield loss and abnormal (reduction) crop } \\
\text { production }\end{array}$ & 1.54 \\
\hline 6 & $\begin{array}{l}\text { A flower farm should never be placed near people because the chemical sprays travel towards our village } \\
(>3 \mathrm{Km}) \text { up to inside our homestead and children get respiratory diseases }\end{array}$ & 0.77 \\
\hline 7 & All our crops these days seek and can't breathe properly because of chemicals they apply there & 0.77 \\
\hline 8 & $\begin{array}{l}\text { Avocado, mango, papaw, and pumpkin are ripening/falling down earlier and are not tasty, ever since the } \\
\text { flower farm came around }\end{array}$ & 0.77 \\
\hline 9 & $\begin{array}{l}\text { Avocado/mangos don't look good anymore since the establishment of the flower farm, may be because of } \\
\text { the pesticides they spray which are poisons }\end{array}$ & 1.54 \\
\hline 10 & Bees are moving away from the flower farm to our villages these days, crops near flower farms suffer & 0.77 \\
\hline 11 & Cassava is stunt; other fruits are rotting these days due to chemicals; it used not be like that & 0.77 \\
\hline 12 & Chemical dumped/deposited, at flower farm edge, during night hours, has a strong smell for $>6$ months & 0.77 \\
\hline 13 & $\begin{array}{l}\text { Chemical of the flower farm is dangerous to humans/livestock/wildlife because can't guarantee keeping } \\
\text { polluted water there everyday }\end{array}$ & 0.77 \\
\hline 14 & Chemical sprays from the flower farm smell alot in our village and they kill flowers of our crops & 0.77 \\
\hline 15 & Chemicals sprayed daily from the flower farm have reduced the bee population in our village & 1.54 \\
\hline 16 & $\begin{array}{l}\text { Chemicals sprayed leave the flower farm and move in the air and we smell them too much; my kids fall } \\
\text { sick regularly }\end{array}$ & 0.77 \\
\hline 17 & Emerging pests and diseases in many crops may be due to fume from the flower farm & 0.77 \\
\hline 18 & $\begin{array}{l}\text { Every time the river/swamp water-enriched with water from the flower farm crosses my gardens, I } \\
\text { harvestno fruits (egg plants/tomato) }\end{array}$ & 3.80 \\
\hline 19 & $\begin{array}{l}\text { Few crops are not very affected by these chemicals, but for most crops their yields are reducing } \\
\text { dramatically }\end{array}$ & 0.77 \\
\hline 20 & Flower farm dump regularly chemical wastes into the rivers around our villages and this kills fish & 1.54 \\
\hline 21 & $\begin{array}{l}\text { Crop flowers are quickly aborting and few formed fruits (mangos, avocado, papaw) do not taste well } \\
\text { anymore }\end{array}$ & 0.77 \\
\hline 22 & $\begin{array}{l}\text { From most crops, few flowers are turning into fruits/seeds these days ever since the flower farm was } \\
\text { established around }\end{array}$ & 0.77 \\
\hline 23 & $\begin{array}{l}\text { Fruit rotting problem started some } 3 \text { to } 5 \text { years ago; these days, no more good fruits; most of them are } \\
\text { rotting }\end{array}$ & 0.77 \\
\hline 24 & $\begin{array}{l}\text { Fumes sprayed in the flower farm kill bees and other animals in the nature around because they smell } \\
\text { strongly }\end{array}$ & 0.77 \\
\hline 25 & I am convinced that bees disappearing in the village is due to toxic pesticides applied in the flower farm & 3.08 \\
\hline 26 & I am not affected in my farming business by any activities around the flower farm & 0.77 \\
\hline 27 & $\begin{array}{l}\text { I am now abandoning growing fruit tree crops because they will not give good fruits or if a fruit comes, it } \\
\text { is of low quality }\end{array}$ & 0.77 \\
\hline 28 & $\begin{array}{l}\text { I believe that the flower farm chemicals must have contributed to reduced yields and to poor yield } \\
\text { performance of crops }\end{array}$ & 0.77 \\
\hline 29 & I do not think chemicals sprayed in the flower farm are dangerous to our crops or to bees & 0.77 \\
\hline 30 & I have no problem with the flower farm, either they are there or not I benefit or lose nothing & 5.38 \\
\hline 31 & I have no problem, either they are there or not, it does not matter to me & 0.77 \\
\hline 32 & I regularly see dead fish on the edge of the river that cross the flower farm into our village & 3.08 \\
\hline 33 & I regularly see vehicles moving at night from the flower farm dumping smelly chemicals near our village & 2.31 \\
\hline
\end{tabular}


TABLE 17: Continued.

\begin{tabular}{|c|c|c|}
\hline $\begin{array}{l}\text { Statement } \\
\text { no. }\end{array}$ & Question: Do you have any problem with the presence of the flower farm in the village? & $\begin{array}{c}\text { Frequency (\%) } \\
\text { of } \\
\text { reasons/statements }\end{array}$ \\
\hline 34 & $\begin{array}{l}\text { I see no problem may be because I am a migrant worker, but one from this village has always complained } \\
\text { about bees declining (disappearance) }\end{array}$ & 2.31 \\
\hline 35 & $\begin{array}{l}\text { I strongly believe that the fume of pesticides applied in the flower is responsible for currently observed } \\
\text { flower abortion in most fruit crops in the village }\end{array}$ & 0.77 \\
\hline 36 & $\begin{array}{l}\text { I suspect the flower farm is dangerous to people and animals because of the nature of smelling the toxic } \\
\text { chemicals they apply }\end{array}$ & 0.77 \\
\hline 37 & I used to see many snakes/soil ant colonies around the village, these days I rarely see them passing around & 0.77 \\
\hline 38 & Insect pests chased near the flower farm came in my $(>1000 \mathrm{~m})$ garden to eat/destroy my crops & 0.77 \\
\hline 39 & Many children who went to work at the flower farm got exposed to these pesticides and died & 0.77 \\
\hline 40 & Most of the mango/avocado fruits grown near the flower farm are no longer tasty or juicy & 2.31 \\
\hline 41 & Never place flower farms near people because they don't need bees but farmers need bee'-visits to crops & 0.77 \\
\hline 42 & No activity from the flower farm affects my crops; egg plants and tomato grow here in the village & 0.77 \\
\hline 43 & No one has ever complained about chemicals applied there to kill his crops & 0.77 \\
\hline 44 & $\begin{array}{l}\text { No problem because I was informed that they have constructed several dams for recycling their water and } \\
\text { for containing chemical wastes there }\end{array}$ & 0.77 \\
\hline 45 & $\begin{array}{l}\text { Papaw/avocado are no longer sweet, too many fruit diseases emerging these days; tree crops are currently } \\
\text { yielding low }\end{array}$ & 2.31 \\
\hline 46 & $\begin{array}{l}\text { People living near the flower farm breathe polluted air with dangerous chemicals, fall sick frequently, and } \\
\text { many die }\end{array}$ & 0.77 \\
\hline 47 & People working at the flower farm become tiny and die after 3-5 years of working there & 0.77 \\
\hline 48 & $\begin{array}{l}\text { People fear to use the stream water because they believe it is full off chemical wastes dumped regularly by } \\
\text { the flower farm }\end{array}$ & 3.08 \\
\hline 49 & $\begin{array}{l}\text { People living at the edge of the flower farm can smell the fumes (pesticides) scent from the flower farm } \\
\text { daily }\end{array}$ & 2.31 \\
\hline 50 & $\begin{array}{l}\text { People who grow mango/avocado/papaw near (at the edge of) the flower farm experience low yields these } \\
\text { days; they are complaining }\end{array}$ & 2.31 \\
\hline 51 & $\begin{array}{l}\text { People who work at the flower farm all get sick because of chemical breathing and many die after } 2-5 \text { years } \\
\text { working }\end{array}$ & 0.77 \\
\hline 52 & People who work in the flower farm start falling sick 3-5 years later & 1.54 \\
\hline 53 & Pesticides applied in the flower farm are decolorating (changing the colour) our crops in the village & 0.77 \\
\hline 54 & $\begin{array}{l}\text { People who work in these flower farms complain all time about their health status andlow salaries (not } \\
\text { paid in time) }\end{array}$ & 3.08 \\
\hline 55 & $\begin{array}{l}\text { Pumpkin and watermelon flowers do not turn into fruits anymore near the flower farm, but in the village } \\
(>2 \mathrm{~km}) \text { fruits are many }\end{array}$ & 0.77 \\
\hline 56 & $\begin{array}{l}\text { Since the farm was established here, we experience rotting of fruits (avocado, papaw) and it may be due to } \\
\text { chemicals }\end{array}$ & 1.54 \\
\hline 57 & $\begin{array}{l}\text { When smelling chemicals up to } 2-3 \mathrm{Km} \text { here in the village, I lose my appétite and my children fall sick all } \\
\text { the time }\end{array}$ & 0.77 \\
\hline 58 & $\begin{array}{l}\text { So far no complaint apart from the risk of our cows drinking the river water-enriched with chemical water } \\
\text { from the flower farm }\end{array}$ & 0.77 \\
\hline 59 & $\begin{array}{l}\text { The flower farm is dumping the crop residues full of chemicals in our village and they smell a lot for } 6 \\
\text { months }\end{array}$ & 0.77 \\
\hline 60 & The flower farm pollute river/wetland waters crossing our village & 1.54 \\
\hline 61 & $\begin{array}{l}\text { The flower farm pour chemically-enriched water into the river that people use as drinking water and we } \\
\text { drink that water }\end{array}$ & 0.77 \\
\hline 62 & The flower farm spray daily massive toxic chemical that flies up to $2-4 \mathrm{~km}$ in the village & 0.77 \\
\hline 63 & $\begin{array}{l}\text { The fumes from the flower farm smell badly everyday their are applied; and we fall seek after being } \\
\text { exposed for long time }\end{array}$ & 0.77 \\
\hline 64 & $\begin{array}{l}\text { The rate of abortion of my cows is very high these days and I think it is due to drinking polluted water } \\
\text { from the flower farm }\end{array}$ & 0.77 \\
\hline 65 & $\begin{array}{l}\text { The rate of abortion of my cows is very high these days and I think it is due to drinking polluted water } \\
\text { from the flower farm }\end{array}$ & 1.54 \\
\hline
\end{tabular}


TABLE 17: Continued.

\begin{tabular}{|c|c|c|}
\hline $\begin{array}{l}\text { Statement } \\
\text { no. }\end{array}$ & Question: Do you have any problem with the presence of the flower farm in the village? & $\begin{array}{c}\text { Frequency (\%) } \\
\text { of } \\
\text { reasons/statements }\end{array}$ \\
\hline 66 & $\begin{array}{l}\text { The recycling of water around the flower farm is not properly done/controlled, there is still leakage of their } \\
\text { water into the river }\end{array}$ & 0.77 \\
\hline 67 & $\begin{array}{l}\text { The reduction in crop yields in the village may be due to the fact that bees smell pesticides from the flower } \\
\text { and die }\end{array}$ & 1.54 \\
\hline 68 & The soil from the waste dumping point can smell a lot for more than 5 months & 2.31 \\
\hline 69 & $\begin{array}{l}\text { The yield of fruits (mango/avocado/passion fruits) has reduced to } 15 \text { to } 35 \% \text { since the flower farm came } \\
\text { around }\end{array}$ & 0.77 \\
\hline 70 & $\begin{array}{l}\text { There are rumors that chemicals applied spoil our crops, but I am not sure if it is linked to } \\
\text { seasonal/climate changes }\end{array}$ & 2.31 \\
\hline 71 & There are several dumping holes of chemical wastes near our gardens & 1.54 \\
\hline 72 & There are no more bees and honey production is absent in the village ever since the flower farm is around & 0.77 \\
\hline 73 & There are several dumping points of chemically-enriched soils in our village & 1.54 \\
\hline 74 & $\begin{array}{l}\text { There was a problem of water leakage from the flower farm into the river, but they claimed to have } \\
\text { controlled it (properly closed it), it is not correct }\end{array}$ & 0.77 \\
\hline 75 & These days I see many fish dying/stunting because the water I use in my 12 fish ponds cross the flower farm & 1.54 \\
\hline 76 & These days, there is too much water in the swamp because the flower sends a lot there daily & 0.77 \\
\hline 77 & $\begin{array}{l}\text { These people claim recycling/reutilizing water } 2 \text { times only, after that water, where do they put it? Not in } \\
\text { the river? }\end{array}$ & 0.77 \\
\hline 78 & These days, there is too much crop failure due to pests/diseases/chemicals applied in the flower farm & 1.54 \\
\hline 79 & $\begin{array}{l}\text { They kill bees with chemicals in the village because they don't want any single bee to land on the flower } \\
\text { farm }\end{array}$ & 0.77 \\
\hline 80 & $\begin{array}{l}\text { Water from the flower farm is currently still leaking into the river and both human beings and cows drink } \\
\text { that water and fall sick and die. }\end{array}$ & 1.54 \\
\hline 81 & We meet several hundreds of dead bees/snakes/fish/lizard in the fields a day after they have sprayed & 0.77 \\
\hline 82 & We are all migrant and care little about effects of pesticides on crops grown here & 0.77 \\
\hline 83 & $\begin{array}{l}\text { We regularly see several thousands fish dying near the flower farm where they eject water into Lake } \\
\text { Victoria }\end{array}$ & 0.77 \\
\hline 84 & $\begin{array}{l}\text { Whenever they are at spraying the flower farm, the fumes comes into the air and reaches our houses and } \\
\text { make us fall sick; including our wives and children }\end{array}$ & 0.77 \\
\hline 85 & $\begin{array}{l}\text { Yields of my crops are reducing because I think the flower farm killed all the bees in the village that } \\
\text { pollinate my crops }\end{array}$ & 0.77 \\
\hline
\end{tabular}

Chi-square test for difference in frequency of statements: $\chi^{2}=59.98, N=100, \mathrm{DF}=84, P=0.983$.

habitats that may be used by various bee species as refugia/nesting sites or as foraging habitats). Also, several other pollinator groups (Table 19) were identified during the course of this study although it was difficult to ascertain their role in the reproduction success of plants/crops visited.

\section{Discussion}

In this study, it was hypothesized that (i) pesticide applications inside greenhouses of the different flower farms, had no negative effects on bees inhabiting/foraging in the surrounding habitats; (ii) there was no difference in bee species and visitation frequencies among different types of landscape vegetations, fields, and habitats (land-uses) found in the surrounding of the flower farms; (iii) farmers were not aware of the importance of pollination in their farming business, (iv) small-scale farmers living in the surrounding of flower farmers benefited a lot from the presence of the flower farm in their villages.

The results indicated (i) a lack of scientific evidence for direct effects of pesticides applied inside greenhouses on bee biodiversity although bee species richness and visitation intensities tended to increase with distance from the flower farm into farmlands; (ii) that bee species and visitations varied according to flower farm location, to the distance from the edge of the flower farm into farmland, to field types, landscape vegetations, and to habitat types found in the surroundings of the flower farms; (iii) that more than $60 \%$ of smallscale farmers were aware of the value and importance of pollination in their farming business and believed that causes of bee decline were pesticides applied by flower farm and natural habitat degradation (forest clear cut); and (iv) that the majority of farmers declared benefiting nothing from the presence of the flower farm in their village and requested that flower farm should be removed from their villages since it is 
TABLE 18: Opinion of farmers about sustainable solutions to solve the conflicts created by the establishment of the flower farm (farmers' sustainable and win-win solution) to the development of the flower industry in the villages of Uganda.

\begin{tabular}{|c|c|c|}
\hline $\begin{array}{l}\text { Statement } \\
\text { no. }\end{array}$ & Question: Which sustainable solution do you propose to resolve your conflicts with the flower farm? & $\begin{array}{c}\text { Frequency }(\%) \text { of } \\
\text { statements by farmers } \\
\text { interviewed }\end{array}$ \\
\hline 1 & Destroy or move away the flower farm where there are no people & 5.9 \\
\hline 2 & I do not know what should be done because they have consulted politicians to come here & 3.0 \\
\hline 3 & $\begin{array}{l}\text { I do not know what should be done, but I am worried that chemicals will continue to kill/finish } \\
\text { people in the village }\end{array}$ & 2.2 \\
\hline 4 & I want them to leave our village & 2.2 \\
\hline 5 & I want them to pay (buy) my land and I will leave the place, no other solutions & 1.5 \\
\hline 6 & I want to go away to farm and leave this land for them & 1.5 \\
\hline 7 & Isolate or remove the flower farm from our village & 5.2 \\
\hline 8 & Maintain the flower farm around because we get clean water/electricity and charge our phones there & 0.7 \\
\hline 9 & $\begin{array}{l}\text { Need regular meeting with them to tell us that chemicals applied are not dangerous to living } \\
\text { organisms }\end{array}$ & 2.2 \\
\hline 10 & $\begin{array}{l}\text { No problem, no need to disturb them in the village; they provide employment opportunity to } \\
\text { communities }\end{array}$ & 5.2 \\
\hline 11 & Sensitize people about the bad and the good things from the flower farm & 2.2 \\
\hline 12 & $\begin{array}{l}\text { Since the flower farm was established here, we are worried and we keep speculating about the } \\
\text { negative effects on our crops and health }\end{array}$ & 1.5 \\
\hline 13 & The flower farm should leave the village and go to a place where people are not & 1.5 \\
\hline 14 & They can stay there because their activities do not affect me at all & 8.1 \\
\hline 15 & $\begin{array}{l}\text { They need to show us evidence that chemicals applied are not dangerous to } \\
\text { crops/livestock/wildlife/fish }\end{array}$ & 1.5 \\
\hline 16 & They should stop application of dangerous pesticides to humans and crops & 5.9 \\
\hline 17 & They should use no toxic chemicals on bees/snakes/fish/lizard & 2.2 \\
\hline 18 & I don't know what should be done (I have no power to propose what should be done) & 47.4 \\
\hline
\end{tabular}

Chi-square test for difference in frequency of statements: $\chi^{2}=347.129, N=99.9, \mathrm{DF}=17, P<0.0001$.

The frequency is the number of times the statement was given by people interviewed; as one interviewed person could offer several statements for each question asked by the researcher.

polluting their environment as well endangering the health of people working there.

\subsection{Declining Status of Bee Diversity and Numbers in Flower} Farm Zones and in Ugandan Farmlands. Worldwide pollinators (bees) decline has been declared. However, in the African context and particularly in Uganda, there is no historical data collection to verify decline in pollinator species. It is therefore difficult to accurately say that pollinators have ever declined or not in Uganda. In the absence of historical databases, the only source of information is through asking small-scale farmers (local residents), particularly those who know pollination and pollinators and who care and believe pollination is an important production factor in their farming business. Reading from the memory of small-scale farmers, it appears that there has been some decline in bees in central Uganda, although it is difficult to say exactly at which rate bees did decline compared to current inventories or to identify the exact causes.

Although it was perceived in this study that bees have been declining around flower growing regions, there exist no or very few long-term data on bee populations; and this makes their conservation status difficult to assess in rural landscapes of Uganda. It is difficult to know which species are clearly declining given the absence of long-term monitoring data in Uganda. In addition, recent studies [19-23] indicated that bee communities from farmlands of central Uganda were characterized by a high rate of rare and unique taxa, and this indicated that the Apoidea communities from Uganda farmlands were at high risk of extinction. Obviously the current population of bees cannot be the same as to what happened some $10-50$ years ago.

\subsection{Influence of Habitat Types on Bee Richness and Abundance.} Bee communities living in the surrounding of the flower farms can show a stronger response to changes in habitat structural properties (vegetation composition) and to landscape composition [31]. Although bee community composition differed between habitats/land-uses within study sites (flower farms), only bee species richness showed a consistent difference between habitats across the studied sites (flower farms). The degree to which bee community composition differed between habitats within sites may be related to landscape variables. In fact, it was found in this study that the difference in bee species richness and abundance between habitats was strongly related to the difference in farm-land-scape vegetation types (croplands, grasslands). However, the strong influence of landscape vegetation on bee species richness and 
TABLE 19: Preliminary list of other pollinators recorded in farmland/grassland habitats surrounding the four flower farms during the course of the study.

\begin{tabular}{|c|c|c|c|c|}
\hline Order & Family & Subfamily & Species, morphospecies, and doubtful identification & Abundance $^{*}$ \\
\hline Coleoptera & Chrysomelidae & & Eurythenes sp. & 1.3 \\
\hline Coleoptera & Melolonthinae & & Peritrichia albovillosa (Schein) & 0.6 \\
\hline Coleoptera & Nitidulidae & & Meligethes variabilis (Reitter) & 2.2 \\
\hline Coleoptera & Scarabaeidae & & Rhabdotis sp.? & 2.5 \\
\hline Diptera & Agromyzida & Agromizinae & Melanagromyza sp. & 6.3 \\
\hline Diptera & Calliphoridae & Calliphorinae & Hemigymnochaete varia & 5.3 \\
\hline Diptera & Calliphoridae & Rhiniinae & Rhinia apicalis? & 3.0 \\
\hline Diptera & Calliphoridae & Chrysomyinae & Chrysomya chloropyga & 15.4 \\
\hline Diptera & Lauxaniidae & Lauxaniinae & Lauxania sp. & 10.6 \\
\hline Diptera & Muscidae & Muscinae & Musca sp. & 47.8 \\
\hline Diptera & Sarcophagidae & Sarcophaginae & Sarcophaga inaequalis & 50.9 \\
\hline Diptera & Sarcophagidae & Miltogramminae & Hoplacephala tesselata & 8.5 \\
\hline Diptera & Syrphidae & Syrphinae & Allobaccha sp. & 51.3 \\
\hline Diptera & Syrphidae & Syrphinae & Betasryphus adligatus? & 79.6 \\
\hline Diptera & Syrphidae & Syrphinae & Allograpta nasuta? & 116.7 \\
\hline Diptera & Bibionidae & & Bibio turneri (Edwards) & 16.2 \\
\hline Diptera & Bombyliidae & Bombyliinae & Bombylisoma sp. & 82.8 \\
\hline Diptera & Calliphoridae & Chrysomyinae & Chrysomya regalis (Desvoidy) & 41.1 \\
\hline Diptera & Calliphoridae & Rhiniinae & Rhyncomya cassatis (Walker) & 67.0 \\
\hline Diptera & Muscidae & Phaoniinae & Atherigona addita (Malloch) & 7.9 \\
\hline Diptera & Muscidae & Muscinae & Musca lusoria (Wiedemann) & 27.6 \\
\hline Diptera & Mycetophilidae & Mycetophilinae & Phronia sp. & 27.3 \\
\hline Diptera & Sarcophagidae & Miltogramminae & Pterella sp. & 52.7 \\
\hline Diptera & Syrphidae & & Eristalinus laetus (Wiedemann) & 38.6 \\
\hline Diptera & Syrphidae & & Phytomia natalensis (Macquat) & 76.4 \\
\hline Diptera & Syrphidae & & Senaspis haemorrhoa (Gerstacker) & 58.8 \\
\hline Diptera & Syrphidae & Milesiinae & Phytomia incisa (Wiedemann) & 118.3 \\
\hline Diptera & Syrphidae & & Metasyrphus sp. & 151.8 \\
\hline Diptera & Tachinidae & Goniinae & Aplomya sp. & 156.0 \\
\hline Diptera & Tephritidae & & Neoceratitis sp. & 86.3 \\
\hline Hymenoptera & Formicidae & Formicinae & Acantholepis sp. & 3.5 \\
\hline Hymenoptera & Formicidae & Formicinae & Anoplolepis sp. & 5.3 \\
\hline Hymenoptera & Formicidae & Formicinae & Camponotus sp. & 8.9 \\
\hline Lepidoptera & Nymphalidae & Nymphalinae & Hypolimnas misippus (Linnaeus) & 0.7 \\
\hline Lepidoptera & Nymphalidae & Nymphalinae & Junonia hierta cebrene (Trimen) & 1.0 \\
\hline Lepidoptera & Nymphalidae & & Byblia ilithyia (Drury) & 0.6 \\
\hline Lepidoptera & Nymphalidae & Nymphalinae & Vanessa cardui cardui (Linnaeus) & 0.5 \\
\hline Lepidoptera & Hesperiidae & Coeliadinae & Coeliades anchise anchise (Gerstaecker) & 0.4 \\
\hline Lepidoptera & Hesperiidae & Pyrginae & Celaenorrhinus proxima proxima (Mabille) & 0.7 \\
\hline Lepidoptera & Hesperiidae & Pyrginae & Spialia dromus (Pl“otz) & 0.4 \\
\hline Lepidoptera & Hesperridae & Hesperiinae & Acleros mackenii (Trimen) & 0.4 \\
\hline Lepidoptera & Hesperridae & Hesperiinae & Gegenes hottentota (Latreille) & 0.6 \\
\hline Lepidoptera & Lycaenidae & Polyommatinae & Anthene amarach (Guerin) & 0.9 \\
\hline Lepidoptera & Lycaenidae & Polyommatinae & Anthene butleri (Oberthur) & 0.3 \\
\hline Lepidoptera & Lycaenidae & Polyommatinae & Anthene larydas (Cramer) & 0.2 \\
\hline Lepidoptera & Lycaenidae & Polyommatinae & Anthene lunulata (Trimen) & 0.4 \\
\hline Lepidoptera & Lycaenidae & Polyommatinae & Cacyreus palemon palemon (Stoll) & 0.6 \\
\hline
\end{tabular}


TABLE 19: Continued.

\begin{tabular}{|c|c|c|c|c|}
\hline Order & Family & Subfamily & Species, morphospecies, and doubtful identification & Abundance ${ }^{*}$ \\
\hline Lepidoptera & Lycaenidae & Polyommatinae & Cupidopsis cissus (Godart) & 1.1 \\
\hline Lepidoptera & Lycaenidae & Polyommatinae & Cupidopsis jobates (Hopffer) & 3.2 \\
\hline Lepidoptera & Lycaenidae & Polyommatinae & Euchrysops osiris osiris (Hopffer) & 10.8 \\
\hline Lepidoptera & Lycaenidae & Polyommatinae & Leptotes pirithous (Linnaeus) & 2.4 \\
\hline Lepidoptera & Lycaenidae & Polyommatinae & Zizeeria knysna (Trimen) & 1.3 \\
\hline Lepidoptera & Lycaenidae & Polyommatinae & Zizula hylax (Fabricius) & 0.5 \\
\hline Lepidoptera & Lycaenidae & Polyommatinae & Zizina antanossa (Mabille) & 0.5 \\
\hline Lepidoptera & Lycaenidae & & Leptosia nupta nupta (Butler) & 0.4 \\
\hline Lepidoptera & Lycaenidae & Theclinae & Hypolycaena hatita ugandae (Sharpe) & 0.3 \\
\hline Lepidoptera & Lycaenidae & Theclinae & Iolaus poultoni (Riley) & 0.3 \\
\hline Lepidoptera & Nymphalidae & Danainae & Amarius ochlea (Boisduval) & 0.4 \\
\hline Lepidoptera & Nymphalidae & Danainae & Danaus chrysippus L. & 0.3 \\
\hline Lepidoptera & Nymphalidae & Limenitinae & Byblia anvatara acheloia (Wallengren) & 0.2 \\
\hline Lepidoptera & Nymphalidae & Limenitinae & Pseudacraea boisduvali (Doubleday) & 0.4 \\
\hline Lepidoptera & Nymphalidae & Nymphalinae & Junonia stygia gregorii (Butler) & 6.8 \\
\hline Lepidoptera & Nymphalidae & Nymphalinae & Junonia terea elgiva (Hewitson) & 0.2 \\
\hline Lepidoptera & Nymphalidae & Satyrinae & Bicyclus safitza safitza (Hewitson) & 2.0 \\
\hline Lepidoptera & Nymphalidae & Satyrinae & Ypthima antennata antennata (van Son) & 0.3 \\
\hline Lepidoptera & Nymphalidae & & Hamanumida daedulus & 0.2 \\
\hline Lepidoptera & Nymphalidae & & Junonia eonone eonone (Linnaeus) & 0.3 \\
\hline Lepidoptera & Nymphalidae & Acraeinae & Acraea zetes Hewitson & 0.2 \\
\hline Lepidoptera & Nymphalidae & Acraeinae & Acraea acerata (Hewitson) & 0.4 \\
\hline Lepidoptera & Nymphalidae & Acraeinae & Acraea acrita (Hewitson) & 0.4 \\
\hline Lepidoptera & Nymphalidae & Acraeinae & Acraea aganice (Butler) & 0.2 \\
\hline Lepidoptera & Nymphalidae & Acraeinae & Acraea cabira (Hopffer) & 0.8 \\
\hline Lepidoptera & Nymphalidae & Acraeinae & Acraea eponina (Cramer) & 0.3 \\
\hline Lepidoptera & Nymphalidae & Acraeinae & Acraea neobule (Doubleday) & 0.9 \\
\hline Lepidoptera & Nymphalidae & Acraeinae & Acraea zonata (Hewitson) & 0.3 \\
\hline Lepidoptera & Papilionidae & & Papilio demodocus (Esper) & 0.7 \\
\hline Lepidoptera & Pieridae & Pierinae & Belenois thysa (Hopffer) & 0.6 \\
\hline Lepidoptera & Pieridae & Pierinae & Colotis antevippe zera (Lucas) & 0.2 \\
\hline Lepidoptera & Pieridae & Pierinae & Leptosia alcesta (Bernardi) & 0.8 \\
\hline Lepidoptera & Pieridae & Pierinae & Mylothris agathina agathina (Cramer) & 0.8 \\
\hline Lepidoptera & Pieridae & Pierinae & Nepheronia argia (Suffert) & 0.4 \\
\hline Lepidoptera & Pieridae & Pierinae & Pontia helice johnstoni (Crowley) & 0.5 \\
\hline Lepidoptera & Pieridae & Coliadinae & Catopsilia florella (Fabricius) & 0.6 \\
\hline Lepidoptera & Pieridae & Coliadinae & Colotis danae (Fabricius) & 0.3 \\
\hline Lepidoptera & Pieridae & Coliadinae & Eurema brigitta (Stoll) & 0.7 \\
\hline Lepidoptera & Pieridae & Coliadinae & Eurema hecabe solifera (Linnaeus) & 0.5 \\
\hline Lepidoptera & Sphingidae & & Agrius convolvuli (Linnaeus) & 0.7 \\
\hline Lepidoptera & Sphingidae & & Hippotion celerio (Linnaeus) & 0.6 \\
\hline Lepidoptera & Sphingidae & & Leucostrophus hirundo (Gerstaecker) & 0.4 \\
\hline Lepidoptera & Sphingidae & & Macroglossum trochilus (Hubner)? & 0.3 \\
\hline
\end{tabular}

${ }^{*}$ Total visitations: average numbers of individuals counted collecting floral resources (nectar/pollen) on flower patches/180 min/24 h (night or day) across the 4 flower farms during faunistic surveys of 2010-2012. 
abundance is likely to be caused by differences in quality and availability of floral resources and nesting sites across flower farms visited. Seminatural habitats like fallows had the greatest species richness and abundance in both croplands and grasslands; and this information indicated that increasing proportion cover of fallow resources in flower growing regions can benefit species diversity at both habitat and landscape scale levels through their ability to support a greater number of flowering species and nesting resources per unit area than other seminatural habitats/land-uses. Overall, a growing body of work has shown a positive relationship between crop yield per unit area, the diversity and abundance of insect pollinators, and the amount of native vegetation in the area around the crop. When temporally and spatially integrated into the agricultural matrix, natural environments benefit pollinators (bees) and become important sources of a diversity of pollinator species, probably because they provide good nesting sites and food resources [20-25].

4.3. Drivers of Bees in the Surrounding Habitats of Flower Farms. Two processes globally threatening natural ecosystems, biodiversity, and services delivered are changes in landuse and deforestation [47]. Bees are ecologically and functionally diverse, foraging on a broad array of floral forms, nesting in a wide variety of substrates [19], and responding to both nesting and foraging resources at a wide range of spatial scales. Bees require multiple resources to complete their life cycle, including pollen, nectar, nest substrates, and nestbuilding materials. These resources are often gathered from different locations, making bees reliant on multiple, "partial habitats." This might make bees vulnerable to disturbance insofar as they would be negatively affected by the loss of any of these habitats. Thus, rural landscapes that offer heterogeneous nesting and floral resources, in both cultivated and noncrop areas provide a good habitat for a diverse suite of bees. Also, the main cause of bee decline in the UK, USA, and Western Europe is widely agreed to be the agricultural intensification that took place in the 20th century $[28,47]$.

When asked about the causes of bee biodiversity decline in the village, most participants linked it to various factors. The vast majority of households interviewed were aware of significant changes in the local bee populations, most of which they interpreted as a product of several interacting anthropogenic factors. Among threats to pollinators identified by farmers included deforestation, habitat fragmentation, fires-slash and burn agriculture, use of agrochemicals, charcoal production, pests and diseases, poor honey harvesting methods, and climate change. However, nearly half (50\%) of the interviewees believed that few factors played key a role in the decline of wild bees, including pesticide application and habitat alteration (fragmentation/degradation) as primary causes of pollinator declines. Most frequently, interviewees often pointed out forest clear cut and agricultural chemicals as key drivers of pollinator decline in their villages. Several other farmers commented with details on how pesticides used in the flower farm affect bees and their crops. Very few farmers assigned the problems of bees decline to climate change. Two to three households noted the importance of bee diseases in the decline processes. Overall, this study surveys agrees with previous findings [35] about the role played by habitat alteration and pesticide applications as key drivers of bee decline worldwide. Pollinator unfriendly farming practices such as pesticides application, forest clearance, and annual fire burning are well acknowledged by farmers (from various tribes) as important factors accelerating bee decline in villages in Uganda [22]. However, such disturbances and related drivers (pressures) and associated loss of bees will have severe impacts on crop production and the livelihood of rural people in the nearest future, if nothing is done by the government (policy-makers).

Bees have been shown to increase plant seed set, improve fruit quality, and improve fruit quantity. Given their importance for floral biodiversity and food production, the status of bees is subject to increasing concern, with evidence of declines found in some species/groups from the local to the national scale. Several factors are recognized as potential drivers of bees decline [40]. The use of pesticides in agriculture, parasites, habitat loss, and fragmentation have all been linked to pollinator decline. As mentioned above, agricultural intensification, of which an increased use of pesticides is an integral part, is often argued to be a key driver of pollinator decline $[36,40,48]$ worldwide. It is well documented that agricultural intensification (pesticides and fertilizers application intensification) has negative effects on species richness, abundance, and diversity of wild bees $[37,38,41]$. The application of pesticides quickly affects bees, particularly susceptible species. The loss or reduction in abundance of a species can subsequently indirectly affect other trophic levels, within the ecological network of which they are a part [40]. Pesticides are likely to affect whole plant-pollinator interactions and communities [40]. Pesticide application is an anthropogenic disturbance that can promote pollinator species extinction and induce a sudden collapse in pollination networks $[49,50]$; and such situation can pose serious threats leading to high levels of crop production failure in rural landscapes.

For example, while studying the effects of farmland management (agriculture intensification) and environmental factors at local and landscape scales on bees in central Hungary, it was realized that increasing the amount of fertilizer decreased total and small bee abundance and increased the coefficient of variation of total bee abundance [50]. The study also realized that insecticide use had a significant negative effect on total and small bee species richness and on large bee abundance, although the percentage cover of seminatural habitats in a $500 \mathrm{~m}$ radius did not influence bee species richness and abundance. It was concluded that the intensification of farmland management poses a threat to bee diversity and thus may reduce pollination services [50]. The reduction of the amounts of fertilizer and a cessation of insecticide application were advocated for to lead to high bee species richness and abundance and ensure the pollination of wild plants and flowering crops [50]. The disappearance of bees has great a impact on the livelihood and food security of the population. It also has an impact on the national and regional economy for development. 
4.4. Role Played by Pesticides Applied inside Flower Farms on the Decline in Pollinators Living in the Surrounding Landscapes in Uganda. During field visits, information on agrochemicals used by the different flower farms was collected. A checklist of different fertilizers and pesticides used and dosages is given in Tables 4 and 5. Among the different agrochemicals used, the effects of fertilizers on pollinators are not clearly documented; however, the effect of pesticides on pollinators is largely documented in the literature $[35,40]$. Herbicide applications are known to diminish food resources in fields and in field margins and fallows. Insecticides are expected to directly affect bees with lethal or sublethal effects. Fungicides can also be harmful to bees sometimes through synergic mechanisms with insecticides [41].

To our knowledge, there exists not one study of the impact of inorganic fertilizer (NPK) application in greenhouses of flower farms on pollinators living in the surrounding habitats. This is the first study examining such effect. Even when studies of the impact of fertilizers on biodiversity exist, they generally conclude that the overall range of effects of inorganic fertilizers on species richness and abundance is arguably negligible or of little impact [51]. For example, a recent study was conducted in UK farmlands to identify the impacts of farm management practices (cattle grazing, inorganic fertilizer applications) on species richness, abundance, and community composition and on functional groups of diverse invertebrate taxa (beetles, plant hoppers, true bugs, butterflies, bumblebees, and spiders) and plants (forb species richness, grass species richness, and sward architecture). The study concluded that the effects of inorganic fertilizer applications were generally weak, both across trophic levels and within the phytophagous feeding guilds of invertebrate groups studied [51]. Even bumblebees showed no strong response (reduction, increase) to inorganic fertilizer applications [51]. However, plant species richness and abundance increased with intensity of fertilizer application [51]. Contrastingly, another study showed that increased nitrogen (and related inorganic fertilizes) input can cause a decline in floral resource diversity and abundance (nectariferous native plants) in European farmland habitats [41]. Overall, there is a need to determine the trends in the response of bees to inorganic fertilizations in and outside flower farms since they are agrochemicals and they cannot be without disturbance of surrounding local ecosystems.

All insecticide types used by the flower farms are well documented to be toxic to bees and to other beneficial insects [20-26]. With the exception of fungicides to which negative effects on bees are less documented, most of the insecticides (including miticides/nematicides) and herbicides used by the flowers are of broad spectrum action and are very toxic to bees $[35,52]$. Most of these insecticides are on the "red list of the World Health Organisation (WHO) classification of pesticides" with negative effects on beneficial organisms. Some other pesticides used are not on the list of dangerous pesticides by the WHO (because they are commercialized with different names) but are highly toxic to bees. It was commonly found that flower farms used WHO highly (Ia and Ib) and moderately (II) hazardous pesticides. Pesticides like Dithane, Gramaxon, Round-up, Decis, Copper, Pyrethrins,
Score, Previcur, Confidor Cypermethrin, Ambush, Larvin, Decis (Deltametrin), Rogor (Dimethoate), Dimethoate, Mancozeb, Malathion, Ambda-Cyhalothrin, and so forth have been classified by the WHO as highly (Class-I) to moderately (Class-II) hazardous. There is a need for flower farms to adopt the use of pesticides that are slightly hazardous to the environment or pesticides unlikely to present acute hazard in normal use following WHO guidelines [53]. Flower farms should adopt using approved pesticides with lowest residual toxicity, which should be selected and sprayed when bees are not actively foraging, during the late evening times, at night, or in very early morning hours.

Currently, a mechanism by which agrochemicals applied inside flower farms may affect bee biodiversity inhabiting habitats in the surrounding of flower farms remains largely unknown. No previous studies have compared pesticide toxicity in wild bees in Uganda [23]. However, laboratory studies suggest that bees feeding on contaminated pollen/nectar at high concentrations are likely to encounter/experience lethal effects in the wild [21]. In Uganda, there exist several other causes of pollinators decline including pests and diseases and climate change, but the application of agrochemicals weighs heavy compared to other causes (drivers). Responses of farmers interviewed about the negative effects of agrochemical applied by the flower farms were almost similarly immediate with a large proportion of households responding that these chemicals directly killed bees, indirectly disturbing the reproduction process of crops and directly damaging the quality of fruits they grow. However, it was difficult to verify such assumptions by farmers.

Pesticide application causes a lot of damage to wildlife and ecosystem biodiversity [54]. Pesticides have a major impact on both honeybee and wild bee populations; and most pesticides used in agriculture are toxic to bees [52]. For example, the annual external cost of honeybee and pollination losses from pesticide applications in the USA was estimated to be of US\$409.8 million in $2002[52,54]$. Later, it was estimated that the annual agricultural losses due to the reduction in pollination services caused by pesticides may be as high as $\$ 4$ billion a year in the USA [52].

The government of Uganda should regulate importation of pesticides, mainly an officer should be trained and attached to flower farms to control the quality of chemicals imported, particularly verifying the name of active ingredients and commercial names and the degree of toxicity of these chemicals to living organisms (including bees), the length of residual toxic effects in hours or days.

Most of the chemical pesticides used by flower farms can easily diffuse into the environment. These chemicals pesticides are also of high persistence in the environment and highly toxic to several member species of Apoidea communities. Insecticides applied by the flower farms can affect the foraging and homing behaviour of wild bees at sublethal to lethal concentrations with acute effects [40]. Once the air is polluted by these chemicals, most bee species foraging in the surrounding environment cannot survive.

Much as there was no direct evidence of the impact of chemicals applied on bees, it was realized that bee species richness increased with distance from the edge of the flower 
farm into farmlands/grasslands, and this indicated that something was happening around flowers that may be one of the causes of low bee species richness and abundance in the proximity of different flower farms. Bees are highly sensitive to many insecticides [35] like those applied by the different flower farms in Uganda. Honeybees, and likely other bees as well, have relatively few detoxification genes, which increases their susceptibility to pesticides. Native bees nesting near crops can experience more exposure since they forage frequently on floral resources nearby their nesting sites in the surrounding of fields; thus, there is a need for growers to reduce or avoid spraying pesticides during periods of bee activities.

Although little is known about the effects on wild bee communities of typical insect pest management programs used pre- and postcrop blooms, native bees exhibit a wide range of responses to pesticide applications to crops, but most bees are very sensitive to toxic insect pest management practices [55]. Recent studies show that wild bee communities are negatively affected by increasingly intensive chemical pest management activities in crop fields. It is likely that a significant link between typical crop pesticide applications and bee abundance and species richness in the field exist [55] in most cropping systems of the world. The study also demonstrated that both solitary and social foraging bee species declined with increasing exposure to applied pesticides in the field [55]. Insecticide application before crop bloom has ceased and that is likely to have a greater impact on social species than on the solitary [55].

Much as it is not yet clear how pesticide application affects pollinator community structures and how these alterations subsequently affect pollination service delivery to crops, it remains a major threat to crop production in Uganda, particularly in regions where flower farms have been established.

Bees are highly sensitive to many insecticides [35] like those applied by the different flower farms in Uganda. All over the world, honeys have been found to be positively sensitive [56] to various types of pesticides (herbicides acaricide, fungicide, insecticide, nematicide, molluscicide, etc.). Although honeybees (Apis mellifera L.) are among the most important pollinators in natural and agricultural settings, they are like other beneficial insects, very sensitive to insecticides (carbamates, nicotinoids, organochlorines, organophosphates, pyrethroids and miscellaneous, etc.). Honeybees, and likely other bees as well, have relatively few detoxification genes, which increases their susceptibility to pesticides. Native bees nesting near crops can experience more exposure since they forage at times of day and times of year. In Uganda, there exist several other causes of pollinators decline including pests and diseases [57] and climate change, but application of agrochemicals weight is heavy compared to other causes (drivers). There is therefore a need for smallscale growers to reduce or avoid spraying pesticides on their crops during periods of bee activities on flowers.

While studying the effects of insecticide Phosmet application on solitary bee foraging and nesting in orchards in the USA, no difference was found in the number of native bee visits to several species of plants flowering in and near orchards immediately before and 1 day after spraying [58].
Conversely, the nesting studies using the semidomesticated alfalfa leaf cutting bee, Megachile rotundata (F.), showed strong significant declines in the number of adult males, nesting females, and progeny production subsequent to spraying at distances of up to $160 \mathrm{~m}$ from sprayed orchards where the bees were presumably foraging [58]. This result from the USA indicated that pesticide application does not only directly affect foraging activities of bees in the field sprayed but the effect can go far away from the central point of spraying in any areas where bees are apt to forage from. Hence, currently, much as there was no evidence for direct effects of pesticides applied in greenhouses on bees foraging in the habitats surrounding flowers farms, it is believed pesticides applied inside greenhouses could have broad effects beyond greenhouses.

Despite the fact that only limited research has been done on the topic, studies consistently find pesticide residues in air. Pesticide sprays can directly hit nontarget vegetation or can drift or volatilize from the treated area and contaminate air, soil, and nontargeted organisms such as flowering plants. Some pesticide drift occurs during every application, even from ground equipment. Drift can account for a loss of 2 to $25 \%$ of the chemical being applied, and this can spread over a distance of a few meters to several hundred kms. Practically, various types of pesticides can volatilize (i.e., they can evaporate from soil and foliage, move away from the application, and contaminate the environment). As much as $80-90 \%$ of an applied pesticide can be volatilized within a few days of application. Many pesticides used by the flower farms in central Uganda are of long-lived pesticides; they can be omnipresent in the air (atmosphere) throughout the year. In fact, most of the flower farms visited had their greenhouses open on at least two sides (Figure 1). Application of pesticides was conducted early morning and later in the evening at a time when local wind direction was high and since these greenhouses had two sides open, wind could circulate inside and carry droplets of pesticides outside the greenhouses into nearby farmland habitats. In addition, small-scale farmers located within $10 \mathrm{~m}$ to $1000 \mathrm{~m}$ far away from the flower farm said they could smell pesticide applications and knew when flower farms were applying their toxic fumes. Also, this study found that bee species richness and population density increased with distance away from the flower farm. High bee species richness and population density were found at beyond $1.5-2 \mathrm{~km}$ far away from the flower farms. These observations combined made to believe that pesticides applied inside flower farm were contributing to reduction of bee biodiversity, particularly in habitats immediately surrounding them.

Bees are highly sensitive to pesticides application although the dose may vary from a product to another one. At the current doses of application of pesticides inside the flower farms, it is possible that a high proportion is driven by the air runoff in the farmlands. However, it is not clear at which doses they reach farmland habitats. Bees are sensitive to pesticide applications at any amount. It is likely that most bees flying around the flower farms can die in the next 30 to $60 \mathrm{~min}$ after being exposed to these chemicals. To illustrate this assumption, an example of a scientifically proven study can be used. The impact of bifenthrin on honeybees, Apis mellifera 
(Hymenoptera: Apidae) was evaluated in both laboratory and semifield assays to determine killing time after 15, 30, and $60 \mathrm{~min}$ of honeybee exposure. Bifenthrin was applied at $9.7 \mathrm{~mL} /$ liter, $19.5 \mathrm{~mL} /$ liter, and $29.5 \mathrm{~mL} /$ liter of water to common landscape vegetation, Melampodium paludosum Melanie (show star) and Duranta erecta L. (golden dewdrop), a water control, was also used [59]. The results indicated that both dose and exposure time significantly affected honeybee mortality. The application dose of $35 \mathrm{mg} / \mathrm{mL}$ resulted in $100 \%$ bee mortality at all time intervals. Bee mortality was significantly higher at $29.5 \mathrm{~mL} /$ liter compared to the mortality at $19.5 \mathrm{~mL} /$ liter and $9.7 \mathrm{~mL} /$ liter application rates after $24 \mathrm{~h}$ exposure to the treated vegetation [59].

4.5. Potential Causes of Reduction in Bee Numbers and Species along Distance from the Flower Farms into Farmlands. In this study, it was observed a reduction in bee numbers and species at the edge of flower farms compared to far away from the flower farms. However, it was not clear if chemicals applied inside greenhouses could be the cause. Overall, there is no clear evidence of the decline in bee biodiversity due to activities within the flower farm but the fact that bee abundance and species richness tended to increase at distances beyond $2 \mathrm{~km}$ way from the flower into farmlands indicated that something was happening, forcing some sensitive bee species to find refuge far away from the flower farm.

Although there was no direct evidence for the flower farm activities to cause the reduction in bee species and numbers nearby the flower farm, it is believed that agrochemicals used inside flowers may be responsible for such reduction. Various scenarios (speculations) of some activities happening inside glasshouses may help in explaining possible connections with bee reduction in nearby farmland habitats.

(i) During field surveys, it was observed that the flower farmers did not have good control measures of the runoff of water from inside glasshouses to outside in the surrounding nature. In most cases, chemicals were not fully contained because dead fish and frogs were frequently observed in most wetlands and aquatic zones that receive water from flower farms. As evidence, farmers reported that "they cannot see any snakes, lizards or frogs moving around in the bush ever since the flower farms came around in their village." Also, containing runoff of chemical in the soil, air, and water was difficult in most flower farms. Chemicals in water could affect water bodies and this was visible by animals and fish seen dying along field transects. It was difficult to confirm the existence of chemical accumulation in soil of the surrounding farms; however, it is recommended that further investigations focus on quantifying activities of earthworms in soils around flower farms to determine if they are limited compared to soils sampled from farms located far away. The aim would be to identify if ground-nesting bees are not threatened by chemical accumulation in the soils of small-scale farms and of natural/seminatural vegetation found in the surrounding of flower farms. It is therefore recommended that good methods to contain runoff of water from flowers are set, tested, and evaluated.

(ii) Air is a vector of most dangerous chemical pollutants for bees. Chemicals from industrial factories can be driven in the air and dropped on the vegetation. Thereafter, bees that are busy collecting floral resources can ingest these pollutants. Similarly, a ground nesting bee will fail to make a choice of place as nesting site if felt it is polluted. During the time of surveys, it was difficult to detect pollution of the air by chemicals from flower farms. However, the distance at which these chemicals (commonly called by farmers "fumes") could move was high. During an early morning survey, the researchers were found near inhabitant houses located at $1000 \mathrm{~m}$ far away from the flower farm while chemicals were being sprayed in the flower farm (pearl flower farm) and 30 minutes after ending, the smell of the "fumes" could be felt high and strong. The "fumes" were driven by the air and farmers interviewed indicated that they have to run away from their houses for at least 2 hours when the flower is spraying.

The "walls" of the flower farms were not closed to contain the "fumes" inside glasshouses. Consequently, after spraying, under windy conditions, the "fumes" could move in the air and be felt by communities living even at $2500 \mathrm{~m}$ far away from the flower farm. These chemicals moving in the air, polluting the nearby environment could affect bees that could inhale them and die in their hives. Consequently, few bees could be observed around flower farms. It is therefore recommended that toxicological studies are conducted in all environments nearby flower farms to determine and identify bee toxic components in the air in relationship to the type of agrochemical used in flower farms. It is important to identify most hazardous chemicals among those preferred and imported by flower farms.

(iii) During farms' survey, most farmers indicated some flower farms (eg., Fiduga) were dumping, waste of the agrochemicals they use at the edge of their flower farms nearby villages. Dumping points were counted at the density of 20 per hectare by the researchers during the surveys. These dumping materials were not covered by soils.

(iv) In addition, some farmers living near Mairye estates were observed collecting and using waste of agrochemical and soil wastes soils as fertilizers in their gardens. Agrochemicals and soil wastes collected and used in gardens as fertilizers are actually mixtures of fertilizers and pesticides used inside the glasshouses. Hence, some farmers ignorantly contributed to the spread of chemicals into the farmlands and it was difficult to observe a bee foraging nearby here these waste chemicals have been put in the gardens. Bee nesting is difficult in such environments.

All these above described activities carried out inside glasshouses could lead pesticides outside. Other causes of reduction of bees around flower farms are human activities (of small-scale farmers) that are carried out near flower farms. In their farming process, small-scale farmers may be engaged in farming practices that are not pollinator-friendly or in activities that can negatively affect pollinators. During field work, the researcher inventoried a certain number of bad agricultural practices: bush burning, seminatural habitats clearing, over-cultivation, and herbicides and pesticides application by certain farmers. However, these observations were not generalized. In the surrounding of Fiduga flower farms, some farmers were observing that spraying chemicals and such activities could contribute to the reduction in bee 
numbers and species at the edge of flower farms. It is recommended that future studies are conducted to explore and determine the role played and the contribution of human activities (small-scale farmers' activities) in the reduction of bees in the landscapes immediately surrounding flower farms compared to the role played by agrochemicals from the flower farms. Such further research should be conducted to understand and describe how activities carried out inside greenhouses can affect bees living in adjacent habitats. Such research should identify and clearly point out factors involved in causing the reduction in bees.

4.6. Potential Consequences and Implications of Loss/Decline in Bees on Agricultural Production, the Economy, and Local Community Livelihoods. Evaluating the potential risks related to the loss of pollination services in Uganda is not easy. However, the risks posed by failure of pollination services delivery are many including depletion of biodiversity. The loss of pollinators might also precipitate shift in vegetation communities. Any decline in pollination services could lead to cascading effects on ecosystems and an overall loss of biodiversity and ecosystem services (such as agricultural production). Mutualistic relationships are most directly affected since the loss of individual pollinator species will lead to the extinction of any codependent plant species (and vice versa). Ecosystems possess some robustness to the loss of individual species since multiple pollinators can pollinate most plants, each with somewhat different effectiveness or responses to environmental change. However, the loss of particular pollinator species and the impoverishment of pollinator diversity diminish the resilience of ecosystems to change, which are subsequently less able to provide services to humans. Many pollinators are also important food sources for higher animals, so their loss may threaten birds, bats, and other small mammals. As individual species are lost from an ecosystem, the functional redundancy that diverse ecosystems generally display is reduced and resilience to change also tends to decline.

The consequences of continuing decline/loss of pollinators in rural landscapes of Uganda are many. If bee species richness was 3 to 5 times higher at $2 \mathrm{~km}$ distance away from the flower farm than at the edge of the farm, it means that with intensification of chemical applications, a high number of bee species will continue to get lost. During field work, it was observed that the few species that could forage in the 500$1000 \mathrm{~m}$ were generalist bee species. Specialized bee species were recorded at $1500-2000 \mathrm{~m}$. This means that chemical applications by the different flowers at the current rate of application may erode specialized bee species and leave few common ones to occur. Unfortunately, 70 to $89 \%$ of crop species grown in Uganda require pollination by bees, and most often specialized bee species [22-25]. Practically, the majority of flowering plants and crops grown in Uganda are pollinated by several pollinator species, but about 45 percent of grown crops depend on a single taxon for pollination. The disappearance of specialist bee species may increase pollination limitation of many crops (e.g., Cucurbits, vanilla) that require these specialist bee species (Megachile, Patellapis,
Lipotriches, etc.). Different bee species have got different levels of sensitivity to pesticides applications; once these specialized bees are completely eroded, the remaining common species may not be enough to deliver pollination services of high quantity to different crops and wild plant species that may require these services to set fruits/seeds and for their perpetuation in the landscape. Thus, generalized bees decline in Uganda is likely to lead to high food insecurity in the country. The country will also lose a great deal of income. For example, Uganda earns approximately US $\$ 230-240$ million per annum from coffee exports, yet $60 \%$ of the total value from coffee export is attributable to pollinating services delivered by native bees [20]. Uganda cannot afford losing its pollinators because most of the crops grown are pollinatordependent. Pollinators contribute up to $67-75 \%$ of the annual income of small-scale farmers in Uganda. Total loss/decline of pollinators in Uganda may affect drastically livelihoods of small-scale farmers especially in the rural areas and could lead to high food insecurity. Therefore, the conservation and protection of pollinators by the government of Uganda is a national duty/obligation if the current government is interested in achieving and maintaining the stability of food security of its local population. Agricultural modernisation is good but at what cost?

Any deterioration of pollination services will also have an impact on the rural livelihoods of many rural communities in Uganda, particularly communities growing crops that rely on the specialist bee species. Quite simply, "poor people, with restricted access to resources and with lower integration into the cash economy, are less able to substitute human and physical capital and have less purchasing power, and are therefore particularly, and most directly, dependent on ecosystem services." Such reliance upon ecosystem services makes the poorest more vulnerable to any change in those services. Thus, a functioning pollination process is life-threateningly important to the rural poor who rely on animal-pollinated food crops and medicines for their subsistence.

4.7. Farmers' Knowledge of Pollination, Perceptions, and Attitudes towards Negative Effects of Agrochemicals Applied by Flower Farms on Pollinators, Crop Yields, and Human and Environment Health. Concerning the opinions of local community and agrochemical use and waste disposal by flower farms, in this study, it was realized that $80 \%$ of farmers interviewed knew pollination and were aware of the value of pollination in their farming business. These farmers were willing to cooperate in the restoration and maintenance of pollinators in their villages. These results indicate that a high number of farmers in Uganda understood pollination and were willing to care for pollinator conservation in farmlands. Similarly, Kasina et al. [8] conducted a survey in Kakamga region (western part of Kenya) on farmers' knowledge of pollinators and pollination services conservation. The study concluded about $50 \%$ of 354 farmers interviewed were aware of pollination and could relate it to crop productivity [18], and after having been introduced to the importance of bee pollination in crop production, they showed a willingness to conserve bees for such purposes [18]. 
Local communities accused the flower firms of being responsible for the abortion of flowers of their crops in most cultivated fruit tree species (Avocado, Mango, Papaw) in their village. Overall, it was not clear if farmers were realistic or not since it was difficult to get a scientific explanation of most observations/perceptions by farmers. Farmers also accused flower farms of being responsible for the current high rate of fruit abortion of cucurbit species. Other farmers said that even when the fruit was formed, it could not reach mature stage or if it matures, it was not tasty at all. Many deep investigations were not carried out to provide solid scientific explanation of the farmers' accusations. However, according to field observations, these farmers' accusations were relatively consistent because during field work, the researcher was given a chance to observe some avocado flowers and fruits that prematurely fell on the ground. From a pathological point of view, symptoms observed could not help in thinking of a pathogen as a causal agent. For example, most avocado fruits observed presented some cracking probably due to environmental stresses (e.g., "heat"). The presence of certain chemical components (at high levels beyond the standards) in the air (atmosphere) can also bring similar environmental stresses on plants through interaction with the physiology mechanisms of the plant.

Farmers perceived that current low honey yield received these days is due to death of bees by chemical pesticides applied at the flower farms. This accusation is consistent because the researcher frequently observed in villages neighboring flower farms several dumping points of agrochemical wastes that have been either thrown on the vegetation or buried out in the soil. Honeybee workers collect nectar and pollen from various plants. During foraging activities, bees were observed feeding on flowers parts with a high level presence of toxic chemical compounds; in most cases, they may die while flying towards their hives or die inside hives. Ingestions of contaminated flower parts may have contributed to the reduction in honeybee population in the village; thereby leading to low honey yield despite the presence of abundant floral resources in the surrounding.

Farmers accused flower farms of being responsible for the current high rate of cow abortion and of low yield of fish from ponds they had established in their village. For such an accusation, it was difficult to offer a scientific explanation. It is difficult to link cow abortion with a particular chemical used in greenhouses. However, scientifically, animals drinking chemically polluted water can have their metabolism systems disorganized due to the presence of certain chemical components in their bodies.

Farmers also accused flower farmers of contributing to rise-up of illness and death of children working at the flower farm. For this accusation, it was difficult to offer a scientific explanation but the researcher had interactions with medical personnel working in the surrounding villages who reported that patients working from flower farms were the most difficult patients they received, in most cases, these patients suffered from low blood pressures, blood infection, septicemia, and so forth.

Most farmers responded that they receive no advantage (no single benefit) from living near the flower farm. This perception was correct because when looking at the origin of most workers, very few $(<10 \%)$ of them were from the surrounding with the exception of Mairye estates that employed approximately $20 \%$ of local people. In most cases, companies recruited workers from other districts and countries.

Most farmers did not propose a sustainable solution for the future of the flower industry in Uganda, not because that they were ignorant of what should be done, but in most cases, farmers remained hypocritical on this issue. In fact, some farmers disclosed and that their opinion did not matter because they knew big politicians in the country shared actions in most flower companies such as a political decision cannot be implemented. Farmers said that even if they recommend flowering farms to use nontoxic dangerous chemicals, it will not happen because somebody will make the decision for it not to be implemented.

Overall comments/observations given by farmers may reflect a certain reality that require further investigations to come up with a scientific explanation of how the flower farm affects livelihoods, environment, and ecosystem in the surroundings in Uganda.

As in the case of Uganda, Kenya's cut-flower industry has been praised as an economic success as it contributed an annual average of US\$141 million foreign exchange (7\% of Kenyan export value) over the period of 1996-2005 and about US\$352 million in 2005 alone. The industry also provides employment, income, and infrastructure such as schools and hospitals for a large population around Lake Naivasha. On the other hand, the commercial farms have been blamed for causing a drop in the lake level, polluting the lake, and for possibly affecting the lake's biodiversity [60].

There are many human costs of cut flowers in Uganda. Health risks with flower industries are high. The majority (75\%) of flower workers are women, most of them employed as temporary workers at low pay and in harsh working conditions. Many workers are being forced to enter greenhouses right after fumigation, at least 24 hours between the time flowers are sprayed and the time workers reenter the area. Because they are not consumable, flowers have escaped much of the antipesticide pressure that has begun to reform the way fruit and vegetables are grown. Because cut-flowers have no value if they are not attractive, chemicals are also used to preserve their beauty. Flower workers are exposed to various different pesticides, $10-20 \%$ of which are banned in the international trade market because they are highly toxic or carcinogenic. Because pesticides are used primarily in enclosed greenhouses with often high temperatures, they are more easily inhaled or absorbed through the skin. In Uganda, most flower workers exhibit at least one symptom of pesticide poisoning. Flower workers are constantly exposed to high levels of extremely toxic chemicals, and many report serious health effects, including skin lesions and allergies, respiratory problems, incidences of people fainting, headaches, eye problems, and chronic asthma.

Briefly, flower farm industry in Uganda is associated with several undeclared socioeconomic and environmental problems. During farmers' surveys, some farmers indicated that the health status of children working in the flower farms, fruit (papaw, avocado, and mango) abortion, and abortion of their 
cows could be associated with chemicals applied in the flower farms. As it was found in this study, the flower industry in Kenya is known to suffer from major social and environmental problems [61]. Several negative issues associated with the flower industry in Kenya include (i) sexual harassment; (ii) forced pregnancy testing/sterilization as condition of employment; (iii) severe occupational health and safety deficiencies, including long working hours, lack of training on safe chemical use, forced overtime, and lack of appropriate safety equipment; (iv) use of toxic pesticides and fungicides causing health problems including skin rashes, respiratory problems, eye problems, and miscarriages; (v) use of child labor; and (vi) lack of recognition of labor rights [61].

Practically, the main environmental problems [61-64] associated with flower farms in Uganda and in East Africa are related to the use of water and agrochemicals (pesticides). The need for water is very high in the flower industry. In Kenya, one hectare of chrysanthemums uses 150.000 litres of water per week; unsustainable cultivation led to sinking ground water levels and dry rivers so that the supply of drinking water is no longer guaranteed in neighboring villages.

Pesticides are also used in extreme amounts including sometimes dangerous and prohibited substances. About half of the women working in the flower industry in Kenya have showed symptoms of poisoning from pesticides after working there for 3-5 years. Similarly, acute pesticide poisonings were reported by small-scale farmers living around flower farms in central Uganda, although it was not possible for this study to verify these accusations made by farmers. Kenya principal flower exporters spray about $200 \mathrm{~kg} / \mathrm{hectare} /$ year. This is double to almost the similar amount of pesticides used in most flower farms visited during the course of this study conducted in central Uganda.

\section{Conclusion}

The aim of this study was to conduct a rapid assessment on the status of pollinators around flower farms in central Uganda. This study aimed also at developing an understanding of the different perspectives of local people and see how to propose such information for integration in the decision-making by policy makers. Findings of the study provide insights into the status of pollinators around flower growing areas in Uganda. Although there is a lack of scientific evidence for direct effects of agrochemicals applied inside greenhouses on bee biodiversity, bee species richness and visitation frequencies tended to increase with distance from the flower farm into farmlands. The degree to which bee community composition differed between habitats within sites may be related to landscape variables. In fact, it was found in this study that the difference in bee species richness and abundance between habitats was strongly related to the difference in farm-landscape vegetation types (croplands, grasslands). However, the strong influence of landscape vegetation on bee species richness and abundance is likely to be caused by differences in quality and availability of floral resources and nesting sites across flower farms visited.
Seminatural habitats like fallows had the greatest species richness and abundance in both croplands and grasslands; and this information indicated that increasing proportion cover of fallow resources in flower growing regions can benefit species diversity at both habitat and landscape scale levels through their ability to support a greater number of flowering species and nesting resources per unit area than other seminatural habitats/land-uses. Understanding local perceptions of pollination importance and pollinators decline can be critical for gaining positive attitudes and support from communities for sustainable conservation and restoration of pollination services in rural landscapes, as well as improving livelihoods of local communities.

There are several negative and positive economic, social, and environmental effects associated with flower production in Uganda. Economically, cut flowers are an important export for Uganda, contributing significantly to both the local and national economies. The industry generates several billion Uganda shillings annually. Thus, the cut-flower industry has helped to reduce poverty in Uganda. The flower farms have provided job opportunities, which translate into better living standards. Some of the largest farms employ more than 5,000 workers each, many of them women. Households that are involved in working in cut-flower industries can now afford education and enjoy good health and balanced meals, among other essentials. People living near to the flower farms tend to be relatively well off, since the incidence of poverty there is between $10 \%$ and $29 \%$ compared to a national level that is well above $47 \%$. However, there have been some reports of labour problems in the cut-flower industry. The sector relies heavily on temporary workers (seasonal or casual), which affects income and job insecurity. Casual labour rises during the annual production peaks. Anecdotal evidence suggests that women workers face problems such as sexual harassment, compulsory overtime, and job insecurity. Given the nature of the accusations very few women make public complaints. Several individuals, environmental bodies and NGOs have expressed concern not only about the health hazards involved in flower production but also about the environmental problems caused by the flower industry. Water crossing flower farms are always polluted, which endangers the health of cattles and human beings using that water at the lower level. A rising population also presents major environmental challenges; the other main pressures on Lake Victoria include water abstractions, agrochemicals and sewage pollution, destruction of papyrus, riparian habitat, over-fishing, soil erosion, and so forth. For example, these days, there has been a massive death of fish on the shore of Lake Victoria and this is attributed to poisoning by the agrochemicals emitted by the flower farms. In some cases (Wagagai flower farm), the flower farms rely on the lake for irrigation, and pipes run straight from the lake into the greenhouses.

This study revealed that more than $79 \%$ of small-scale farmers were aware of the value and importance of pollination services in their farming business. Local people tended to be most aware of potential negative effects of chemical applied by flower farms than by chemicals they apply themselves on their plots. Crop yield reductions (fruit abortion) were frequently mentioned possibly because fruit trees were the 
main source of income of small-scale farmers interviewed. Although it was perceived in this study that pollinators have been declining around flower growing areas there exist no or limited long-term data on pollinator populations; and this makes their conservation status difficult to assess in rural landscapes in Uganda. It is difficult to know which species are clearly declining given the absence of long-term monitoring data in Uganda. Thus, maintaining diverse, healthy, and abundant communities of wild pollinators within farmland presents a challenge to farmers, natural resource managers, and policy-makers. However, conserving pollinatorsupporting habitats within farmlands can clearly bring benefits to both agriculture and conservation. Overall, the conservation of pollinators in farmlands of Uganda, particularly in flower growing regions, should be monitored. Also, there is a need to define protocol for conducting faunistic surveys, research, and monitoring of pollinators (bees) in natural and agricultural landscapes in Uganda.

Many farmers interviewed were not open enough to suggest durable solutions, but the understanding of desires and preferences of local people is essential for building support for development projects in a given area. Therefore, education for and dialogue with communities are thus crucial since they can all strongly influence communities preferences, perceptions, and priorities. It is important to build community involvement in the development process to ensure the success of projects. Policy-makers should focus on encouraging dialogue between flower farm managers and local communities for enabling the coexistence of the flower farms in the villages. Local communities living in the surrounding need to be involved/informed about risks and benefits (goods and services) associated with the presence of flower farm in their villages. Conservation managers and policy-makers need to balance the demands of public health protection (for humans, crops, and the environment), agricultural production intensification, and the long-term conservation of bee biodiversity in rural landscapes.

Pesticides are often taken as the first line of defense against pests, yet they also impact at least two of the key ecosystem services that sustain crop yields: natural pest control and pollination [62]. Therefore, there is a need to develop pesticide application legislations that are pollinator-friendly in Uganda. There is also a need to develop, put in place, and enforce laws to control or regulate the use of pesticides to protect workers, environment, and inhabitants in areas where cut-flower industries are established. Greater respect for farmers' rights is key to reducing adverse pesticide impacts in flower growing regions in Uganda. Regulations concerning types of pesticides to be used by flower farms do not need to be flexible, but should be compatible with local demand for a healthy environment. Environmental/agricultural policies that authorize the abandonment of use of toxic pesticides are advocated for here, as part of a win-win solution to softly mitigate negative effects caused by flower farm industry in Uganda. It is also recommended to policy makers to commission studies that investigate and find evidence for all accusations made by farmers about the negative effects of agrochemicals applied on human, plant, and environmental healths.
NEMA (national environmental management agency) is the government body charged with environmental management, issuance of license, and monitoring of activities that are detrimental to the environment. It seems NEMA was not involved in the investment of flower firms in Uganda. However, NEMA should be visible at the feasibility study (to carry out its EIA = environmental impact assessment), and in the documentation of the flora/fauna prior to any investment in the country. Also, NEMA should be present during the implementation and routinely monitor the environment around the flower farms and related investments/projects. The agroinputs department of the Ministry of Agriculture, Animal Industries, and Fisheries need to have a strong presence on the ground in vetting chemicals imported, in monitoring their correct usage, and in monitoring negative impacts on humans, environment, and biodiversity.

In this study it was observed that both the species richness and bee populations were lower near flower farms (despite availability of abundant and diverse floral resources) but increased with increasing distance away from the flower farms. However, it was not clear if chemicals applied inside greenhouses could be the cause. Although, there was no direct evidence that flower farm activities cause the reduction in bee species and numbers nearby flower farms, it is believed that agrochemicals used inside flowers may be responsible for such a reduction. To be more conclusive on this topic, it is therefore recommended that future research (using primary data) is carried out to experimentally test and establish whether or not the decline in bee species richness and numbers is due to the use of agrochemicals by flower farms. It may useful that toxicological studies are conducted in all environments nearby flower farms to determine and identify bee toxic components in the air in relationship to the type of agrochemicals used in flower farms. This may help in determining pesticides directly and indirectly involved in acute bee poisoning.

Flower farms have sprung up in many developing countries to provide a wide range of flowers year-round in western countries. They are a valuable source of foreign income and employment, but may have costs to the environment and local community. This work provides information on some of these potential impacts. To our knowledge, this is the first rigorous study providing useful scientific contribution in the area of pollination services delivery in farm landscapes with large flower farms in Sub-Saharan Africa and in the world. This is the first excellent review of how government involvment, antrophogenic stress, use of pesticides, among other factors are affecting biodiversity of pollinators in Uganda. The present study can serve as a valuable guide to natural resource managers and policy makers in Uganda, as conserving pollinator-supporting habitats within farmlands can clearly bring benefits to both agriculture and conservation.

Overall, a remarkably high diversity of bees was observed in this study; the diversity and numbers of bees were observed to be higher further away from the flower farms and in sites where there was more seminatural vegetation. Also, it was observed in this study that local farmers mostly had a good understanding of the importance of bees as pollinators of their crops. They also mostly felt negatively about the flower 
farms and believed that the farm's high use of pesticides has an impact on bee numbers and hence on the productivity or quality of their crops, and potentially on human health. It was not clear if flower farms were directly responsible for all these accusations by farmers, but it is believed that that there should be further investigation of the flower farms' impacts. It was observed that over time, there was an increase in the amounts of agrochemicals used by the flower farms. An interesting finding was the lack of relationship between farm income and amount of agrochemicals used. This result suggested that the use of chemicals could be reduced without loss of income (and as costs are reduced gross and net income should be increased). It was also interesting to find out that at least one flower farm was showing some environmental responsibility, by taking some care to reduce use of pesticides and also to recycle water and so forth.

It is therefore strongly recommended to conduct toxicological studies (to determine side-effects) on different bee species collecting floral resources or residing in farmlands where flower firms are established. The aim of such study will be to assess the exposure of bees to pesticide residues [62-64] from greenhouses. There is a need for monitoring programs to establish spatial and temporal trends in the abundance and bioavailability of pesticide residues for bees and other insects. Biomonitoring of organisms that accumulate contaminants in their tissues can be used to assess the relative quality of environments, including the presence, levels, and changes in contaminants [56].

Pollen loads/living bees have been suggested to be the best matrix for assessing/detecting the presence of pesticide residues (frequencies, concentrations) in samples from in the environment. Toxicological studies may help in yielding more significant results on influences of pesticides application inside greenhouses by flower firms on health of human communities. To provide more accurate results, there is also a need to conduct analysis of water quality (pond/river/stream flowing through/from flower farms to farm landscape), soil, and resources produced by bees (honey and wax) to check for traces of pesticides in these substances. Stingless bees and honeybee may be useful as environmental indicators for assessing the presence of environmental pollution [61] with heavy metals (important and potentially harmful pollutants such as $\mathrm{Co}, \mathrm{Cd}, \mathrm{Cr}, \mathrm{Cu}, \mathrm{Fe}, \mathrm{Mn}, \mathrm{Ni}, \mathrm{Pb}$, and $\mathrm{Zn}$ ). The link between floriculture industry with the environment and health is poorly documented in Uganda. Management of agrochemicals and effluent from flower farms need to be revised by all flower firms. It is therefore recommended that good methods to contain runoff of water from flowers are set, revised, tested, and evaluated by all flower farmers to reduce pollution of the environment from pesticides and fertilizer runoff.

Long-term effects of regular exposure to pesticides can cause erosion of pollinators. Some pesticides can be persistent in the soils, air, and in plant parts. These can become toxic later to certain organisms in contact with the environment where they are deposited. It is important to determine the levels of certain pesticides (eg., organochlorine) in the local environment (air, soil, water, bee food plants and flower parts, air, etc.) compared to published lethal doses to bees. Explorative studies are recommended to determine the role played and contribution of human activities (small-scale farmers' activities) in the reduction of bees in the landscapes immediately surrounding flower farms compared to role played by agrochemicals from the flower farms. There is also a need to conduct vast awareness campaigns among small-scale farmers about some of their pollinator's unfriendly [65] farming practices. There is a need to conduct further deep research on issues of health risks of workers of cut-flower farms.

\section{Ethical Approval}

Ethical issues (including plagiarism, informed consent, misconduct, data fabrication and/or falsification, double publication, and redundancy, etc.) have been completely observed by the author.

\section{Conflict of Interests}

The author declares that he has no conflict of interests.

\section{Acknowledgments}

Early seed financial supports (2\%) for conducting preliminary surveys (for 3 days) were obtained under a consultancy commissioned by the Economic Policy Research Centre (EPRC) and supported by the National Environment Management Authority (NEMA) Trade and Biodiversity Initiative of the Government of Uganda through a grant offered by the European Union and the United Nations Environment Programme (UNEP) to the Government of Uganda. EMRCDRC funded $98 \%$ of the activities (major activities for 2 years: 2010-1012) related to this study. The author is very grateful to both sources of funding. The author is also very grateful to production managers of the different flower farms visited for allocating some of their busy time to answer the questionnaires submitted to them. The author is very grateful to small-scale farmers living in the surrounding of different flower farms who accepted freely to answer the questions. The author is grateful to Ms. Madina (research assistant) who assisted him with local translation of the questionnaire in local language in the early stages of this work. The author thanks Mr. Ziwa (EPRC driver) for driving safely and bringing us in time to the field and for the kind patience during field data collection by the researcher with his assistant. The author is grateful to the Director of EPRC. The warm and kind collaboration of other staff at EPRC is much acknowledged, mainly from Francis Mwaura (EPRC) and Francis Ogwal (NEMA). The author is also very grateful to various scientific help/support received from Dr. Hafashimana David, Dr. Talwana Hubert, Dr. Michael Otim, Dr. Anne Akol, Dr. Chris Bakuneta, Dr. Robert Kityo, Professor John Tabuti, Professor Samuel Kyamanywa, Professor Kansiime, and Professor Nyeko Philippe (Makerere University-Uganda). 


\section{References}

[1] Economic Policy Research Center (EPRC), "Integrated Assessment of Trade-Related Policies on Biological Diversity in the Agricultural Sector in Uganda. The potential impacts of the EUACP Economic Partnership Agreement. A case study in the horticulture sector. Ministry of Water and Environment, Republic of Uganda, National Environment Management Authority (NEMA), United Nations Environment Programme (UNEP), Kampala, Uganda," 2009.

[2] G. Allen-Wardell, P. Bernhardt, R. Bitner et al., "The potential consequences of pollinator declines on the conservation of biodiversity and stability of food crop yields," Conservation Biology, vol. 12, no. 1, pp. 8-17, 1998.

[3] C. D. Eardley, M. Gikungu, and M. P. Schwarz, "Bee conservation in Sub-Saharan Africa and Madagascar: diversity, status and threats," Apidologie, vol. 40, no. 3, pp. 355-366, 2009.

[4] R. Winfree, N. M. Williams, H. Gaines, J. S. Ascher, and C. Kremen, "Wild bee pollinators provide the majority of crop visitation across land-use gradients in New Jersey and Pennsylvania, USA," Journal of Applied Ecology, vol. 45, no. 3, pp. 793-802, 2008.

[5] P. Neumann and N. L. Carreck, "Honey bee colony losses," Journal of Apicultural Research, vol. 49, no. 1, pp. 1-6, 2010.

[6] A.-M. Klein, B. E. Vaissière, J. H. Cane et al., "Importance of pollinators in changing landscapes for world crops," Proceedings of the Royal Society B: Biological Sciences, vol. 274, no. 1608, pp. 303-313, 2007.

[7] D. Goulso, "Conserving wild bees for crop pollination," Food, Agriculture \& Environment, vol. 1, no. 1, pp. 142-144, 2003.

[8] O. MacIas-Macias, J. Chuc, P. Ancona-Xiu, O. Cauich, and J. J. G. Quezada-Euán, "Contribution of native bees and Africanized honey bees (Hymenoptera: Apoidea) to Solanaceae crop pollination in tropical México," Journal of Applied Entomology, vol. 133, no. 6, pp. 456-465, 2009.

[9] M. G. Park, M. C. Orr, and B. N. Danforth, "The role of native bees in apple pollination," New York Fruit Quarterly, vol. 18, no. 1, pp. 1-24, 2010.

[10] C. Kremen, N. M. Williams, M. A. Aizen et al., "Pollination and other ecosystem services produced by mobile organisms: a conceptual framework for the effects of land-use change," Ecology Letters, vol. 10, no. 4, pp. 299-314, 2007.

[11] L. A. Garibaldi, M. A. Aizen, S. A. Cunningham, and A. M. Klein, "Pollinator shortage and global crop yield," Communicative and Integrative Biology, vol. 2, no. 1, pp. 1-3, 2009.

[12] D. R. Campbell, "Pollinator shifts and the origin and loss of plant species," Annals of the Missouri Botanical Garden, vol. 95, no. 2, pp. 264-274, 2008.

[13] M. A. Aizen, L. A. Garibaldi, S. A. Cunningham, and A. M. Klein, "How much does agriculture depend on pollinators? Lessons from long-term trends in crop production," Annals of botany, vol. 103, no. 9, pp. 1579-1588, 2009.

[14] A. G. S. Cuthbertson and M. A. Brown, "Issues affecting British honey bee biodiversity and the need for conservation of this important ecological component," International Journal of Environmental Science and Technology, vol. 6, no. 4, pp. 695699, 2009.

[15] R. Winfree, "The conservation and restoration of wild bees," Annals of the New York Academy of Sciences, vol. 1195, pp. 169197, 2010.

[16] N. Gallai, J.-M. Salles, J. Settele, and B. E. Vaissière, "Economic valuation of the vulnerability of world agriculture confronted with pollinator decline," Ecological Economics, vol. 68, no. 3, pp. 810-821, 2009.

[17] M. A. Aizen and L. D. Harder, "The global stock of domesticated honey bees is growing slower than agricultural demand for pollination," Current Biology, vol. 19, no. 11, pp. 915-918, 2009.

[18] M. Kasina, M. Kraemer, C. Martius, and D. Wittmann, “Farmerś knowledge of bees and their natural history in Kakamega district, Kenya," Journal of Apicultural Research, vol. 48, no. 2, pp. 126-133, 2009.

[19] M. J. F. Brown and R. J. Paxton, "The conservation of bees: a global perspective," Apidologie, vol. 40, no. 3, pp. 410-416, 2009.

[20] T. M. B. Munyuli, S. G. Potts, and P. Nyeko, "Patterns of bee biodiversity and conservation values of localities with contrasting mini-ecological structures found within, nearby and between agricultural mosaic landscapes from central Uganda," Life Sciences International Journal, vol. 2, no. 4, pp. 866-914, 2008.

[21] T. M. B. Munyuli, "The status of pollinators around flower growing zones in Uganda," Economic policy Research Center (EPRC) and National Environmental management authority (NEMA).

[22] T. Munyuli, "Factors governing flower visitation patterns and quality of pollination services delivered by social and solitary bee species to coffee in central Uganda," African Journal of Ecology, vol. 49, no. 4, pp. 501-509, 2011.

[23] T. M. B. Munyuli, "Farmers' perceptions of pollinators importance in coffee production in Uganda," Agricultural Sciences, vol. 2, pp. 318-333, 2011.

[24] T. M. B. Munyuli, "Pollinator biodiversity in Uganda and in subSaharan Africa: landscape and habitat management strategies for its conservation," International Journal of Biodiversity and Conservation, vol. 3, pp. 551-609, 2011.

[25] T. Munyuli, "Assessment of indicator species of butterfly assemblages in coffee-banana farming system in central Uganda," African Journal of Ecology, vol. 50, no. 1, pp. 77-89, 2012.

[26] T. M. B. Munyuli, "Diversity of life-history traits, functional groups and indicator species of bee communities from farmlands of central Uganda," Jordan Journal of Biological Sciences, vol. 5, pp. 1-14, 2011.

[27] T. M. B. Munyuli, "Micro, local, landscape and regional drivers of bee biodiversity and pollination services delivery to coffee (Coffea canephora) in Uganda," International Journal of Biodiversity, Ecosystem Services and Management, vol. 8, pp. 190-203, 2012.

[28] T. M. B. Munyuli, "Is pan-trapping the most reliable sampling method for measuring and monitoring bee biodiversity in agroforestry systems in sub-Saharan Africa?" International Journal of Tropical Insect Science, vol. 33, no. 1, p. 1437, 2013.

[29] T. M. B. Munyuli, P. Nyeko, S. G. Potts, P. Atkinson, D. Pomeroy, and J. Vickery, "Patterns of bee diversity in mosaic agricultural landscapes of central Uganda: implication of pollination services for conservation for food security," Journal of Insect Conservation, vol. 17, pp. 79-93, 2013.

[30] T. M. B. Munyuli, "Climatic, regional land-use intensity, landscape, and local variables predicting best the occurrence and distribution of bee community diversity in various farmland habitats in Uganda," Psyche, vol. 2013, Article ID 564528, 38 pages, 2013.

[31] T. M. B. Munyuli, "Trends in responses to drivers by different bee ecological traits and functional groups in agricultural landscapes in Uganda," Trends in Entomology, vol. 9, no. 9, pp. 1-23, 2013. 
[32] J. C. Biesmeijer, S. P. M. Roberts, M. Reemer et al., "Parallel declines in pollinators and insect-pollinated plants in Britain and the Netherlands," Science, vol. 313, no. 5785, pp. 351-354, 2006.

[33] J. C. Grixti, L. T. Wong, S. A. Cameron, and C. Favret, "Decline of bumble bees (Bombus) in the North American Midwest," Biological Conservation, vol. 142, no. 1, pp. 75-84, 2009.

[34] A. Holzschuh, I. Steffan-Dewenter, and T. Tscharntke, "How do landscape composition and configuration, organic farming and fallow strips affect the diversity of bees, wasps and their parasitoids?" Journal of Animal Ecology, vol. 79, no. 2, pp. 491-500, 2010.

[35] L. A. Morandin and M. L. Winston, "Wild bee abundance and seed production in conventional, organic, and genetically modified canola," Ecological Applications, vol. 15, no. 3, pp. 871-881, 2005.

[36] K. Goka, "Introduction to the special feature for ecological risk assessment of introduced bumblebees: status of the European bumblebee, Bombus terrestris, in Japan as a beneficial pollinator and an invasive alien species," Applied Entomology and Zoology, vol. 45, no. 1, pp. 1-6, 2010.

[37] R. Jaffé, V. Dietemann, M. H. Allsopp et al., "Estimating the density of honeybee colonies across their natural range to fill the gap in pollinator decline censuses," Conservation Biology, vol. 24, no. 2, pp. 583-593, 2010.

[38] S. Maini, P. Medrzycki, and C. Porrini, "The puzzle of honey bee losses: a brief review, Bulletin of Insectology, vol. 63, no. 1, pp. 153-160, 2010.

[39] S. G. Potts, J. C. Biesmeijer, C. Kremen, P. Neumann, O. Schweiger, and W. E. Kunin, "Global pollinator declines: trends, impacts and drivers," Trends in Ecology and Evolution, vol. 25, no. 6, pp. 345-353, 2010.

[40] L. A. Garibaldi, I. Steffan-Dewenter, R. Winfree et al., "Wild pollinators enhance fruit set of crops worldwide, regardless of honey-bee abundance," Science, vol. 339, no. 6127, pp. 1608-1611, 2013.

[41] V. Le Féon, A. Schermann-Legionnet, Y. Delettre et al., "Intensification of agriculture, landscape composition and wild bee communities: a large scale study in four European countries," Agriculture, Ecosystems and Environment, vol. 137, no. 1-2, pp. 143-150, 2010.

[42] C. A. Brittain, M. Vighi, R. Bommarco, J. Settele, and S. G. Potts, "Impacts of a pesticide on pollinator species richness at different spatial scales," Basic and Applied Ecology, vol. 11, no. 2, pp. 106$115,2010$.

[43] P. G. Kevan, "Pollinators as bioindicators of the state of the environment: species, activity and diversity," Agriculture, Ecosystems and Environment, vol. 74, no. 1-3, pp. 373-393, 1999.

[44] B. A. Woodcock, S. G. Potts, T. Tscheulin et al., "Responses of invertebrate trophic level, feeding guild and body size to the management of improved grassland field margins," Journal of Applied Ecology, vol. 46, no. 4, pp. 920-929, 2009.

[45] K. W. Richards and P. G. Kevan, "Aspects of bee biodiversity, crop pollination, and conservation in Canada," in Pollinating Bees-The Conservation Link Between Agriculture and Nature, P. Kevan and V. L. Imperatriz Fonseca, Eds., pp. 77-94, Ministry of Environment-Brasília, 2002.

[46] A. E. Magurran, Measuring Biology Diversity, Blackwell, Oxford, UK, 2010.

[47] C. Porrini, A. G. Sabatini, S. Girotti et al., "The death of honey bees and environmental pollution by pesticides: the honey bees as biological indicators," Bulletin of Insectology, vol. 56, no. 1, pp. 147-152, 2003.

[48] D. Gabriel, S. M. Sait, J. A. Hodgson, U. Schmutz, W. E. Kunin, and T. G. Benton, "Scale matters: the impact of organic farming on biodiversity at different spatial scales," Ecology Letters, vol. 13, no. 7, pp. 858-869, 2010.

[49] C. N. Kaiser-Bunbury, S. Muff, J. Memmott, C. B. Müller, and A. Caflisch, "The robustness of pollination networks to the loss of species and interactions: a quantitative approach incorporating pollinator behaviour," Ecology Letters, vol. 13, no. 4, pp. 442-452, 2010.

[50] A. Kovács-Hostyánszki, P. Batáry, and A. Báldi, "Local and landscape effects on bee communities of Hungarian winter cereal fields," Agricultural and Forest Entomology, vol. 13, pp. 59-66, 2011.

[51] D. Pimentel, "Environmental and economic costs of the application of pesticides primarily in the United States," Environment, Development and Sustainability, vol. 7, no. 2, pp. 229-252, 2005.

[52] S. Naidoo, L. London, A. Burdorf, R. N. Naidoo, and H. Kromhout, "Agricultural activities, pesticide use and occupational hazards among women working in small scale farming in Northern Kwazulu-Natal, South Africa," International Journal of Occupational and Environmental Health, vol. 14, no. 3, pp. 218224, 2008.

[53] E. M. Tegtemeier and D. Duffy, "External cost of agriculture production in the United States of America," International Journal of Agriculture Sustainability, vol. 2, no. 1, pp. 1-20, 2004.

[54] J. K. Tuell and R. Isaacs, "Community and species-specific responses of wild bees to insect pest control programs applied to a pollinator-dependent crop," Journal of Economic Entomology, vol. 103, no. 3, pp. 668-675, 2010.

[55] M.-P. Chauzat, A.-C. Martel, N. Cougoule et al., "An assessment of honeybee colony matrices, Apis mellifera (Hymenoptera: Apidae) to monitor pesticide presence in continental France," Environmental Toxicology and Chemistry, vol. 30, no. 1, pp. 103111, 2011.

[56] A. Alix and G. Lewis, "Guidance for the assessment of risks to bees from the use of plant protection products under the framework of Council Directive 91/414 and Regulation 1107/2009," EPPO Bulletin, vol. 40, no. 2, pp. 196-203, 2010.

[57] D. G. Alston, V. J. Tepedino, B. A. Bradley, T. R. Toler, T. L. Griswold, and S. M. Messinger, "Effects of the insecticide phosmet on solitary bee foraging and nesting in orchards of Capitol Reef National Park, Utah," Environmental Entomology, vol. 36, no. 4, pp. 811-816, 2007.

[58] R. Kajobe, G. Marris, G. Budge et al., "First molecular detection of a viral pathogen in Ugandan honey bees," Journal of Invertebrate Pathology, vol. 104, no. 2, pp. 153-156, 2010.

[59] M. M. Mekonnen, A. Y. Hoekstra, and R. Becht, "Mitigating the water footprint of export cut flowers from the lake Naivasha Basin, Kenya," Water Resources Management, vol. 26, pp. 37253742,2010

[60] W. A. Qualls, R.-D. Xue, and H. Zhong, "Impact of bifenthrin on honeybees and Culex quinquefasciatus," Journal of the American Mosquito Control Association, vol. 26, no. 2, pp. 223-225, 2010.

[61] D. Holt and A. Watson, "Exploring the dilemma of local sourcing versus international development-the case of the flower industry," Business Strategy and the Environment, vol. 17, no. 5, pp. 318-329, 2008.

[62] H. van der Valk, I. Koomen, R. C. F. Nocelli et al., Aspects Determining the Risk of Pesticides to Wild Bees: Risk Profiles for Focal Crops on Three Continents, FAO, Rome, Italy, 2013. 
[63] D. Van Engelsdorp, N. Speybroeck, J. D. Evans et al., "Weighing risk factors associated with bee colony collapse disorder by classification and regression tree analysis," Journal of Economic Entomology, vol. 103, no. 5, pp. 1517-1523, 2010.

[64] M. N. Rashed, M. T. A. El-Haty, and S. M. Mohamed, "Bee honey as environmental indicator for pollution with heavy metals," Toxicological and Environmental Chemistry, vol. 91, no. 3, pp. 389-403, 2009.

[65] T. M. B. Munyuli, "Influence of functional traits on foraging behaviour and pollination efficiency of wild social and solitary bees visiting coffee (canephora) flowers in Uganda," Grana. In press. 

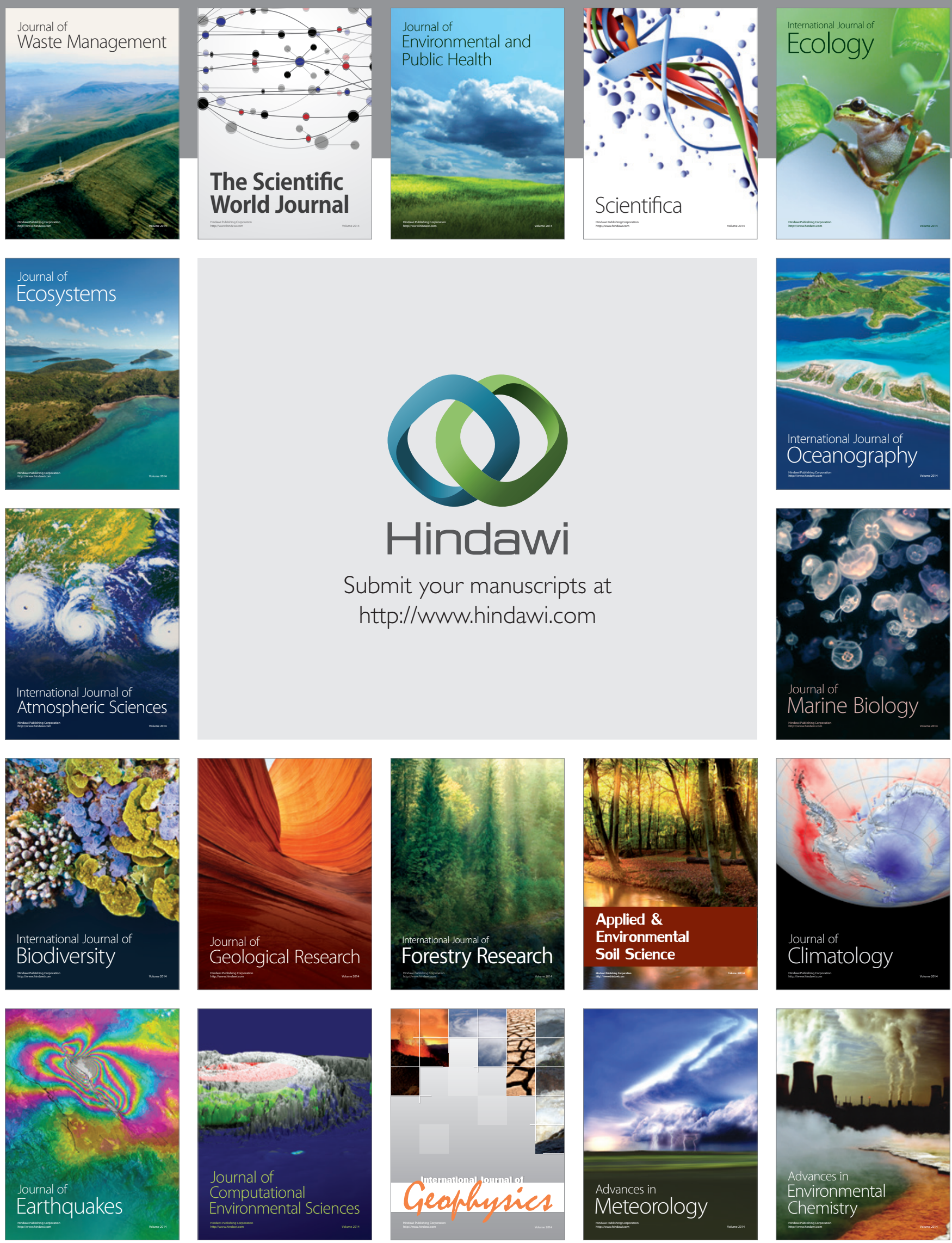